
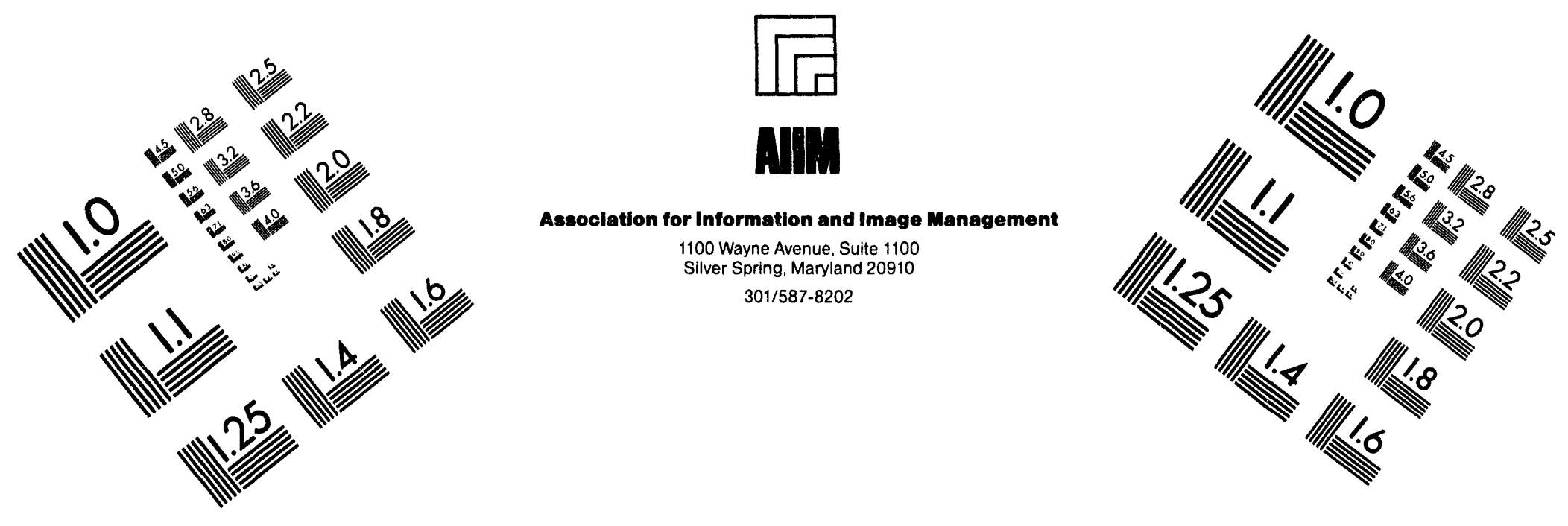

\title{
Centimeter
}

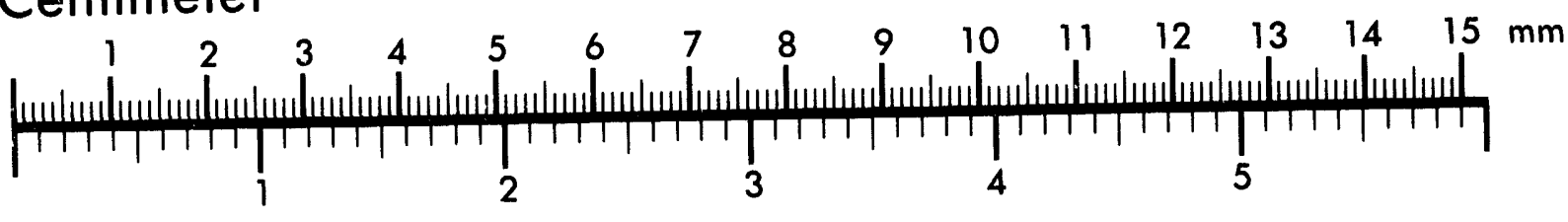
Inches
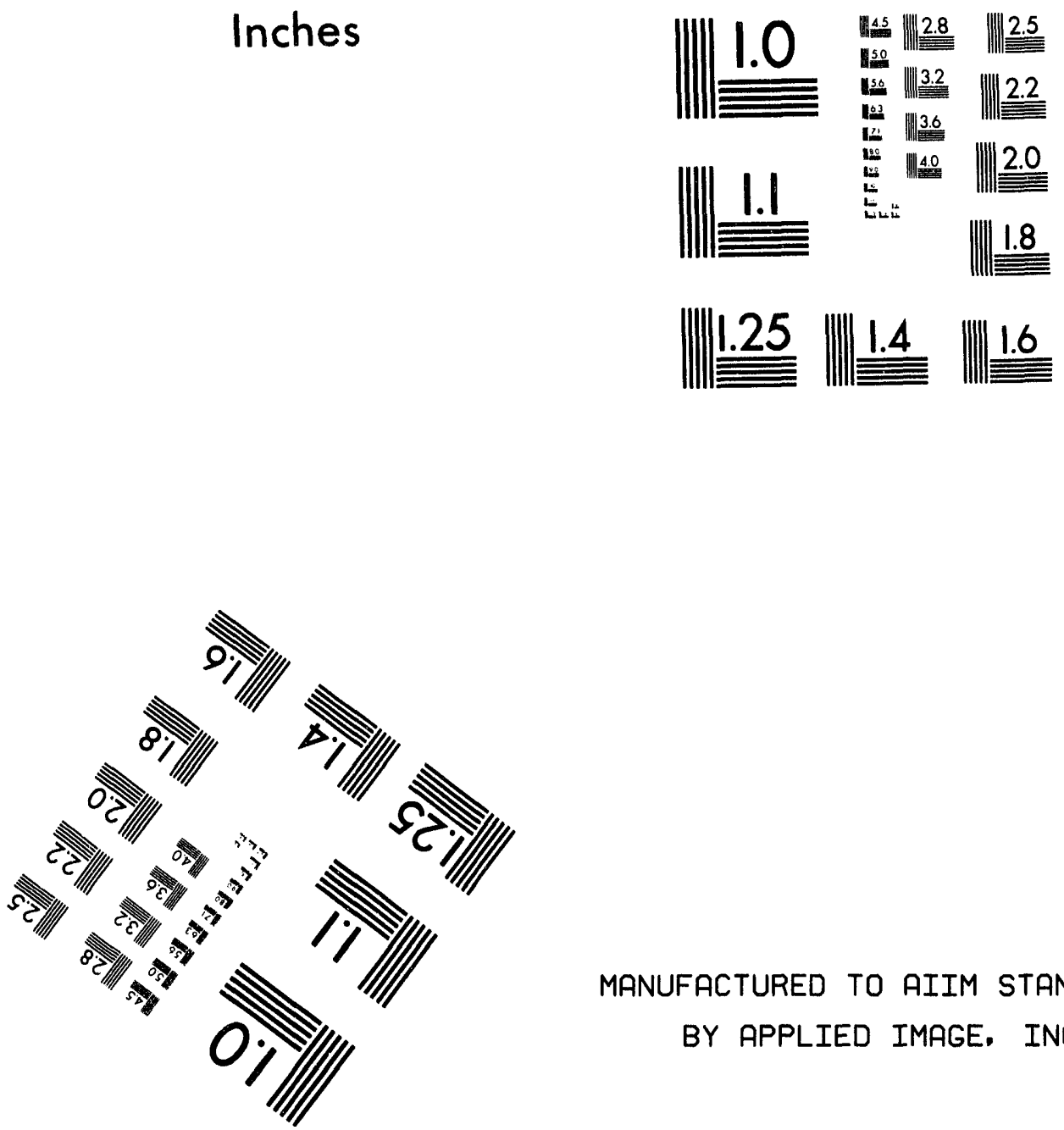

MANUFACTURED TO AIIM STANDARDS

BY APPLIED IMAGE. INC.

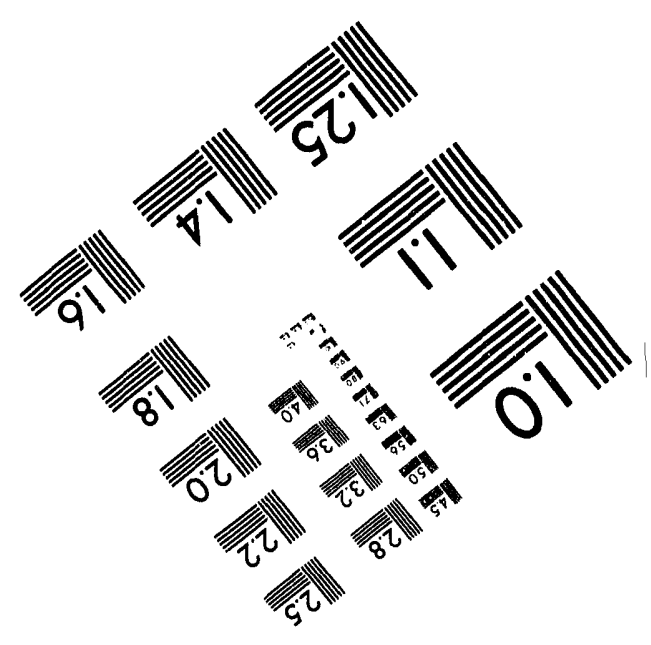



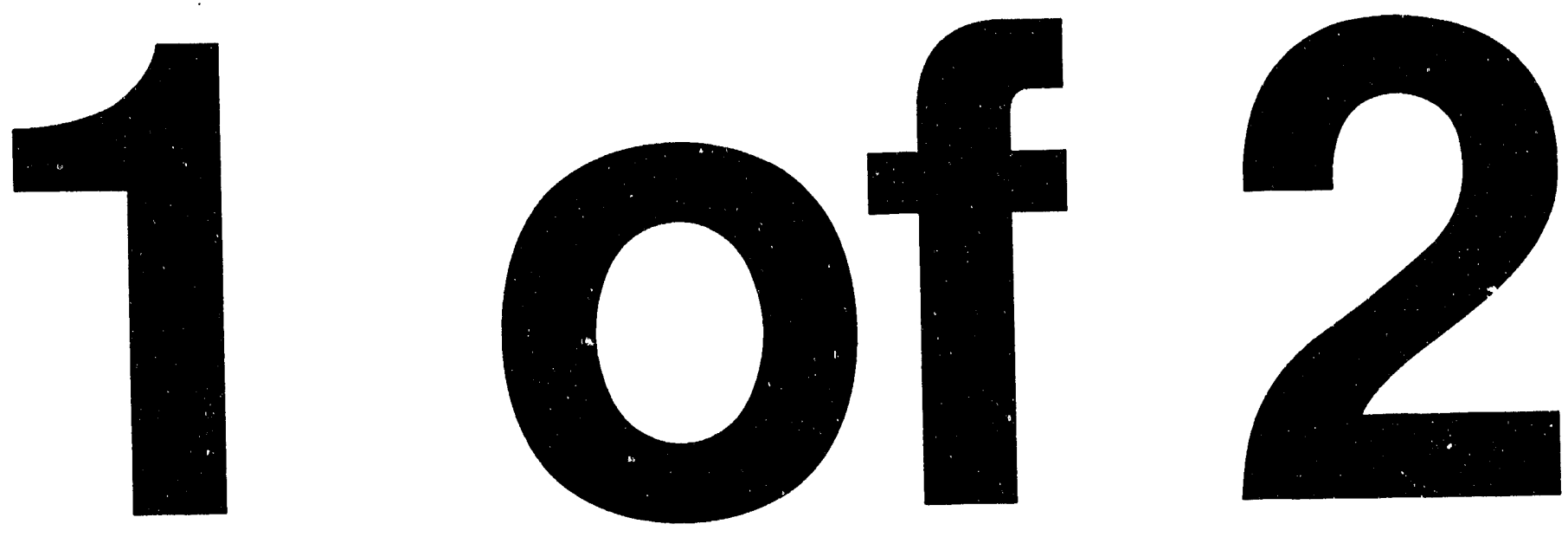
ANNUAL PERFORMANCE REPORT

\author{
for \\ ENVIRONMENTAL MONITORING AND OVERSIGHT \\ at Department of Energy Facilities \\ in \\ New Mexico
}

\author{
by the \\ New Mexico Environment Department \\ DOE Oversight Program \\ (Grant No. DE-FG04-91AL65779)
}

\title{
DISCLAIMER
}

This report was prepared as an account of work sponsored by an agency of the United States Government. Neither the United States Government nor any agency thereof, nor any of their employees, makes any warranty, express or implied. or assumes any legal liability or responsibility for the accuracy, completeness, or usefulness of any information, apparatus, product, or process disclosed, or represents that its use would not infringe privately owned rights. Referprocess do any specific commercial product, process, or service by trade name, tradernark, manufacturer, or otherwise does not necessarily constitute or imply its endorsement, recommendation, or favoring by the United States Government or any agency thereof. The views mendation, or favoring by the United States Government of authors expressed herein do not necessarily state or reflect those of the United States Government or any agency thereof. 


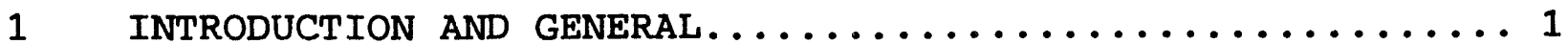

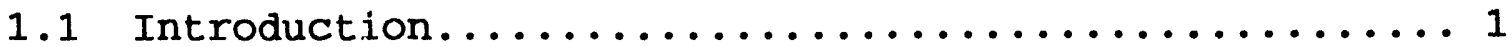

1.2 Agreement and Grant Negotiations................. 1

1.3 Personnel and Administrative Issues..............

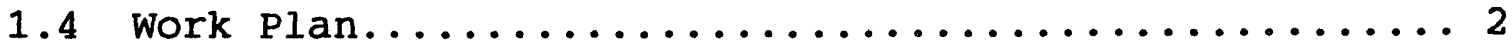

1.5 General............................... 4

2 GUIDANCE DEVELOPMENT .......................4

2.1 Umbrella Protocol - NMED/DOE.................. 4

2.2 Site specific protocols..................... 4

3 ENVIRONMENTAL MONITORING, RESTORATION AND OVERSIGHT..... 5

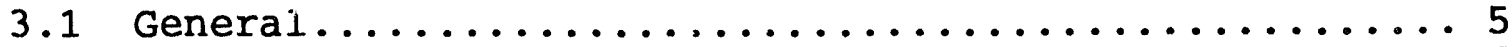

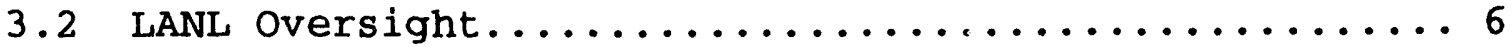

3.2.1 General Oversight Activities.............. 6

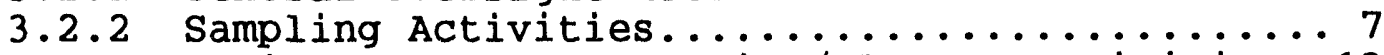

3.2.3 Environmental Restoration/Cleanup Activities..13

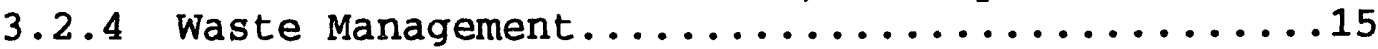

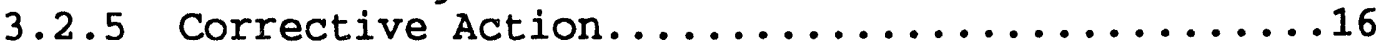

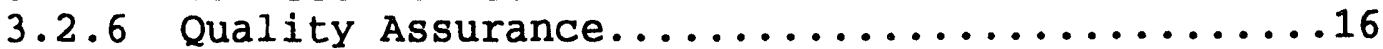

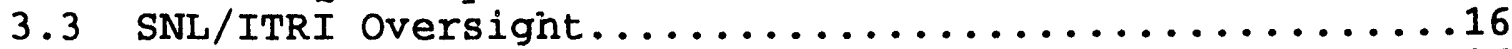

3.3.1 General Oversight Activities...............16

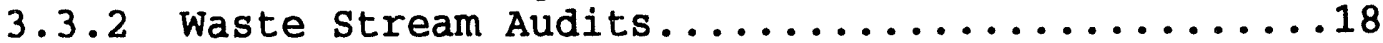

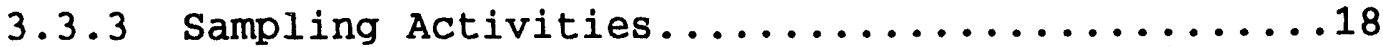

3.3.4 Environmental Restoration/Cleanup Activities...31

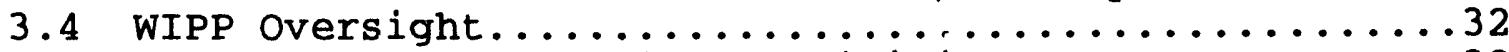

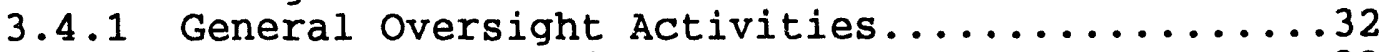

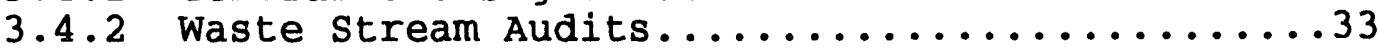

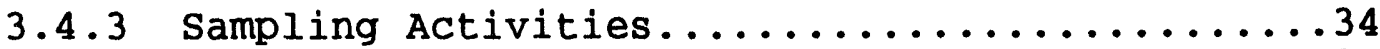

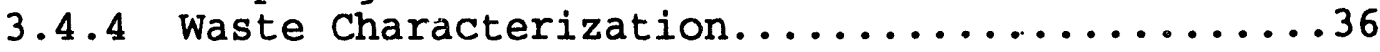

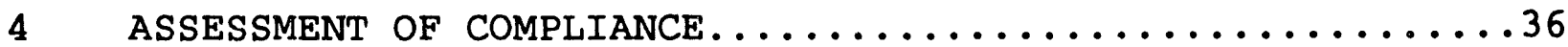

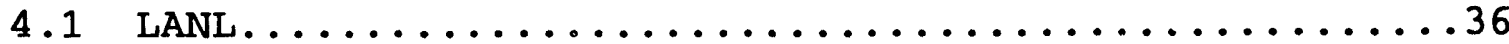

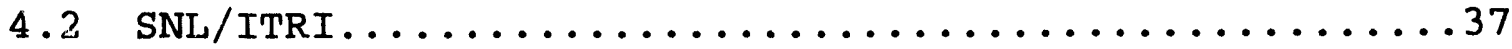

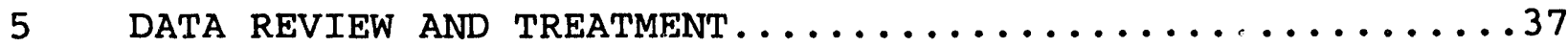

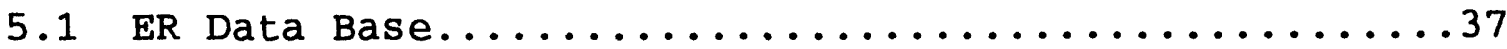

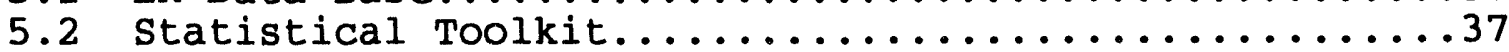

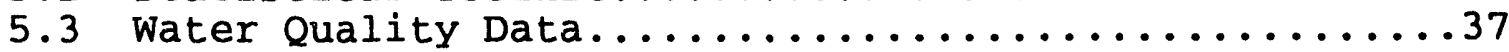

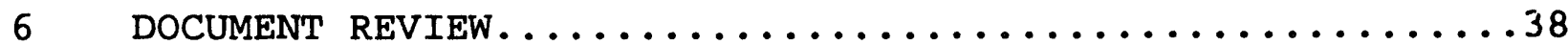

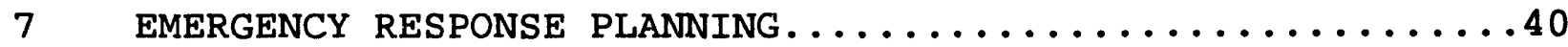

8 PUBLIC INFORMATION/PUBLIC RELATIONS ...............42

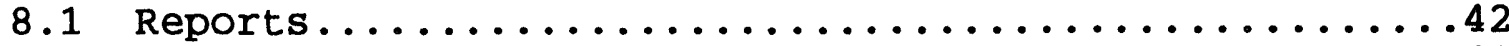

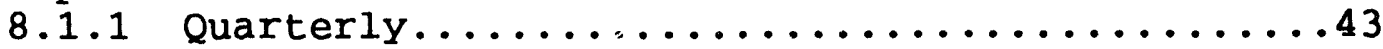

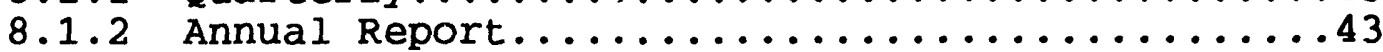

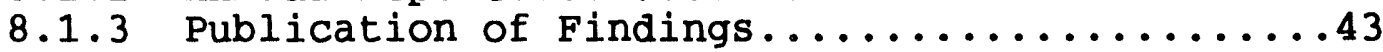

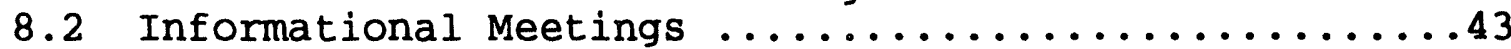

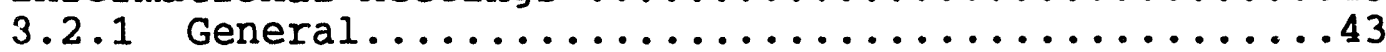


8.2.2 Environmental Restoration/Cleanup.........44

8.2 .3 Facility Meetings..................44

8.3 NMED/DOE Meetings......................

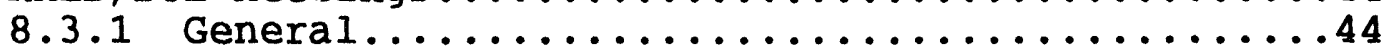

8.3.2 Bi-Monthly Meetings..................

8.3 .3 Annual Meeting...................

$9 \quad$ TRAINING..........................

9.1 Technical Training.......................

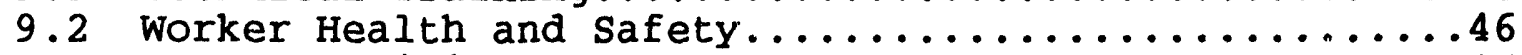

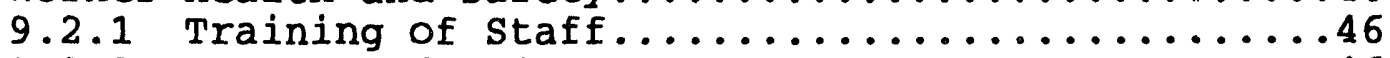

9.2.2 Health and Safety Plans.................

FIGURES

Figure 1 - NMED organization Chart................ 3

Figure 2 - LANL May Sample Locations............... 9

Figure 3 - LANL September Sample Locations............12

TABLES

Table I - May 1992 CME Split Sampling at CWL HRMB/SNLA...21

Table II - November 1992 Split Sampling at CWL HRMB/SNLA..22

Table III- December 1992 split Sampling at TA2 Well TA2-

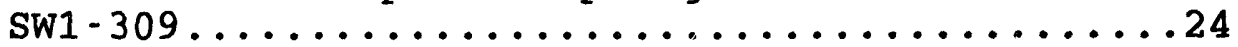

ATTACHMENT A - work Plan Cover Letter to DOE............47

ATTACHMENT B - New Mexico Agreement-in-Principle (AIP)

Implementation Review Exit Briefing........48

ATTACHMENT C - Environmental Sampling standard Operating Procedures for the NMED HRMB DOE Oversight

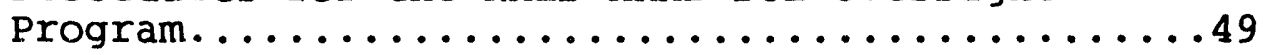




\section{INTRODUCTION AND GENERAL}

\subsection{Introduction}

In October 1990 an Agreement-in-Principle (AIP) was entered into between the U.S. Department of Energy (DOE) and the state of New Mexico for the purpose of supporting state oversight activities at DOE facilities in New Mexico. The State's lead agency for the Agreement is the New Mexico Environment Department (NMED). DOE has agreed to provide the state with resources over a five year period to support state activities in environmental oversight, monitoring, access and emergency response to ensure compliance with applicable federal, state, and local laws at Los Alamos National Laboratory (LANL), Sandia National Laboratories (SNL), the Waste Isolation Pilot Plant (WIPP), and the Inhalation roxicology Research Institute (ITRI). The Agreement is designed to assure the citizens of New Mexico that public health, safety and the environment are being protected through existing programs; DOE is in compliance with applicable laws and regulations; DOE has made substantial new commitments; cleanup and compliance activities have been prioritized; and a vigorous program of independent monitoring and oversight by the state is underway.

Attachment A, Section E, Paragraph 2 of the AIP states that the state will issue annual reports on the result of its oversight, monitoring and analysis activities, and state findings relating to the quality and effectiveness of the facilities environmental monitoring and surveillance programs. This report satisfles that requirement for the January-December 1992 time frame.

\subsection{Agreement and Grant Negotiations}

At the outset of the AIP, DOE agreed to provide the state with $\$ 14,754,000$ over a five year period (October 1,1990 through september 30,1995 ) with the requirement that the State submit on an annual basis, not later than June 1 each year, a proposed work scope and cost estimates for work and services to be performed by the state under the Grant during the upcoming budget period. On June 8 , 1992, NMED submitted to DOE a completed Financial Assistance Application $\mathrm{K} 1 \mathrm{t}$ requesting funding for Year 3 (Federal Fiscal Year 93) in the amount of $\$ 3,132,600$. After numerous revisions and negotiations with DOE, NMED resubmitted a revised budget to DOE. On september 28 , 1992, DOE notified NMED of its provisional obligation of funds in the amount of $\$ 3,125,000$ pending definitization of the budget for the period october 1,1992 through September 30,1993 . The obligation of funds was executed 
by Amendment No. A003 to Grant No. DE-FG04-91AL65779.

\subsection{Personnel and Administrative Issues}

In order to meet the state's obligations under the AIP, NMED has hired additional staff, fully funded by the AIP. staff have been placed in four bureaus within the Department (the Hazardous and Radioactive Materials Bureau, the Surface Water Quality Bureau, the Air Quality Bureau, and the Ground Water Protection and Remediation Bureau). Staff hired under the AIP augment the current regulatory and environmental protection activities being conducted by NMED at the four DOE facilities in the state. Additionally, staff have been hired and are placed on-site at all DOE facilities in the state. Figure 1 illustrates the organizational and hierarchical relationship of staff working in the AIP Program. At present, 8 vacancies exist, the majority of which are stationed at LANL. The state has experienced difficulties in hiring and retaining staff at Los Alamos because of competitive salaries and benefits offered by LANL.

Security Clearances ( $Q$ Clearances) have been issued to 15 staff members at LANL, WIPP, SNL/ITRI, and santa Fe. Currently, clearances for six staff members are still in process by DOE. NMED staff have experienced inordinate delays in the processing of $Q$ Clearances.

After nearly two years of negotiations with DOE, the State has been provided with vehicles for use by the AIP staff in their monitoring and oversight activities. Eight of nine requested vehicles are being leased by NMED from the GSA Motor Pool in Albuquerque. One vehicle is still pending. Vehicles are stationed at WIPP, LANL, SNL/ITRI and Santa Fe.

\subsection{Work Plan}

Attachment A, Section E, Paragraph 1 of the AIP requires that the state prepare a plan for its independent oversight of programs for monitoring the environment at and in the vicinity of the facilities and for assessing compliance with applicable environmental laws and regulations. Additionally, the state is to provide this plan to DOE, the Environmental Protection Agency (EPA), other appropriate federal and state agencies, and affected local and tribal governments for review and consultation. NMED developed a Work Plan for its DOE Environmental Oversight and Monitoring activities, thus meeting its obligation of the aforementioned requirement. The Work Plan was finalized and provided to DOE on 


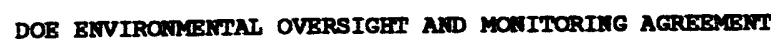

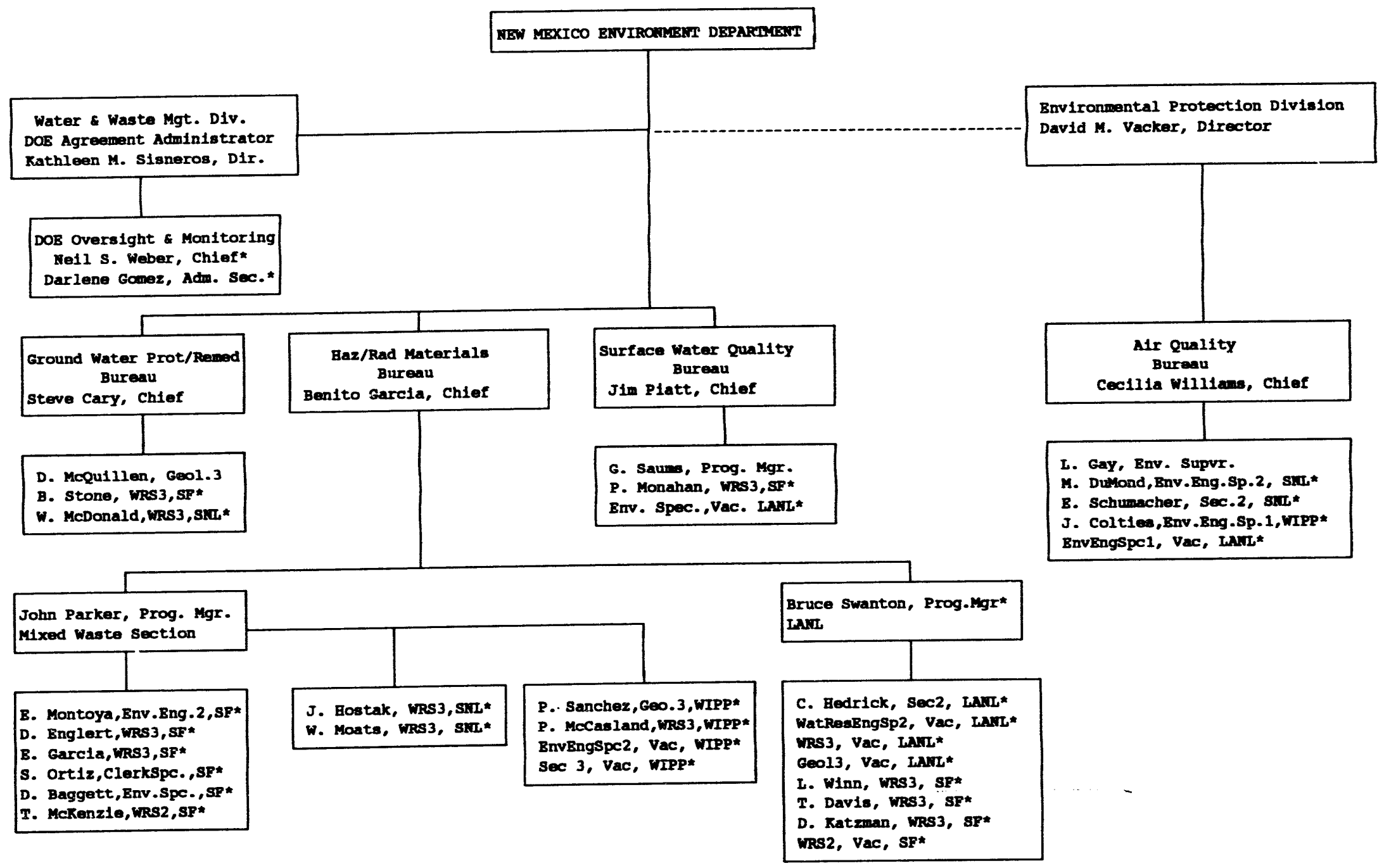

* Funded by DOB Agrcement-1n-Princ1ple (AIP) 
November 25, 1992 (see Attachment A). Additionally, a draft of the Work Plan was provided to federal and state governmental agencies, and local and tribal governments for review and consultation and their comments were incorporated into the final Work Plan.

\subsection{General}

DOE Headquarters (HQ) conducted an implementation review of New Mexico's AIP Program. During the week of December 8, 1992, two staff members from DOE/HQ and six contractor personnel met with DOE-Albuquerque (AL) and NMED staff to review the status of New Mexico's AIP Program implementation and to suggest any improvements to the Program. A draft exit briefing of their findings is attached (Attachment B) and a formal submittal and publication of their findings and recommendations is expected in February 1993.

The NMED DOE Oversight Program Chief has established an open line of communication with SNL's External Interface office. That office has arranged for monthly tours of specific SNL activities of general interest to NMED. During 1992, overview tours of the following SNL programs and/or activities were arranged: the Burn site, the Chemical Waste Landfill, the Air Quality Monitoring Program, Tech Area 2 and the Process Development Laboratory.

\section{GUIDANCE DEVELOPMENT}

2.1 Umbrella Protocol - NMED/DOE

In order to provide general guidance for both NMED and DOE personnel involved in the AIP Program. The "Guidance Protocol for Implementation of the Environmental Oversight, Monitoring and Remediation Agreement at DOE Facilities in New Mexico" was developed and distributed to all staff in July 1992. The purpose of the document is twofold: (1) to establish an "umbrella" protocol that delineates procedures between DOE-AL and NMED for their effective interaction in fulfilling their respective responsibilities under the terms of the AIP, and (2) to provide guidance to DOE Area and Project Offices and NMED "site representatives" in development of "site specific" protocols that establish procedures and guidelines for day-to-day operations between DOE/DOE Contractors and NMED.

2.2 Site Specific Protocols

Once the "Umbrella" Protocol was developed and 
distributed, each NMED site Point of Contact (POC) was directed to develop site specific protocols with their counterparts at the Kirtland Area Office (KAO), the Los Alamos Area office (LAAO) and the WIPP Project site Office (WPSO). The site Specific Protocol for WIPP was developed, finalized and distributed to staff in December 1992. The protocol for KAO has been finalized and is awaiting signature by the KAO Manager. The protocol for LAAO is currently in its initial draft.

\section{ENVIRONMENTAL MONITORING, RESTORATION AND OVERSIGHT}

\subsection{General}

Ground Water Protection and Remediation Bureau (GWPRB) AIP personnel reviewed placement of monitoring wells as part of determining adequacy of monitoring networks at SNL, ITRI, and LANL. This also included evaluating monitoring well construction and sampling parameters.

Reports of comprehensive reviews of current ambient air monitoring systems at LANL, SNL/ITRI, and WIPP were submitted by the Air Quality Bureau (AQB) to the DOE for review and comment during the year. Specific recommendations to the DOE based upon these reviews were: a) that certain discrepancies between TLD (thermoluminescent dosimeter) measurements at SNL and at ITRI be investigated; and $b$ ) that the quality assurance program connected with air emissions of radionuclides at LANL be upgraded.

A standard operating procedures manual was developed by the Hazardous and Radioactive Materials Bureau (HRMB) for the environmental sampling and monitoring program. The manual provides sampling procedures for ground water, surface water, soil and sediment, air borne particulate, and ionizing radiation. A copy of the document is provided in Attachment $C$.

Rehabilitation of low-volume air monitors which NMED had left from environmental monitoring efforts dedicated to the uranium mining district in western New Mexico was completed in 1992. The monitors will be co-located with selected monitoring locations at LANL and ITRI. At present sandia has no ambient air monitoring network, therefore NMED will locate monitors at sites downwind of emission sources, and at perimeter locations with greatest proximity to a human population.

A company has been selected to provide the thermoluminescent dosimeter (TLD) chips which will be used for NMED's radiation monitoring networks at LANL, SNL, ITRI, 
and WIPP. A contract has been developed and is now undergoing internal review. The TLD's chosen are an aluminum oxide, which is 100 times more sensitive than the lithium fluoride more typically used. As with the air monitors, these devices will be co-located with existing environmental dosimeters deployed by the facilities.

\subsection{LANL Oversight}

\subsubsection{General Oversight Activities}

LANL scientists provided a geologic tour of the Pajarito Plateau for NMED oversight staff. The objective of the tour was to provide a detailed overview of the geological setting of LANL. Oversight staff also attended a field trip along the Rio Grande Rift and Pajarito Plateau sponsored by the Seismological society on Quaternary faulting. Discussions were held on the potential for future seismic activity at LANL.

Information obtained from these tours and meeting with LANL scientists was instrumental in the preparation of a report on the adequacy of ground water monitoring efforts at LANL. The report is being written by oversight staff in both the HRMB and the GWPRB. The report is complete and is being transmitted to DOE in fulfillment of a deliverable under the AIP.

Analytical data from sampling trips at LANL in the spring and fall of 1992 is being compiled and summarized. A summary of the activities and data is provided at the end of this section.

Staff met with LANL environmental surveillance program representatives as part of an ongoing assessment of the radiation monitoring programs. Information derived from the meeting and subsequent tours will also be used in the planning of independent monitoring programs at LANL, SNL/ITRI and WIPP. A report detailing the findings of the assessment on the radiological surveillance program at LANL is in preparation. A first draft is undergoing internal peer review. The report will be transmitted to DOE early in the first quarter of 1993.

After meeting with the San Ildefonso Pueblo Lt. Governor, a tour of LANL environmental surveillance locations on Pueblo land was provided by LANL employees. The tour visited a number of springs where samples are taken, as well as two ground water monitoring wells. NMED is purusing a memorandum of understanding with the san Ildefonso Pueblo to allow the emplacement and monitoring 
of wells on Pueblo land in the main aquifer and perched zones near the LANL property boundary.

Surface Water Quality Bureau (SWQB) AIP staff toured the accelerator at TA-53 LAMPF facility. The purpose of the tour was to investigate existing discharges from the accelerator flow to the TA-53 sanitary lagoons (NPDES outfall 09S).

GWPRB AIP staff attended three tours at the lab which included a half-day orientation session and a 2-day tour of monitoring sites. In August, LANL staff took DOE and NMED personnel on a visit to the new consolidated sewage treatment facility site as well as two outfalls in Mortandad Canyon. LANL staff led a tour in November, including an overview of TA-1, TA-16 and TA-41, a discussion of the work on/setting of Los Alamos Canyon bel'JW TA-21 and an examination of a newly discovered unnamed spring. GWPRB AIP staff also researched and visited typical areas of several of the major geologic units of the Pajarito plateau (Guaje Pumice, puye Conglomerate, Totavi Lentil, Tshirege Member of the Bandelier Tuff).

\subsubsection{Sampling Activities}

During 1992 the NMED/AIP Oversight Program has undertaken independent sampling activities as well as co-located sampling with LANL environmental surveillance groups within and around the Los Alamos National Laboratories property. AIP oversight staff of the HRMB and the SWQB have teamed in these activities. Samples from ephemeral streams and springs were taken during the months of May and September. Results of the sample analysis are discussed below.

The HRMB collected samples and reviewed analyses for radiologic, organic, and metallic constituents. The SWQB collected samples and reviewed analyses for general water chemistry and specific metals. The results of the analysis were compared to maximum contaminant levels established in DOE order series 5400, Title 10 Code of Federal Regulations 20, and the New Mexico Water Quality Control Commission regulations and standards.

\section{SPRING SNOWMELT SAMPLING}

Samples were taken between May 5 and 7 from ephemeral streams in the LANL area. Flow in the streams result from spring snowmelt run-orf and effluent release from NPDES permitted sanitary and industrial treatment facilities. Four background samples were collected 
upstream of LANL boundaries and eight samples including one duplicate sample were collected within LANL boundaries below selected technical areas. See figure 2 for locations of the samples.

\section{Parameters}

Analytical parameters for each sample include a number of radiochemical, organic, Metal paramuters and Water Chemistry. Radiochemical parameters include: Gross Alpha/Beta, Gamma Scan, Uranium 238/234, Thorium 230/232, Americium 241, Plutonium 238 and Plutonium $(239+240)$. Organic parameters include sixty-five Base/Neutral/Acid Extractable (semivolatile) organic and sixty-three Mass spectrometer Purgeable (Volatiles). Those methods are equivalent to EPA Methods 8270 and 624 respectively. The Metal parameters include an ICAP Scan that screens for 21 metals. Eleven metals were analyzed by Atomic Absorption to achieve lower detection levels.

Radiochemical Results

of the Radiochemical analysis one sample location demonstrated levels that were above allowable effluent release standards set by NRC regulations and the Clean Water Act Standards. The sample taken at Mortandad Canyon had levels above standards for Gross Alpha (15 $\mathrm{pCi} / \mathrm{L})$ and Gross Beta $(50 \mathrm{pCi} / \mathrm{L})$. The results for these measurements are respectively $15 \mathrm{pC} 1 / \mathrm{L}$ and $1210.00 \mathrm{pCl} / \mathrm{L}$.

other constituents which were not above standards but demonstrated levels above background include; Gamma peaks for Cesium 137 (1.59 E -7 micro $C I / L)$ and Selenium 75 (4.7 $\mathrm{E}-8$ micro $\mathrm{Ci} / \mathrm{L})$, in addition to other radioisotopes, Uranium $234(2.20 \mathrm{E}-9 \mathrm{micro} \mathrm{Ci} / \mathrm{L})$, Americium 241 (2.60 E -9 micro C1/L), Plutonium 239+240 (2.30 E -9 micro $\mathrm{Ci} / \mathrm{L})$ and Plutonium $238(6.00 \mathrm{E}-10$ micro $\mathrm{Ci} / \mathrm{L})$. These levels were 2 to 3 orders of magnitude above the samples taken for background but 1 to 2 orders of magnitude below standards for effluent release.

The Mortandad sampling location was within one kilometer of the TA-50 Rad Wastewater Treatment Plant NPDES outfall 051. Surface Water flow has been monitored by LANL since 1960 , before operations at the wastewater 
FIGURE 2

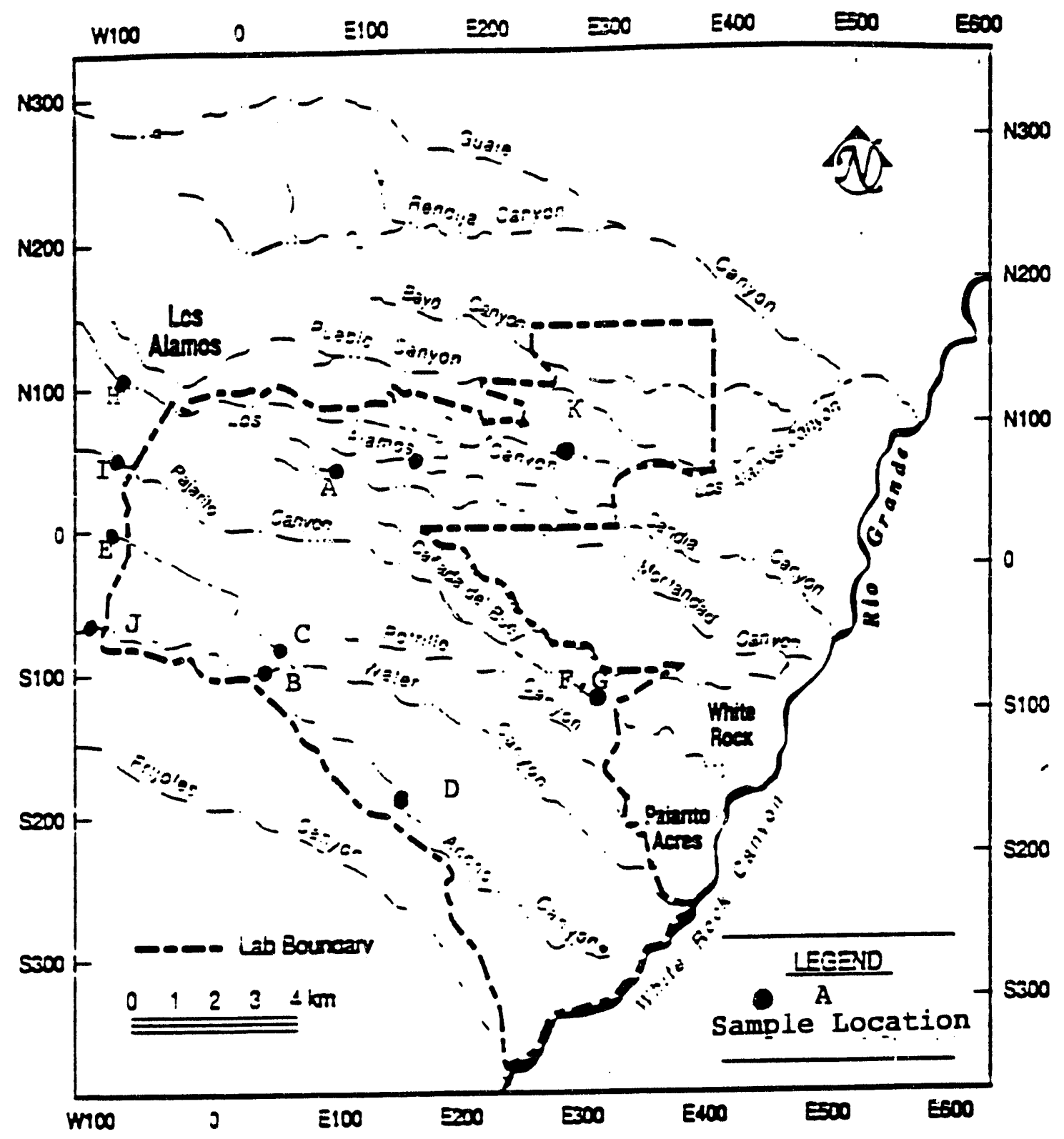

Figure 2. May Sample Locations
A - Mortandad
B - Water Canyon below TA-37
C - Canon de Valle / Water Canyon
D - Ancho Canyon below TA-49
E - Water Canyon at St. Rd. 4 (Background)
F - Pajarito Canyon
G - Pajarito Canyon (Duplicate)
B - Los Alamos Reservoir (Background)
I - Pajarito Canyon at St. Rd. 4 (Background)
$J$ - Canon de valle at St. Rd. 4 (Background)
$R$ - Los Alamos Canyon below TA-53
I - Sandis Canyon 
treatment plant began and have been reported not to have flowed beyond laboratory boundaries since monitoring began. Reporting requirements described in DOE Orders $5000.3 \mathrm{~A}$ indicate that the release should be reported as an off-Normal occurrence including corrective actions that might be taken.

\section{Organic Analysis}

No volatile organic constituents were detected in samples taken during this sampling event. The samples were analyzed by EPA Method 624 ; Mass Spectrometer Purgeable Volatile Organic Analysis. Quality Assurance documentation and results from split samples taken by LANL indicate these analyses to be accurate.

Phthalate compounds were detected in the semi-volatile organic screen, using EPA method 8270, Base/Neutral/Acid Extractable Analysis. These compounds are not likely to be present within the environment at Los Alamos and therefore are probably the result of post-sampling contamination. Phthalate compounds were not detected in samples taken and analyzed by LANL representatives.

Field and laboratory quality control samples suggest that these attached data are reliable, with the exception of the phthalate compounds. A duplicate sample was taken in Pajarito Canyon in addition to co-location of samples taken by LANL. All the analytical results for the duplicate and co-located sampling were comparable.

Metal Analysis

Twelve samples were submitted for Metal analysis, of which the results for four samples have not been reported. Analytical methods selected for the metal analysis include an ICAP Scan which screens for twentytwo metals and analyses by atomic absorption which analyzes for eleven parameters at lower detection levels. Results of the analysis were compared to New Mexico Water Quality Control Commission (WQCC) standards and U.S. E.P.A. Maximum Contaminant Levels.

The results of the analyses for metals confirmed levels above drinking water standards and in many cases above WQCC ground water standards. This should not be overemphasized for a number of reasons: the water sampled was neither drinking water or ground water, the numeric standards exceeded were aesthetic not human health based standards, and the background samples taken 
from upper Pajarito Canyon and Los Alamos Reservoir were also elevated. Two samples approached health based standards. The sample taken in Pajarito Canyon had an elevated level of Lead. The level reported was .0060 $\mathrm{mg} / 1$ which is below E.P.A. MCL of $.015 \mathrm{mg} / 1$. Barium was detected in the Canyon de Valle sample at $0.90 \mathrm{mg} / 1$, just below the standard of $1.0 \mathrm{mg} / 1$.

It may be that metals were elevated due to the "pulse" of acidic runoff known to occur in mountainous regions during the spring snowmelt. This acidic water would leach metals from the soll. Field measurements taken found $\mathrm{pH}$ to be neutral, possibly due to the buffering ability of the alkaline soils in the region.

\section{WHITE ROCK CANYON SAMPLING EVENT}

Samples were collected from ten locations on september 8 th and 9 th from springs and streamflow within white Rock Canyon. The Rio Grande River flows through White Rock Canyon parallel to the west boundary of the Los Alamos National Laboratory. The water from the springs are reported to originate from the main water aquifer beneath the Pajarito plateau. Stream flow that was sampled originates from main aquifer springs and in Mortandad Canyon, treated sanitary effluent from the White Rock community. Refer to Figure 3 for sample locations.

\section{Parameters}

Analytical parameters for each sample include a number of radiochemical, metal and water chemistry parameters. Organic screens were not taken due to sample preservation requirements and the low probability of detection so far from the source. Radiochemical parameters are identical to parameters selected for the May sampling event and include: Gross Alpha/Beta, Gamma Scan, Uranium, 238/234, Thorium 230/232, Americium 241, Plutonium 238 and Plutonium $(239+240)$. Metal parameters include an ICAP Scan that screens for 21 metals and eleven metals were analyzed by Atomic Absorption Methods in order to achieve lower detection limits.

The samples were submitted to the New Mexico Scientific Laboratory Division. At this time only the radiochemical analysis have been reported. Results for the metals analyses are still pending. 


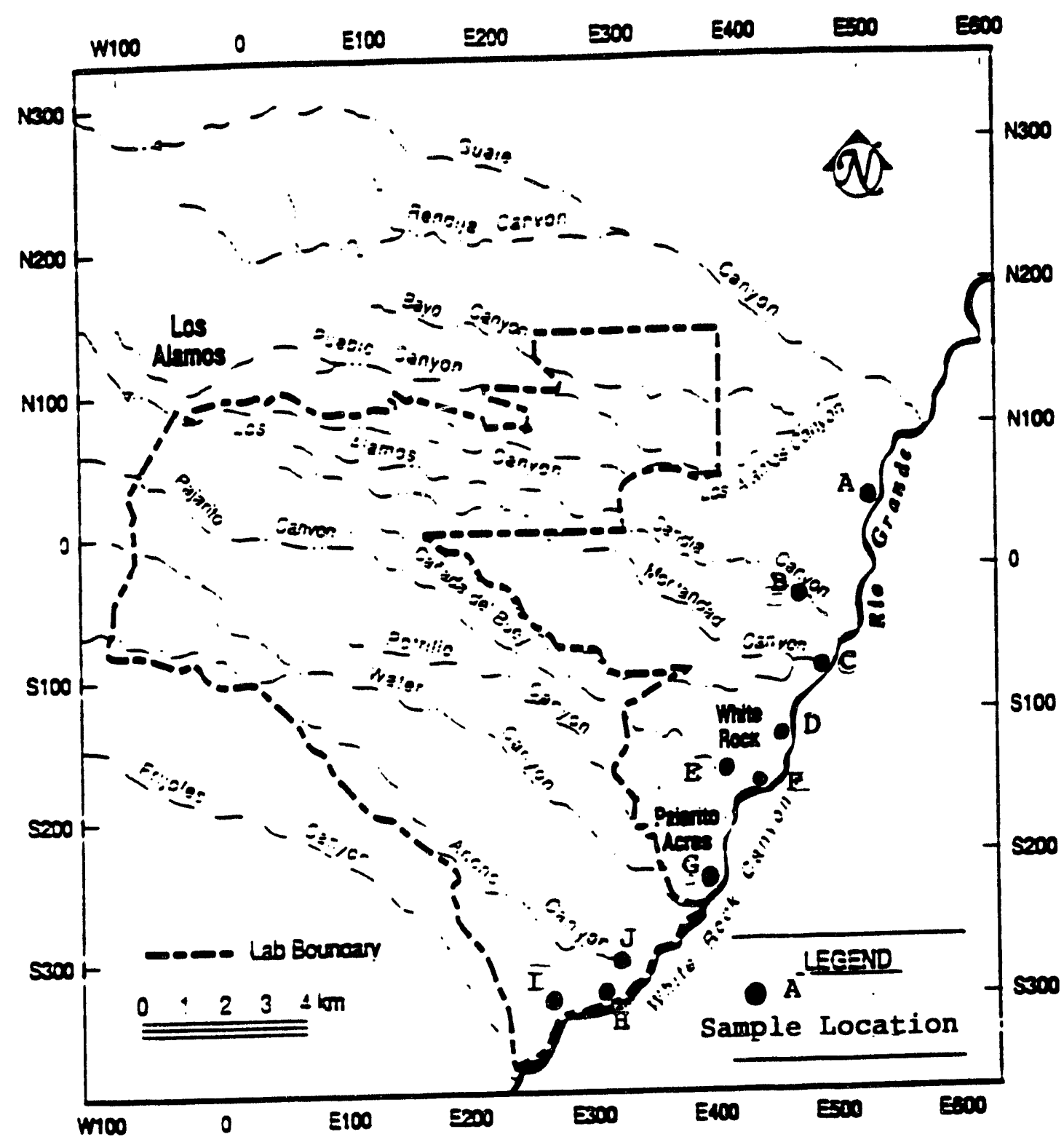

Figure 3. September Sample Locations

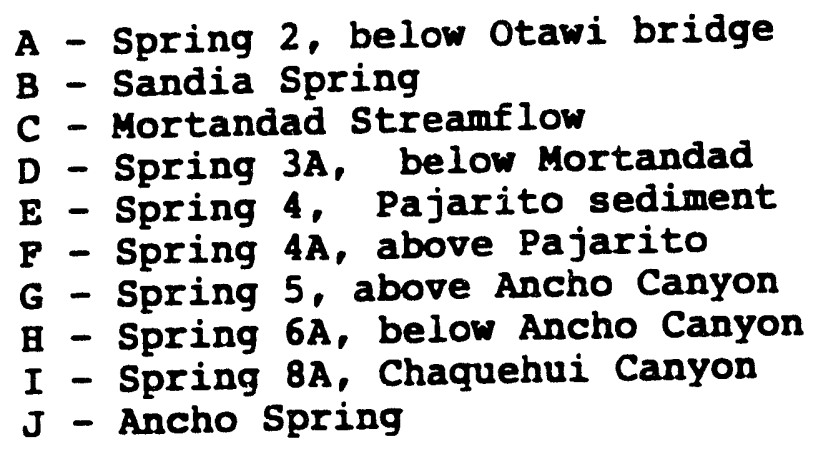




\section{Radiochemcial Results}

The analysis of the spring 2 sample, downstream of Otaw1 bridge, appears elevated for the Uranium 238 and Uranium 234 parameters. Reported value for Uranium 238 is 810.00 $\mathrm{fCl} / 1$ compared to a range of 50.00 to $310.00 \mathrm{fCl} / 1$ reported for the other samples collected. The reported value for Uranium 234 is $1000.00 \mathrm{fCi} / 1$ which was compared to a range of -30.00 to $710.00 \mathrm{fCl} / 1$. The relationship between Uranium 238, Uranium 234 and Thorium 230 appears out of equilibrium suggesting an anthropogenic source.

Analysis for the Ancho Spring sample appeared elevated for Thorium 232 at $120.00 \mathrm{fCl} / 1$. Values reported for other samples range from 0 to $27.00 \mathrm{fCl} / 1$. The value reported for the Ancho analysis is lower that the derived concentration guide for Thorium of $400 \mathrm{fCi} / 1$.

Only one sediment sample was taken and it did not exceed the background data available from the Los Alamos Environmental Surveillance Report. The sample was taken in Pajarito Canyon and compared to background data developed during the years 1974 through 1986 by LANL. The only parameters that could be compared were plutonium $(239+240)$, Plutonium 238 and Total Uranium.

The SWQB collected samples for the TA-53 sanitary lagoons outfall O9S on December 11,1991 and April 16, 1992 . Samples on December 11 were analyzed for water chemistry, radio chemistry, organics and heavy metals by the Scientific Laboratory Division (SLD). The April 16 samples were analyzed for the same parameters in addition to tritium and were analyzed by TMA-Eberline.

\subsubsection{Environmental Restoration/Cleanup Activities}

The largest and potentially most costly environmental program within DOE is Environmental Restoration (ER), which is designed to locate and assess for contamination at 2000 sites at LANL. Each site is called a solid Waste Management Unit (SWMU, pronounced "schmoo"), and generally a number of SWMU's are grouped into an Operable Unit (OU). It is DOE's intention to proceed as follows: if historical documentation does not rule out the possibility of hazardous materials disposal or spillage at a given SWMU, a sampling and analysis plan is included for the site in that OU's RCRA Facility Investigation (RFI) Workplan. If contamination is identified at the site above acceptable levels, a corrective action plan is to be drafted. NMED's DOE Oversight Program includes a component whose objectives are 1) to review the RFI workplans to ensure they provide high confidence that all 
contaminated sites and all health risks they present will be identified, 2) to take samples of environmental media from these sites for analysis by an independent laboratory, 3) to see that the sample data from DOE's contractor laboratories is valid and that it is correctly interpreted, and 4) to provide for full public involvement in decision-making regarding the objectives and methodologies employed in the ER program, as well as to respond meaningfully to publicly expressed concerns regarding the direction and goals of NMED's own oversight program.

\section{ER Groundwater Issues}

DOE/LANL has taken the position that contamination of groundwater by its operations is not a realistic possibility (e.g., Operable Unit 1078 RFI Workplan, section 2.3, page 2-10, Fact sheets for ous 1129, 1071, etc.). NMED's Oversight Program is withholding fudgement on this issue, but has identified several reasons for serious doubt regarding the lack of a groundwater contamination threat. These are that 1) seismic faults in the area are of relatively recent (Holocene) age and may provide pathways to groundwater, 2) groundwater recharge areas exist near waste generation/discharge points, 3) buried alluvial drainages (epiclactic units) 300 feet into the Bandelier tuff could provide contaminant migration pathways, and 4 ) open joints in the tuff are extremely common and have been identified as continuous over distances exceeding 50 feet. Accordingly, NMED's DOE Oversight Program has concluded that direct, physical evidence must be obtained in order to address this issue.

Co-disposal/Co-location

LANL has proposed in many RFI Workplans that chemical contaminants have been almost invariably disposed of in combination with radiological wastes (co-disposal) and that chemical contamination will generally be found together with radiological contamination (co-location). If this assumption is made, chemical contamination can be reliably located using radiation detecting field instruments (e.g., oU 1078 RFI Workplan, section 7.2.2). NMED has stated reasons why this may not be a technicaliy acceptable practice: 1) records are generally not complete enough to verify co-disposal, and 2) soils act to separate contaminants of different chemical makeup, a process which might cause contaminants which were codisposed to no longer be co-located. 
Miscellaneous RFI Workplan Problems.

The RFI workplans have been generally inadequate in their approach to determinations of the total depth of contamination at SWMU's. After comments on this issue from both NMED and EPA, this problem has been resolved.

The workplans seemed to rely too much on "expert judgement" to determine exactly where samples would be taken. After several site visits with LANL team members, oversight staff agreed that in the frequently rocky and steep terrain found on and around the plateau, there may frequently be no better means of sample location determination than "expert judgement". NMED's conclusion has been that NMED staff need to participate fully in these "expert" decisions in order to ensure that the public interest is protected.

Analytical data is grouped by the level of quality control used in verifying accuracy and precision. The RFI Workplan for Technical Area 21 employs data of an inappropriately low level for the final site assessment. This issue has been resolved.

Many RFI Workplans have been too vague regarding the certainty and nature of site assessment which will follow the initial phase. This issue is being addressed.

NMED has indicated it would like to see closer spacing in the radiation surveys performed at sites, e.g., TA-21.

NMED staff attended a meeting with LANL, DOE, and Kaiser Engineering to discuss the state's comments on the Sampling and Remediation Plan for Mercury-Contaminated Solls at TA-3-30. LANL essentially agreed to meet all the state's recommendations and requirements. It was decided that the NMED will accept compositing of samples when the detection limits are low enough that existing problems will not be missed by compositing.

In general, NMED has found LANL and DOE to be reasonable and responsive to NMED suggestions.

\subsubsection{Waste Management}

NMED is also evaluating the environmental impacts of waste management at LANL. Staff are currently assigned to evaluate both the existing practices at TA-54, Area G, and the technical elements of the Mixed-Waste Disposal Facility proposed for TA-67. Oversight staff who have toured the Area $G$ facility have noted the existence of significant and apparently continuous joints or cracks in 
the volcanic tuff which comprises the rock matrix into which the disposal pits and shafts have been excavated. Review of studies performed to date by LANL regarding tritium movement through this matrix is underway.

\subsubsection{Corrective Action}

The SWQB acting as the lead NMED Bureau, investigated a mercury release at SWMU \#3-010 and initiated immediate response for corrective action and cleanup. AIP staff met with DOE, LANL and EPA regarding corrective actions. Staff reviewed and commented on the corrective action and sampling plan.

\subsubsection{Quality Assurance}

During 1992 it was decided that quality assurance of environmental air measurements would be a major focus of the Air Quality Bureau (AQB) portion of the AIP program. The need for improved quality assurance of air measurements at the facilities is a general observation of NMED facility representatives and also a conclusion reached by the Tiger Team that visited LANL during 1992 . The Hazardous and Radioactive Materials Bureau plans to deploy TLD's and low volume samples at the facilities, and it has been agreed between the $A Q B$ and HRMB that the quality assurance of these measurements should be done by the $A Q B$ so that monitoring and quality assurance personnel are separate.

\subsection{SNL/ITRI Oversight}

\subsubsection{General Oversight Activities}

NMED staff accompanied SNL environmental staff on offsite radiation surveillance sampling of soil, sediment, surface water and biota. In addition, staff observed exchange of environmental dosimeter TLDs. Information derived from these activities will be used in the preparation of a deliverable regarding radiation surveillance and in development of NMED's monitoring program.

NMED staff observed drilling of monitor wells at the SNL Chemical Waste Landfill, Mixed Waste Landfill and ITRI lagoons. Oversight staff continued to provide technical support to the HRMB on issues regarding closure of the Chemical Waste Landfill.

Staff toured remote SNL Environmental Restoration Sites. Radiation surveys were conducted and composite samples taken for gamma-spectral analysis. Levels of 
radioactivity many times in excess of background were detected at one site not previously characterized as being radioactively contaminated. Other tours were to Manzano Base to evaluate potential waste management concerns and the SMERF burn at the SNLA's burn site.

Analytical data from sampling activities at ITRI has been received from the laboratory and are being compiled and analyzed. Staff is coordinating review of closure plans for ITRI lagoons with the Ground Water Protection and Remediation Bureau.

Staff performed oversight of ground water sampling procedures employed during the February 1992 Quarterly Ground Water Sampling at the Chemical Waste Landfili (CWL). The NMED critically evaluated all aspects of SNLA's field sampling procedures including: sampling equipment, field instrumentation, field calibration techniques, well purging, measurements of standard fleld parameters and well stabilization, sample collection, sample containers, sample preservation and filtration, sample handiling, well site conditions, and field quality control. DOE oversight staff identifled very few problems with the fleld sampling procedures currently employed by SNLA. Minor deficiencies noted include:

no plastic drop cloth was used during sampling to contain potentially hazardous water spills and a photoionization detector is not a suitable method for determining the presence of nonaqueous-phased liquids.

Oversight staff observed water level measurements and inspection of sampling pumps being performed by SNL at the CWL in May. The purpose of NMED's oversight of such measurements was to critically assess SNLA's equipment, survey procedures, and decontamination procedures. Accurate and careful measurements of static water levels are required to determine the direction and gradient of ground water flow. Other than a couple of wells lacking permanent survey reference points (since corrected), no other deficiencies concerning water level measurements were identified.

NMED Oversight staff inspected sampling pumps at the CWL on May 13-14 to assess corrosion reported by SNLA. SNLA has long argued that $C r$ contamination seen at the CWL is the result of well component corrosion and natural sediments. There was extensive variability in the amount of corrosion observed. When substantial corrosion is present, most of the corrosion is generally concentrated on one side of each pump. NMED staff have speculated that the bulk of this corrosion may be the result of storing the pumps wet, wrapped in plastic, between 
sampling events. Other independent evidence suggests that the chromic acid surface impoundments are the source of chromium contamination at the CWL.

Oversight staff accompanied SNL staff on basewide ground water sampling in August. Only wells considered by SNLA to be uncontaminated are included in the basewide ground water monitoring program. The objective of NMED's oversight of SNLA's basewide monitoring program is to evaluate SNLA's sampling procedures and to become familiar with the locations of the vasious monitor wells, springs, and other sampling points included in the program.

NMED staff observed the quarterly ground water sampling at the CWL. This oversight effort was intended as an "unannounced inspection" to check the consistency of SNLA's field sampling procedures. The same field procedures were being followed as before, and no other problems other than those discussed previously were noted.

SWQB AIP staff toured SNL's stormwater monitoring sites with SNL and IT Corp. Staff. There are 10 locations located throughout SNL which are being monitored for SNL's NPDES Stormwater Permit.

The GWPRB AIP representative at SNL has reviewed SNL and ITRI Site Characterization work Plans and NEPA Environmental Assessment documents and has toured the various ER Sites, observing soll-vapor surveys, monitorwell installations and innovative-technology demonstrations.

\subsubsection{Waste Stream Audits}

HRMB-DOE Oversight staff accompanied NMED RCRA inspectors on an unannounced compliance evaluation inspection (CEI) the week of August $17-21$. The inspection covered most of the treatment, storage and disposal sites, including some remote sites which had not been covered in previous inspections.

\subsubsection{Sampling Activities}

Sampling at SNL

May 1992 RCRA Comprehensive Monitoring Evaluation

NMED DOE Oversight staff provided technical and logistical support to the HRMB-RCRA program in conducting a RCRA comprehensive monitoring evaluation (CME) of the 
Chemical Waste Landfill (CWL) in May 1992. Tlie objectives of the CME are to determine facility compliance with 40 CFR 265 subpart F, evaluate technical vs regulatory compliance of the groundwater monitoring system, make recommendations to bring groundwater monitoring systems into compliance, and to ensure that data collected are valid and of high quality.

The history of the CWL, as taken from the Sandia National Laboratories "Ground-water Monitoring Program Calendar Year 1991 Annual Report, is as follows. A monitoring well network was established at the CWL in the summer of 1985. Five monitoring wells (MW-1, $M W-2, M W-3, B W-1$, and BW-2) were installed at this time using a mud-rotary drililing method. These wells were determined to be inadequate as RCRA monitoring wells as they were completed at various depths within the aquifer, with screened intervals ranging from 70 to 460 feet in length. In 1988, four additional monitoring wells were installed at the CWL using air-rotary casing hammer techniques. These wells (MW-1A, $M W-2 A, M W-3 A$, and $B W-3$ ) have 20 feet screened intervals located from 5 feet above the water table to 15 feet below the water table. Another well (CWL-MW4) was drilled in 1990, using a combination of auger and mud-rotary techniques.

After establishing background conditions by sampling for indicator parameters on a quarterly basis for one year, the sampling interval was changed from quarterly to semiannually for groundwater contamination indicator sampling and annually for groundwater quality sampling, as allowed by $40 \mathrm{CFT} 265.92(\mathrm{~d})(2)$. However, on the first semiannual sample collection event, a statistically significant change in the values of contamination indicator parameters was detected, and trichloroethene (TCE) was discovered in downgradient well MW-2A. Therefore, indicator parameters were resampled in accordance with 40 CFR $265.93(\mathrm{C})(2)$. In addition, volatile organics were resampled to confirm the presence of TCE. The May 1990 resampling results confirmed the presence of TCE in the groundwater. Subsequently, an assessment monitoring program was begun in accordance with 40 CFR 265.93(d)(2). The assessment monitoring program includes quarterly monitoring for the constituents of concern (TCE) and annual monitoring for the Appendix IX parameters.

NMED staff performed full Appendix IX sampling using methods with the lowest method detection limits (MDLs) including Method 8010 and 8240 for VOCs, and Method 7191 for Total Chromium. SNLA only analyzed for their quarterly assessment monitoring target compound list 
which lncludes among other methods sampling for voc's using method 8240 , metals using various methods including method 7191 for total chromium. A comparison of these results is provided in Table I.

Because HRMB requested analytical methods which had lower MCLs some compounds were identifled in the groundwater that were not detected by SNLA (see Table I). SNLA has subsequently been requested by the HRMB RCRA program to use methods with the lowest MDL's (e.g. method 8010 as well as 8240 for volatiles) when performing subsequent Appendix IX sampling.

November 1992 CWL Split Sampling

The objective of splitting senples at the November 1992 quarterly sampling event at the CWL was to confirm contaminants found during the above CME and to determine that SNLA was indeed using analytical methods required by HRMB as a result of the CME. The history of the landfili is summarized above.

The following laboratory analytical methods were used during this split sampling event; 1) Method 8010 for VOCs, 2) Method 8240 for semi-volatiles (looking particularly for TEPP), and 3) Method 7191 for Total Chromium (samples for chromium in BW-2 only). See the results of SNLA's and HRMB's sampling in Table II.

December 1992 Tech Area 2 Split Sampling

The objective of splitting samples at the Tech Area 2 (TA2) was to determine if there was groundwater contamination in a perched aquifer located 330 feet below ground surface.

This is the first groundwater investigation at TA2 which is a result of the SNLA "Interim RCRA Facility Investigation Workplan for Technical Area 2". TA2 is the only SNLA facility which qualifies as time-critical investigation activity in the Environmental Restoration Program. This is the case because of the long history of waste disposal, the nature and volume of contaminants disposed, and the proximity to the Kirtland Air Force Base groundwater production wells. The first well was 
TABLE I

\section{MAY 1992 CME SPLIT SAMPLING AT CWL BRMB/SNLA}

ORCRMICS (PPB) mi1a MH2A MH3A

BRIB

Bria

TCE

1.1

ND $<5$

$3 \cdot 9$

5.3

1.3

ND $<5$

TCA

. 8

ND $<5$

TEPP

1

NS

$1,1-D C E$

.3

ND $<5$

FREON

$$
.6
$$

ND $<5$

METAIS (PPM)

MN1A

GRMB

BRLA

cr

.003

ND<.0004

MHA

MN4

BK3

Bพ2

Bพ1

1.4

NS

BW1

Bw2

BW3

2 
ORGMICS (PPB) MN1A

\section{GRIB}

SRTA

TCE $\quad .6$

TCA

\section{TABLE II \\ NOVEMBER 1992 SPLIT SAMPLING AT CWL HRMB/SNLA}

MN2A

MT3A

Mars

BW3

Bพ2

2.6

.2

2.2

3

.2

METRTS IN-1A

M2A

MW3A

NW4

BW3 BW2

(PPH)

ERUB

BERA

Cr

.003

.0084

.012

.0019

$.190 \quad .123$

Ni

.057

.048

.073

.07

.156

.107

$\mathrm{Ba}$

$$
.06
$$

.063

.057

.074

$.044 \quad .056$

Zn

$$
.018
$$

.036

.0063

.031

.025

.0075 
installed with the experimental sonic drill rig. Perched water was detected at 330 feet below ground surface. As per the RFI Workplan, SNLA completed a well screened in the perched aquifer. SNLA attempted to develop the well to reduce turbidity but were unsuccessful and proceeded to sample the well regardless of the high turbidity readings.

Partial results of the split sampling performed by HRMB are listed in Table III. The well was sampled for Appendix IX parameters, gross alpha and beta, gamma spectroscopy $(100-2000 \mathrm{KeV})$, major anions/cations, specific conductance, pH, nitrate, total Kjeldahl nitrogen, ammonia, and total dissolved solids. An additional one galion sample was taken for radionuclides (currently in storage), but the sample will not be submitted to SLD unless warranted by other radiochemistry results. The Appendix IX parameters were analyzed by a contract laboratory; all other parameters are being analyzed by SLD. Only the HRMB Appendix IX analysis has been completed to date. The sampling results from SNLA are not yet available and are not expected for at least a few months.

May 01-08 CWL, split Sampling for Immiscibles and Metals

Split sampling was conducted at the CWL on May 1-8 to determine if nonaqueous-phased liquids (immiscibles) were present in the downgradient monitor wells. Split sampling was also done to evaluate SNLA's claim that chromium contamination in "background" monitor well CWLBW3 was caused by corrosion of stainless steel well components.

A. Split Sampling for Immiscibles

Results for trichloroethane (TCE) are tabulated below:

$\begin{array}{lll}\text { We11 \# } & \text { TCE/TOP } & \text { TCE/BOTTOM } \\ \text { CWL-MW1A } & \text { NS } & 0.6 \mathrm{~J} \\ \text { CWL-MW2A } & 19 & 18 \\ \text { CWL-MW3A } & \text { NS } & 16 \\ \text { CWL-MW4 } & \text { NS } & 0.5 \mathrm{~J}\end{array}$

*NOTES: Method Detection Limit (MDL) was 1 ppb. " $J$ " means compound present below MDL, but not quantifiable. "NS" means not sampled. "TOP" means the sample was bailed from the top of the stagnant water column. "BOTTOM" means the sample was bailed from the bottom of the stagnant water column. 
TABIE III

DECEABER 1992 SPLIT SAMPLIKG AT TA2 WELI TA2-8W1-309

MRYB

$\begin{array}{ll}\text { ORGANICS (PPB) } \\ \text { TOLUENE } & 2 \\ \text { METALS (PPM) } & \\ \text { Cr } & .023 \\ \text { Lead } & .006 \\ \text { Cu } & .012 \\ \text { Ba } & .245 \\ \text { Vanadium } & .016 \\ \text { Zn } & .040\end{array}$


In addition to TCE, methylene chloride was detected above MDL in CWL-MW4 and CWL-MW3A at 1.10 and $1.80 \mathrm{ppb}$; respectively. 1,1,1-trichloroethane (TCA) was found in CWL-MW3A at 2.60 ppb and in CWL-MW2A at $2.00 \mathrm{ppb}$ (Top and Bottom). 1,1-Dichloroethene was detected in CLW-MW2A at $2.30 \mathrm{ppb}$ (top) and $2.10 \mathrm{ppb}$ (bottom).

The low levels of TCE and other organic compounds encountered during this split sampling suggests that no immiscibles were present in the downgradient monitor wells at that time.

\section{B. Split Sampling for Chromium}

The sample bailed from CWL-BW3 without purging the well resulted in $0.15 \mathrm{mg} / \mathrm{l} \mathrm{Cr}$ (and $<0.05 \mathrm{mg} .1 \mathrm{Ni}$ ). Another sample collected following standard well purging procedures (for low-yield wells) during the May $1992 \mathrm{CME}$ resulted in $0.113 \mathrm{mg} / \mathrm{l} \mathrm{Cr}$ (this sample was analyzed by Analytical Technologies, Inc.). The data indicate that stainless steel well components are contributing very little to the chromium load of contaminated groundwater in CWL-BW3. The data also indicate that the chromium concentration in CWL-BW3 exceeds the New Mexico Water Quality Control Commission (WQQC) standard for Chromium $(0.05 \mathrm{mg} / 1)$.

May 20 CWL, Sampling of Monitor Well CWL-BW3 for Chromium

A ground water sample was taken from CWL-BW3 following standard well purging procedures on May 20 for comparison with a sample collected on May 1 (details discussed above). The sample was submitted to the scientific Laboratory Division (SLD) to be analyzed for $\mathrm{Cr}$ and $\mathrm{Ni}$. Analytical results are not yet available from SLD.

A second sample, analyzed by Analytical Technologies, Inc., as part of the May $1992 \mathrm{CME}$ resulted in $0.113 \mathrm{mg} / \mathrm{l}$ Cr.

July 17 Sampling at Mixed Waste Landfill

SNLA's Mixed Waste Landfill (MWL) was established in 1959 as a land disposal facility for radioactive, hazardous, and mixed wastes. The MWL occupies approximately 1.6 acres and is located in the north-central portion of Tech Area 3. Hazardous wastes were accepted at the MWL from 1959 to 1962, until establishment of the CWL. Radioactive wastes were disposed at the MWL from 1959 to December 1988. Wastes disposed at the MWL include acids, heavy metals, beryllium, organic solvents, oil and petroleum products, lead shielding, liquid scintillation 
cocktails, uranium, thorium, transuranic wastes, fission products, and tritium. Very large amounts of liquids have been historlcally discharged at the MWL. Preliminary data suggest that groundwater at the MWL may be contaminated with heavy metals. In addition, the direction of groundwater flow at the MWL is not known with certainty.

Priox to July 1992, groundwater at the MWL had only been sampled using parameters specified in 40 CFR 265.92 (b) (1$3)$, which included Appendix III parameters for drinking water quality, parameters establishing groundwater quality, and parameters used as indicators of groundwater contamination. DOE Oversight staff were concerned that such parameters are not effective for cases such as the MWL. For this reason, all four of the monitor wells at the MWl were sampled as a preliminary screen for volatile organic compounds (VOCs), chromium, and nickel. The monitor wells were sampled using a bailer (without purging). All groundwater samples were field-screened for radiation; however, no radiation levels above background were detected.

1,1-dichloroethene, ranging form 1.4 to $2.6 \mathrm{ppb}$, was detected in all of the monitor wells. Methylene chloride was found in trace concentrations in all wells, except MWL-MW1. The above data are inconclusive. Split samples collected by NMED, on July 27-29, 1992, support a preliminary conclusion that groundwater at the MWL has not been contaminated with vOCs or other organic compounds at this time.

Chromium and nickel results for all of the monitor wells have not yet been reported by SLD. Additional sampling for heavy metals and organics is strongly recommended.

Radiochemistry: Results of gamma spectroscopy revealed no gamma emitting nuclides in any of the samples submitted. However, the methodology employed would discriminate against any volatile materials such as radioiodine. Additional analysis for gross alpha/beta and tritium further revealed low levels commensurate with background.

October 29 G-Spring, G Spring Sampling for Metals, BNAs, TOC, SWQB Nutrients, VOCs, and Radionuclides

Surface water sampling was conducted at G-Spring, a seep located in Arroyo del Coyote approximately $0.5 \mathrm{miles}$ west of Coyote spring. The spring was sampled by NMED/DOE Oversight staff after hearing rumors that SNLA has dropped the spring from its basewide sampling program on 
the grounds that it was "found to be contaminated".

G-Spring was sampled for SDWA metals (plus nickel), SWQB Nutrients (nitrates, ammonia, TKN, Total Phosphorus), Gross Alpha, Gross Beta, Gamma Spectroscopy (SLD Method 841), $\mathrm{Am}, \mathrm{Pu}$, and $\mathrm{U}$. Laboratory results for all of the above are not yet avallable.

Sampling and Oversight at ITRI

Sampling and oversight of sampling was conducted at the ITRI sewage lagoons during the months of May and October, 1992. These activities are described briefly below.

May 27 Lagoons, Quarterly Sampling

The sewage lagoons at ITRI (now inactive) have contaminated groundwater with nitrates and Total Dissolved Solids above New Mexico WQCC standards. The lagoons were operated under Discharge Plan DDP-519 issued in June 1988 by what is now the Ground Water Protection and Remediation Bureau of the NMED.

As mentioned previously, sampling procedures must be conducted carefully to ensure environmental samples are of the highest quality. Thus, the objective of NMED's oversight of quarterly groundwater sampling at ITRI was to comprehensively evaluate their field sampling procedures and to obtain split samples to verify that the facility is collecting representative, high-quality samples. The NMED critically evaluated all aspects of ITRI's field procedures including: sampling equipment, field instrumentation, field calibration techniques, well purging, measurements of standard field parameters and well stabilization, sample collection, sample containers, sample preservation and filtration, sample handling, well site conditions, and field quality control.

NMED DOE Oversight staff Identifled several problems with the field sampling procedures currently employed by ITRI, including: excessive flow rates are used during the collection of samples for volatile organic compounds, filtering of samples taken for metals, inadequate purging of monitor wells, lack of a detalled written groundwater sampling and analysis plan, and insufficiently trained sampling personnel.

The following monitor and piezometer wells were sampled by NMED staff and submitted to SLD: 
Well ID\#

$\mathrm{p}-4$

MW-4

$M W-6$

$M W-8$

MW-1

$M W-3$

$M W-3$

$M W-15$
Parameters

N

VOCs, $N *$

$\mathbf{N}$

N

VOCs, N

VOCs, BNAs, $N$, Metals**

VOCs (Fleld Replicate)

Field Blank (for $N$ )

* NOTE: N means nitrugen as nitrate and nitrite, TKN, and ammonia

* * NOTE: Metals include $\mathrm{Hg}, \mathrm{Cu}, \mathrm{Zn}, \mathrm{Cd}, \mathrm{As}, \mathrm{Be}, \mathrm{Pb}, \mathrm{Cr}$

Laboratory results for heavy metals have not been received from SLD at this time.

\section{A. Nitrate Results}

Concentrations of nitrate exceeded the WQCC standard of $10 \mathrm{mg} / 1$ in monitor wells $\mathrm{MW}-1$ and $\mathrm{MW}-3$. Except for a low level reported for one sample, nitrate levels were found to exceed $10 \mathrm{mg} / 1$ in $\mathrm{MW}-4$.

The following tables summarize sampling results for the HRMB, GWPRB, ITRI, and GWP-DOE for the May 27, 1992 sampling event: 
NITRATE (N as Nitrate + Nitrite, $\mathrm{mg} / \mathrm{l}$ )

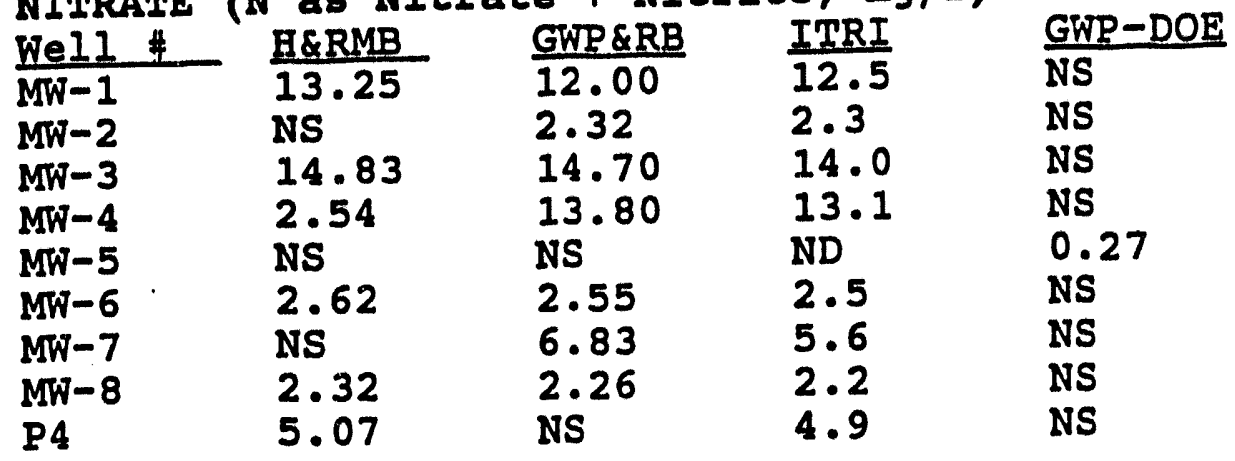

\begin{tabular}{|c|c|c|c|c|}
\hline We11 \# & H\&RMB & GWP\&RB & ITRI & GWP-DOE \\
\hline$M W-1$ & 0.67 & 0.70 & 0.68 & NS \\
\hline$M W-2$ & NS & 0.10 & ND & NS \\
\hline$M W-3$ & 0.60 & 0.95 & ND & NS \\
\hline$M W-4$ & 0.91 & 1.35 & 1.2 & NS \\
\hline MW-5 & NS & NS & ND & 0.32 \\
\hline$M W-6$ & 0.19 & 0.16 & ND & NS \\
\hline$M W-7$ & NS & $<0.10$ & ND & NS \\
\hline$M W-8$ & 0.18 & $<0.10$ & ND & NS \\
\hline P4 & 2.70 & NS & ND & NS \\
\hline
\end{tabular}

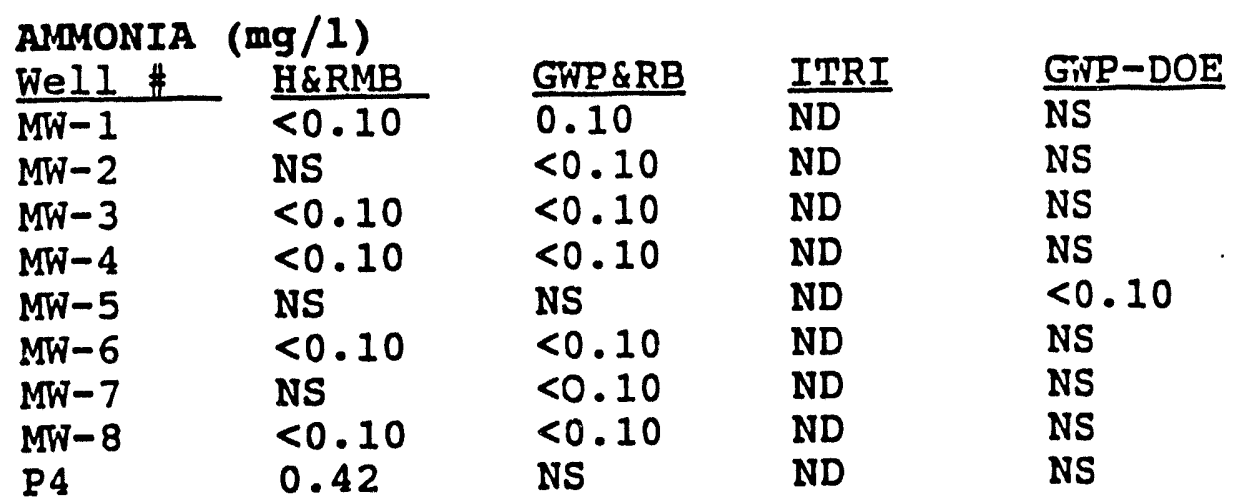


NOTES: ND means no detect. NS means not sampled. ITRI data taken from ITRI CY-1992 Quarterly Report Apr11 1 June 30, 1992. GWP-DOE samples taken by B111 MCDonald as sample SLD \#022030.

\section{B. Base/Neutral/Acid Extractables (BNA) Results}

No BNA compounds were detected in MW-3, with the exception of Bis (2-ethylhexy1) phthalate (56 ppb) and D1-n-octylphthalate (trace at 1 ppb). However, both detected compounds (phthalates) are used as plasticizers in the manufacture of plastic tubing and containers, and thus are common laboratory and fleld contaminants.

\section{VOC Results}

Despite problems with ITRI's sampling procedures, oxylene was detected in monitor well $\mathrm{MW}-1$ at $2.50 \mathrm{ppb}$. A trace of o-xylene was also found in MW-3 in one of the field replicate samples.

Three volatile organic compounds were detected above their minimal detectable levels in both MW-3 field replicate samples, preserved in $\mathrm{HgCl}$ and $\mathrm{HCl}$; respectively:

1. Trichlorofluoromethane was found in concentrations of $19.70 \mathrm{ppb}$ and $15.60 \mathrm{ppb}$.

2. Naphthalene was detected at 2.90 and $3.40 \mathrm{ppb}$.

3. $1,2,4$-trimethylbenzene was detected at $1.30 \mathrm{ppb}$ in both samples.

In acdition, traces of $\mathrm{p}$ - and m-xylene; 1,3,5-trimethylbenzene, and methylene chloride were also found in monitor well $\mathrm{MW}-3$.

D. Radiologic Analysis

NMED results confirmed elevated gross alpha values in monitor wells $1,2,3,4$ and 5 . NMED sampling also confirmed slightly elevated levels of Uranium 234 and 238 in all four wells. Thorium-230 was detected in wells 1 and 3. Plutonium-239 and 1ts ingrowth product, Americium-241 were also detected, the former in wells 2,3 , and 5 . Well 2 is the only well in the monitoring net in relative proximity to the inactive "hot ponds".

June Sewage Lagoon Monitoring

While overseeing annual sampling by ITRI of the sewage lagoons, duplicate samples of the sludge and supernate were obtained for analysis by the SLD. Sampling 
locations in each lagoon consist of six points on a regularly spaced grid which are composited into a single sample for each lagoon. Llquid supernate samples are depth integrated composites from three depths: surface, half of total depth, and just above the bottom. The results for the sludge samples are as follows:

$\begin{array}{clll}\text { Lagoon * } & \text { Pu-238 } & \text { Pu-239/240 } & \text { C8-137 } \\ 2 & 0.10(0.32) & 0.00(0.11) & 6.1(21 \\ 3 & 0.10(1.10) & 0.00(0.88) & 0.8(5) \\ 5 & 0.00(0.01) & 0.00(0.05) & 0.7(0.9) \\ 6 & 0.00(0.10) & 0.00(0.06) & -\end{array}$

Results are in $\mathrm{pCl} / \mathrm{g}$, the first figure is for ITRI, those in parenthesis are NMED.

General observations of comparative trends suggest that ITRI analysis results slightly underestimate activities. This may be a consequence of spatial or temporal varlabllity or of the generally higher variablilty in the ITRI counting data. Results for the supernatant revealed lower concentrations.

October 06-07 Lagoons, VOC Sampling

Samples were collected from the following ITRI monitor wells for the purpose of confirming the presence of VOCs in groundwater: MW1, MW3, MW4, MW5, and MW15 (fleld blank). Sample results are pending analysis by the SLD.

The GWPRB AIP staff member at SNL collected samples for background water chemistry sitewide at KAFB, for a stable/nitrogen isotope study of the Tijeras Arroyo/Hells Canyon area and for determining contamination levels at ITRI and SNL environmental restoration (ER) sites. These samples were analyzed for one or more of various parameters: organics, metal, radionuclides and general chemistry. The background water chemistry involved splitting samples with sNL from 20 wells and 2 springs. The isotope study involved sampling approximately 30 wells, 5 springs and 2 streams, on and off the base. The ITRI study involved sampling 8 monitoring wells and 2 piezometers. The SNL ER-site study involved sampling 8 monitoring wells, one septic system leachfield and one explosives burn pit.

\subsubsection{Environmental Restoration/Cleanup Activities}

The Environmental Restoration program at SNL will address approximately 226 suspected disposal or spill sites. This program is about a year behind that at LANL. No 
complete REI workplans have been drafted to date. MMED staff have begun famillarizing themselves with sNL's organizational structures and operable unit histories.

Sample results collected for the Environmental Restoration component of the oversight program are located in section 3.3 .3 of this report.

\subsection{WIPP Oversight}

\subsubsection{General Oversight Activities}

Three tours of the surface and underground at WIPP were provided to NMED AIP staff located in santa Fe. Additionally, the SWQB AIP staff member toured the surface to familiarize himself with the surface water runoff during storm events. The SWQB staff member met with WIPP representatives and discussed the best management practices for storm water runoff from the s1te.

NMED WIPP Oversight staff met with Westinghouse Environmental Monitoring personnel to discuss the WIPP well inventory and information on well completion, water quality and interpretation of the information (all part of a DOE deliverable to NMED).

Sampling and analysis plans for the NMED soll sampling program FY 1992 at WIPP were developed following a review of historical environmental data collected at the site. An assessment by NMED staff of the 1985-1991 DOE/WIPP Operational Environmental Monitoring Plan (OEMP) revealed that no significant measurement of nonradiological constituents ( $1.0 .$, organlc chemicals and heavy metals) in solls surrounding the WIPP site had been documented. Radiological soll sampling was found to be sufficient, given the scope of the DOE/WIPP program and duplicate split samples taken 1985-1991 by the Environmental Evaluation Group (EEG). Although the emphasis of the radiological solls program is to collect spilt samples to ensure analytical accuracy, three new previously unsampled locations chosen for FY 1992 provided NMED staff an opportunity to measure DOE/WIPP representativeness of sample population.

NMED staff finalized the sampling and Analysis Plan (SAP) In preparation of a sampling event to assess WIPP SWMUs. The SAP was also implemented in acquiring soll and drilling mud pit waste samples. Staff developed a unique method of obtaining sediment samples using a modified hand auger and syringe. The technique minimizes 1088 of volatile organic contaminants in the sample. 
MED staff continued to work on preparation of the RCRA Fac1lity Assessment (RFA) for WIPP. A progress report was prepared and transmitted to the HRMB in santa Fe. The assessment involves fleld verification of all the potentialiy contaminated sites within the WIPP facility boundary that are reported in the 11 terature, as well as a systematic survey for any additional potentially contaminated sites.

\subsubsection{Waste Stream Aud1t8}

MMED Oversight staff have particlpated as observers on two WIPP Waste Acceptance Criterla Certification Committee (WACCC) audits during 1992, one at the Rocky Flats Plant, and another at Argonne National Laboratory East.

Rocky Flats Plant (RFP) Aud1t

NMED staff geologist Paul Sanchez foined zeola smith (Analytical Chemist, EPA) and $M$. Silva and J. Channel (EEG) as oversight observers for the August 10-14, 1992 Rocky Flats Plant by the WIPP WACCC certification team. The scope and purpose of the audit was to verify implementation of programs, procedures, and plans identified in the following Rocky Flats documents:

- TRU Waste Management Plan (TWMP, RFP Manual 110000-EWQA, Section 1.2, Rev. 0, Dated 3-16-92)

- RFP Compliance Plan for TRUPACT-II Authorized Methods of Payload Control (TRAMPAC, RFP Manual 110000-EWQA, WP-1900, Rev. 1.0, Dated 1-10-92)

- Quality Assurance Profect Plan for WIPP ExperImental Waste Characterization Program (QAPJP, RFP Manual 1-10000-EWQA, Section 1.2.1, Rev. O Dated 48-92)

NMED staff accompanied the subgroup of auditors concerned with waste characterization, waste handling, and RCRA 18sues. Four general points of interest and 9 specific comments were complled for an inhouse NMED report. The overall assessment of the RFP program was favorable, Including waste certification procedures, resolution capability of the RTR system, and waste stream documentation system.

Argonne National Laboratory - East Audit

John Parker, Program Manager for the Mixed Waste Section of the Hazardous and Radloactive Materials Bureau 
particlpated as an observer on the October 26,1992 audit of Argonne National Laboratory East. Also representing New Mexico were Loren Berge, and Rick Meyerhein, who manage the state scientific Laboratory Division's Radiochemistry and Organic Chemistry Laboratories. The scope of the audit was to verify the Laboratory's compliance with the requirements contained in the ANLEast Quality Assurance Project Plan. NMED's perception of the audit was that while written procedures were thoroughly reviewed, the evaluation of the Laboratory seemed superficial. It was stated during the exit briefing that another audit would follow where actual procedures employed by laboratory personnel would be compared to the appropriate written procedures.

Rocky Flats Plant Tour

Three NMED staff participated in a tour of the waste generation, storage and characterization facilities at Rocky Flats Plant (RFP) in January 1992. The tour was very beneficial as it acquainted staff with the size of the waste storage problem at RFP and provided an opportunity to see equipment such as the real-time radiography unit, supercompactor, and waste reduction vault.

\subsubsection{Sampling Activities}

Radiological Sampling of Solls

Radiological solls samples were collected by DOE/WIPP between September 1-11, 1992 at six locations, including the WIPP Far-Field (WFF) station, Lo Vol locations WSS, WEE, SEC, and Mills and Smith Ranch. NMED staff accompanied and observed DOE/WIPP sampling events at the WEE location (near the east salt pile) on september 10, 1992 and at the Mills Ranch on September 11, 1992 , Samples collected by Westinghouse staff from all 6 locations were split and submitted to NMED for independent analysis.

NMED staff focused analytical tests on split samples collected from WFF, Mills Ranch and Smith Ranch for two reasons: 1) no analytical data has ever been collected for these sites and 2) a preoperational baseline has already been established for Lo Vol stations WSS, WEE, and SEC. Three samples $(0-2 \mathrm{~cm})$ were sent to SLD to determine background levels for gross alpha/beta, gamma spectroscopy (100-2000kev), and $\mathrm{Pu}-238 / 239+240$ for each of the respective sites.

Nonradiological Sampling of Soils 
An independent sampling program was developed to quantify artificial levels of organics, hydrocarbons and heavy metal constituents at the WIPP site. One sampling event consisted of sampling three sites immediately adjacent to zone 1 at the WIPP site in minor drainages, areas of sediment accumulation, and areas of suspected artificial 1111. Another sampling event was initlated to investigate mudpits associated with WIPP exploratory wells, and private-venture 011 and potash exploration wells inherited by DOE following the legislative withdrawal of the 16 section area. Three mudpits, out a total of approximately 46 units, were sampled as part of th1s event: DOE-1, Badger Unit, and Cotton Baby.

Twenty-elght soll samples were collected by NMED staff between October 5-7, 1992. Samples were collected by hand auger and placed in containers provided by SLD. stratigraphy and sample locations were logged by NMED staff. DOE/WIPP representatives were invited to the sampling events and collected duplicate samples in their own sample containers. Types of analyses requested from SLD include:

- Aromatic and Halogenated Purgeables (VOC Screen EPA $8010 / 8020)$

- Aliphatic Hydrocarbons (SEMI-VOC Screen EPA 8015)

- Base Neutral Extractables (SEMI-VOC Screen EPA 625)

- Heavy Metals (ICAP Scan)

Groundwater sampling

Ten groundwater wells at WIPP were sampled by NMED Oversight staff between May and October, 1992. While observing DOE/WIPP water sampling activities, staff collected over 100 duplicate nonradiological and 20 radiological groundwater samples at Westinghouse sampling stations. Non-radiological background samples were analyzed for volatile and semi-volatile organic compounds, heavy metals, and general chemical parameters. Radiological samples were analyzed for PU-238/Pu-(239 \& 240), Am-241, Th-230/232, U-238/234, and gross alpha and beta. In addition, the samples were scanned for gamma radiation between 100 to $2,000 \mathrm{Kev}$. Groundwater samples were collected from the Culebra formation at the following well designations:

$\begin{array}{lll}\text { H-6B } & \text { WIPP-19 } & \text { H-4B } \\ \text { H-5B } & H-2 C & H-11 B 3 \\ \text { Barn Well } & H-3 B 3 & \\ \text { Ranch Well } & H-14 & \end{array}$


Analytical results from these samples are still being collated. Once the data packages have all been recelved and reviewed, they will be compared with the DOE/WIPP results.

\subsubsection{Waste Characterization}

One role of the NMED staff located at WIPP is participating in Waste Acceptance Criteria Certification Committee (WACCC) audits of DOE generator sites and to assess the waste characterization program implementation at DOE facilities. This task has required formal and informal review of the following non-WAC documents:

- LLNL Tru-Waste Certification and Quality Assurance Plan (Doc. M-078-121, Rev. 1).

- Rocky Flats "Quality Assurance Project Plan" for the WIPP Experimental-Waste Characterization Program (April, 1992; Rev. 0)

- Argonne Chemistry Laboratory, ANL-East "Quality Assurance Project Plan" for the WIPP ExperimentalWaste Characterization Program (December, 1991; Rev. 1).

- Background - WIPP Waste Characterization Program Sampling and Analysis Guidance (DOE/WIPP 91-043)

- Background - Quality Assurance Program Plan (QAPP) for the WIPP Experimental-Waste Characterization Program (July 1991, Rev. 1) DOE-EM/48063-1

- Background - Performance Demonstration Program Plan for the WIPP Experimental-Waste Characterizatic.z Program.

\section{ASSESSMENT OF COMPLIANCE}

\subsection{LANL}

The SWQB AIP staff member has reviewed the monthly Discharge Monitoring Reports (DMR) submitted by LANL and as required by their NPDES permit \#NM0028355. Also, LANL's weekly monitoring reports of discharge f:om the TA-53 sanitary lagoons outfall 09s are carefully tracked for compliance and protection of state water quality standards. Staff reviewed LANL's surveillance reports to determine if they were monitoring point source discharges associated with LANL's NPDES permit \#NMO028355 in an appropriate and compliant manner. Additionally, staff reviewed Notices of Intent (NOIs) for potable water releases, fire water discharges, and steam condensate discharges. Twenty splll sites at LANL that had corrective actions according to 1-203 WQCC Regulations were inspected. 


\subsection{SNI./ ITRI}

During 1992 AQB AIP staff reviewed the SNL NESHAP Compliance Plan, the draft 1991 NESHAP Annual Report for Sandia National Laboratories, and the 1991 Radionuclide Air Emissions Annual Report for ITRI. Comments were submitted to the DOE on these documents and offsite dose calculations were verified in the latter two. Staff observed several test firings at the smoke emissions reduction facility. To date, tests have not been successful in meeting the 208 visibility limit found in Albuquerque/Bernalilio County Air Quality Control Regulation 5 .

\section{DATA REVIEW AND TREATMENT}

\subsection{ER Data Base}

LANL and NMED have decided to set up a shared data base which will track LANL actions and NMED conclusions regarding all SWMU assessments. This will allow all parties, including the public, to quickly determine the status of any specific sWMU at the Lab as well as the NMED opinions regarding this status.

5.2 Statistical Toolkit

Many sites at both SNL and LANL are suspected of contamination whose specific location and nature is unknown. In many cases the size of a disposal area is also unknown. A variety of statistical approaches are proposed in the eight LANL RFI workplans, and SNL has indicated its intention to use a battery of highly sophisticated, computer-based statistical approaches. NMED has evaluated some of the approaches proposed and has found some to be straight-forward and acceptable while others are convoluted and confusing. The oversight program has recommended that DOE, LANL, SNL, EPA, and NMED select a statistical "toolkit", to include a limited set of statistical approaches to be used at all ER sites in the state. Having done this, DOE/LANL/SNL would organize a statistics seminar to provide basic statistical instruction, an overview of each statistical approach to be included in the toolkit, and a hands-on workshop using each tool. This seminar would be presented for NMED and EPA staff, LANL/SNL/DOE staff, and members of the public.

\subsection{Water Quality Data}

The SWQB has developed a programmable spreadsheet for all water quality data collected at each facility. This 
spreadsheet will be used to facilitate submittal of analytical reports to DOE as deliverables according to the AIP. This format was also developed to allow uploading the data to the EPA computerized national water quality database STORET.

\section{DOCUMENT REVIEW}

The following documents were reviewed by NMED AIP staff. Dates in parentheses indicate if and when comments were submitted to DOE:

Quality Assurance Program Plan for the Waste Isolation Plant Experimental Waste Characterization Program DOE/EM/48063-1 Rev. 2 (January 8, 1992)

- Strategy for the Waste Isolation Pilot Plant Test Phase (January 31, 1992)

Plan for Handling Newly Generated Contact-Handled Transuranic Solid Waste at Pacific Northwest Laboratory - Rev. 2 (January 16, 1992)

- Westinghouse - Quality Assurance Program Plan Certification of CH-TRU Waste WHC-5D-WIA-QAPP-005 Rev. 0 (March 19, 1992)

Lawrence Livermore National Laboratory "TRU-Waste Certification and Quality Assurance Plan" M-078-121 Rev. 1 (April 15, 1992)

Quality Assurance Project Plan (QAPjP) for the Waste Isolation Pilot Plant's (WIPP) Experimental Waste Rev. 1 (ANL-E) WIPP/ANLE-ACL/91-001 (MaY 8, 1992)

Quality Assurance Project Plan for WIPP Experimental Waste Characterization Program (QAP JP), RFP Manual 1-10000-EWQA-Section 1, 2 1, Rev. $0-04 / 08 / 92$ (June 18, 1992)

- Rocky Flats Plant Compliance Plan for TRU-PACT-II Authorized Methods for Payload Control WP-1900, Rev. 1.0 (RFP-TRAMPAC) (JulY 5, 1992)

Los Alamos TRU-Waste Certification Plan Attachment \#7 for the Processing of Contact-Handled (CH) TRU Solids from Hot Cell Operations TRU-MST-14-CPA-07, Rev. 1 (July 5, 1992)

- Argonne National Laboratory West - Remote Handled Transuranic Waste Certification Plan W0001-0898-ES- 
01 (November 2, 1992)

- Oak Ridge National Laboratory Contact-Handled Transuranic Waste Certification Program Plan ORNL/TM-10322/R3 (December 28, 1992)

- Computational Approach to determine voc Concentrations Throughout Waste Drum Headspace (December 22, 1992)

- Waste Characterization Program Plan (WCPP), DOE/WIPP 89-025 Rev. 2.0 (December 28, 1992)

Sandia National Laboratory Technical Documents Intergranula: Fluid Compositions from the Waste Isolation Pllot Plant (WIPP) - Southeastern New Mexico SAND 90-0584*VC-721

- TA-21 RFI Workplan, LANL (comments provided to DOE and appropriate contractor)

Interim RFI for Technical Area 2, SNLA (comments provided to DOE and appropriate contractor)

OU1078 RFI Workplan, LANL (comments provided to DOE and appropriate contractor)

OU1071 RFI Workplan, LANL (comments provided to DOE and appropriate contractor)

OU1079 RFI Workplan, LANL (comments provided to DOE and appropriate contractor)

TA-35, TSL 125 Closure Plan, LANL (comments provided to DOE and appropriate contractor)

TRU Waste Size Reduction Facility, LANL (comments provided to DOE and appropriate contractor)

Workplan for Investigation and Remediation of SWMU 3-010, LANL (Mercury spill site) (comments provided to DOE and appropriate contractor)

Environmental status of TA-49, LANL

Geohydrology of White Rock Canyon of the Rio Grande from Otowi to Frijoles Canyon, LANL

TA-16 Area P Landfill Closure Plan, LANL

Public Involvement and Regulatory Case Study: Denver Radium and Monclair, Glen Ridge and West 
Orange sites.

- SNL, ITRI, and LANL Environmental Surveillance Reports pertaining to ground water quality (comments submitted to DOE)

- SNL Annual Ground Water Monitoring Reports and site investigations pertaining to ground water quality (comments submitted to DOE)

- SNL's Environmental Restoration and Waste Management five year plan pertaining to cross connections of wastewater for industrial and sanitary facilities.

\section{EMERGENCY RESPONSE PLANNING}

The role of the NMED with respect to emergency response is to ensure that emergency planning is adequate, that training is comprehensive and realistic, and that communication among all institutions involved and the populace is sufficiently prompt in an emergency.

The AIP provides for a number of activities by the state in emergency response. The necessary expertise to perform these activities does not rest within a single state agency, however, the Department of Public safety (DPS) has the statutory responsibility to direct and coordinate the civil emergency preparedness activities of all state departments, agencies and political subdivisions and to maintain liaison with and cooperate with civil emergency agencies and organizations of the federal government. Therefore, the NMED entered into an agreement with DPS to accomplish the following:

Update and maintain State Emergency Response Plans and assist local governments in updating and maintaining their emergency response plans, based on the threats identified by Response offices.

- Conduct emergency response training and exercises jointly with the DOE, state agencies identified as having a role under the state Hazardous Materials Emergency Response Plan, and local governments (i.e. city, county). Ensure that local and county governments are properly trained to respond to a DOE generated hazardous, mixed or radioactive material emergency.

- Provide incident response support in accordance 
with the state Hazardous Materials Emergency Response Plan, state and local emergency response plans and appropriate memorandums of understanding between the state of New Mexico and DOE.

Emergency response planning and coordination required by the AIP was established on May 6, 1992 with the signing of an Affidavit Agreement between NMED and DPS. During the past eight months a foundation has been set in place which will allow for the coordinated development of plans and agreements between counties/cities which are impacted by DOE facilities.

All Hazard Emergency Operations Plans have been completed and distributed to Emergency Coordinators/managers of Eddy and Bernalillo Counties. These Plans lack in-depth hazard assessment and emergency response capabilities with respect to DOE facilities and will require modification to address these facilities.

An agreement was reached on October 22, 1992 which will allow DPS to coordinate the placement and use of computers and the state supported standard software system, Emergency Information System/Chemical (EIS/C), in communities where DOE facilities are located. This will provide a common platform for city/county/state and DOE facilities to bulid their coordinated emergency response plans (Annex's) and required agreements.

In the past, county and city governments were inundated with SARA Title III reporting requirements, 313 release reports, DOE and DOD Emergency Plans, Natural Hazard and Hazardous Materials Planning and other requirements of EPA, EMA and the state. It would have taken a large staff to assimilate and make use of the information in Emergency Response Planning without the necessary tools. Computer Systems and software packages have been ordered and as soon as they are provided to affected county Emergency Coordinators, the state can begin to input existing data and isolate those areas requiring additional information for Emergency Preparedness. The acquisition of data processing equipment will allow NMED, DPS and DOE to input data to the Emergency Management Plan in a substantive manner.

A two day Beginning EIS/C training session for representatives of each of the DOE impacted Counties was held in santa $\mathrm{Fe}$ and advanced training for the Eddy County representative was provided during a course held in Raton for the WIPPTREX Exercise.

In anticipation of receiving the program, Eddy County has 
purchased its own computer, capable of handling the EIS/C System. While the computer is destined for other uses, it will temporarily allow the Eddy County Emergency Preparedness Director to begin the data input process. By the time the impacted counties receive their data processing equipment and software, Eddy County will be able to establish a rapport with DOE and Westinghouse Emergency Management personnel to bulld a comprehensive, coordinated Emergency Response Plan.

Los Alamos County has recently hired a new Fire Chief who should be on board in January 1993. Unt1l that time, the County officials are reluctant to begin the emergency planning process. However, DPS has been working closely with the Assistant County Manager and the Assistant Fire Chief to make as much progress as possible until the new Chief arrives. DPS has been able to provide the Beginning EIS/C Course to the individual who will be responsible for entering the data. Also a meeting was arranged with County officials and the state Emergency Management Assistance (EMA) Program Representative to explain the Program requirements and monetary assistance. We anticipate Los Alamos County foining the EMA community in the near future. This should allow the hiring of a full time Emergency Coordinator and provide a dedicated point of contact with which the DPS and DOE representatives can work.

Emergency Planning personnel at Los Alamos National Lab have been helpful and seem eager to participate in Emergency Planning at the County level once the County is in a position to utilize their data and expertise. Elements are in place for progress to occur during 1993.

Bernalillo County is in a unique position since they have highly qualified personnel, the ability to handle HAzMAT incidents in a very professional manner, and an existing Memoranda of Agreement for mutual alde response with DOE and DOD facilities.

The State felt it was very important that representatives of the DOE impacted counties attend the WIPPTREX Exercise in Raton. All three counties were represented and came away with the mutual understanding of the importance of emergency planning, exercise and cooperative coordinating effort required to successfully handle a major incident.

8. PUBLIC INFORMATION/PUBLIC RELATIONS

8.1 Reports 


\subsubsection{Quarterly}

As a management tool and to facilitate the development of an annual report each NMED bureau participating in the AIP Program submits quarterly reports to the Director of the Water and Waste Management Division and to the DOE Oversight Chief, describing significant activities and accomplishments during the 3 month reporting period. These reports are utilized as internal documents only.

\subsubsection{Annual Report}

As required by the AIP, NMED submits an Annual Performance Report for environmental monitoring and oversight at DOE facilities in New Mexico. The 1991 Annual Report was submitted on February 11, 1992. This document satisfies the requirement for the 1992 Annual Report.

\subsubsection{Publication of Findings}

Reports by the GWPRB on the isotope study at SNL and the adequacy of monitoring at SNL/ITRI and LANL will be avaliable to the public. More specifically, the 1sotope study will be published in a technical journal and the Adequacy reports will be distributed to various groups and agencles, for example, Isleta and San Ildefonso Pueblos, BIA, and citizen environmental groups, after they are submitted to DOE.

\subsection{INFORMATIONAL MEETINGS}

\subsubsection{General}

On October 15, 1992, NMED hosted a Public Information Meeting at which time NMED Oversight staff presented an overview of the State's involvement in the AIP Program. Invitations were sent to over 220 parties, which included state and federal agencies, local governments, tribal governments, state legislators and public interest groups. Additionally, notification of the meeting was provided to the printed and the electronic news media.

NMED staff stationed at SNL/ITRI have participated in meetings of the Kirkland Air Force Base Working Group and have made presentations regarding AIP activities at SNL and ITRI. Also a good working relationship has been established with the Albuquerque/Bernalillo County Air Quality Control Board, the Air Pollution Control Division of the Albuquerque Environmental Health Department, and citizens groups such as the East Manzano Alliance. Staff periodically attend meetings of these groups. 


\subsubsection{Environmental Restoration/Cleanup}

MMED staff stationed at LANL hosted a meeting with representatives of the San Ildefonso Pueblo, the Los Alamos Study Group, Concerned Citizens for Nuclear Safety, and Citizens for Alternatives to Radioactive Dumping. The major conclusion of this meeting was that NMED was putting all of 1 ts efforts into ensuring an adequate resolution to existing contamination at LANL, but that unless waste management practices at the Lab, specifically; those employed at TA-54, Area G, were environmentally appropriate, as one set of problems were being resolved, a new set could be in the process of being created. Consequently the NMED has included the oversight of waste management practices at the Lab as an objective and considers this to be a major responsibility.

Staff attending the Colorado Center for Environmental Management conference in September and the state and Tribal Government Working Group Meetings reported that there appears to be a virtually universal agreement among states and tribes as well as within both EPA and DOE that public involvement in decision-making with regard to the assessment and cleanup of existing contaminated sites 18 essential to any hope of a successful outcome. NMED has learned that EPA intends to convene site specific Advisory Boards (SAABS) for each federal facility in the country with significant environmental problems. The SAABS will play a major role in decision making on ER issues and will include members of the public.

\subsubsection{Facility Meetings}

NMED AIP staff attend the quarterly public information meetings sponsored by LANL and SNL/ITRI. These meetings provide the public an opportunity to be educated on DOE and DOE/Contractor activities in environmental restoration and address concerns on the facilities operations.

\subsection{NMED/DOE MEETINGS}

\subsubsection{General}

Weekly meetings are held between NMED staff and DOE staff at WIPP. Monthly meetings are held with NMED staff and DOE/KAO staff. The purpose of these regularly scheduled meetings is to discuss upcoming activities, monitoring and sampling schedules and to provide on open line of communication between NMED on-site personnel and DOE Area office staff. 


\subsubsection{B1-Monthly Meet1ngs}

A schedule of bi-monthly meetings has been developed for NMED and DOE AIP staff. The purpose of the meetings 18 to discuss site specific technical 1ssues, administrative matters and to provide an avenue for improved coordination between DOE and NMED. These meetings are attended by both NMED and DOE site Polnte of contact (POCs), a representatlve from each NMED Bureau involved in the AIP Program, the NMED DOE Oversight Program Chief and DOE/AL personnel responsible for administering the AIP.

\subsubsection{Annual Meetings}

Each year an annual meeting 18 scheduled between NMED and DOE to develop an integrated schedule and prioritization of clean-up, environmental restoration, environmental compliance and permitting activities for the upcoming year.

\section{TRAINING}

\subsection{Technical Training}

Four NMED HRMB Oversight staff attended a July 21 seminar on Waste Acceptance Criteria taught by Paul Drez, which covered important modifications to the WAC since the last revision. The focus included analysis of the different regulatory drivers and their impact on the WIPP waste characterization program and waste acceptance criteria requirements for mixed waste at the WIPP facility.

Six HRMB staff attended a seminar on Radloactive site Remediation Technologies provided by EPA in Albuquerque.

One HRMB oversight staff member completed a home study course in emergency management operations.

SWQB oversight staff attended the following training activities: a stormwater Management Workshop in Albuquerque sponsored by EPA Region VI and a stormwater Management Symposium in Dallas, sponsored by EPA Region VI.

GWPRB staff attended the following training activities:

- RCRA Sampling Techniques (EPA)

-Solid and Hazardous Waste in New Mexico: Management, Cleanup and the Law

- Comprehensive Monitoring Evaluation for RCRA Sites (EPA) -RCRA Sampling Procedures and Workshops (EPA) 
-Radiation site Remediation for Superfund sites (EPA) - The Annual Meeting of the Now Mexico Chapter of AWRA

\subsection{Worker Health and Safety}

\subsubsection{Training of staff}

In accordance with OSHA 29 CFR 1910.120, all MMED AIP Oversight staff whose fob entalls work in the field, attended a Hazardous Waste Worker Training, elther the 40 hour course or the 8 hour refresher for those having already completed the 40 hour course within the appropriate time frame.

SWQB AIP staff attended a safety training course specifically designed for access to the TA-53 LAMPF facility.

GWPRB AIP staff attended the EPA 40 hour Radiation Worker Safety Training for Superfund Sites and the 8 hour SNL Radiation Safety Training course.

\subsubsection{Health and Safety Plans}

On July 17, 1992 an "umbrella" Health and Safety Plan was finalized and distributed to all NMED staff involved in the DOE Environmental Oversight and Monitoring Program along with a directive that all such staff adhere to the policies, procedures and directives outlined in the plan. Additionally, "site specific" Health and Safety Plan for WIPP was developed, finalized and distributed to NMED staff on November 20, 1992. The "site specific" Health and Safety Plans for LANL and SNL/ITRI are in final draft and NMED expects to finalize the plans and distribute to staff during the first quarter of 1993. 


\section{ATTACHMENT A}

WORK PLAN COVER LETTER FO DOE 


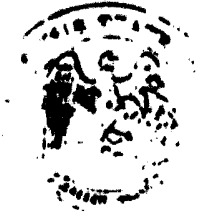

BRUCE KING

GOVERNOR

November 25,1992

W. John Arthur, III

Project Director

WIPP Profect Integration office

U.S. Department of Energy

Albuquerque Field office

P.O. Box 5400

Albuquerque, New Mexico 87115

Dear Mr. Arthur:

Enclosed you will find a copy of the New Mexico Environment Department DOE Environmental Monitoring and Oversight Agreement work Plan. The completion of the work Plan satisfies the requirement specified in section E.1.. Attachment $A$ of the Agreement-in-Principle.

As required, a draft of the work Plan was provided to DOE, EPA, other appropriate federal and state agencies, and affected local and tribal governments, for review and consultation. A copy of the letter requesting their review and comment and a list of addressees are attached. Comments received were incorporated into the final draft.

If you have any questions or need additional information, please feel free to contact Neil Weber of my staff at 827-2728.

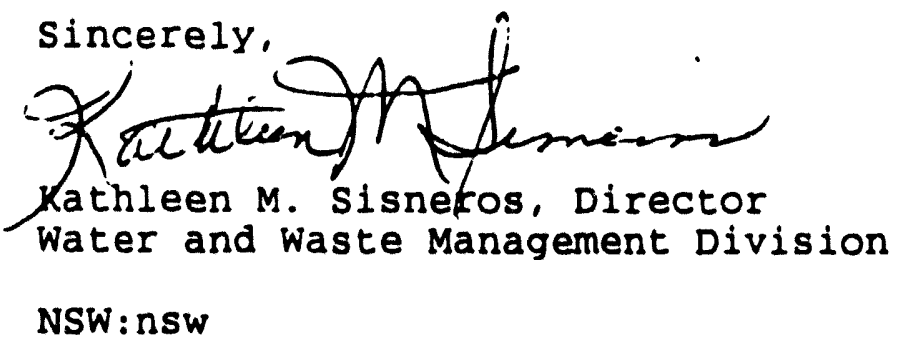

CC:Tracy Loughead, DOE Gil Maldonado, DOE

Ron Smith, Lamb Assoc.

Bob Grieve, DPS

Neil Weber, NMED -

Benito Garcia, NMED

Cecilia Williams, NMED

Jim Piatt, NMED

Steve Cary, NMED 
W. John Arthur, III

November 25, 1992

Page Two

cc (continued)

Bruce Swanton, NMED

Mike Lu Mond, NMED

Pat McCasland NMED

John Parker, NMED

Larry Gay, NMED

Dennis MCQuilian, NMED

Glenn Saums, NMED

Enclosures 


\section{$\because \cdot r$ \\ .}

BRUCE KING

COVERNOR
ENVIRONMENT DEPARTMENT

Harold Runnels Building

1190 St. Francis Drive, P.O. Box 26110

Santa Fe, New Mexico 87502

(505) 827.2850
JUDITH M. ESPLNOSA SECRETARY

RON CURRY DEPUTY SECRETARY

October 13, 1992

\title{
Dear
}

In June you were provided the opportunity to review and comment on an outline of a work plan for state oversight activities at Department of Energy (DOE) facilities in New Mexico. The comments you provided were beneficlal and enabled us to develop the narrative of the work plan.

The Agreement which the state entered 1nto with the DOE requires that State prepare a plan for its independent oversight of programs for monitoring the environment at and in the vicinity of the facilities and for assessing compliance with applicable environmental laws and regulations. Additionally, the state is to provide this plan to DOE, the Environmental Protection Agency (EPA) an other appropriate federal and state agencies, and affected local and tribal governments for review and consultation.

Enclosed you will find the initial draft of the work plan. We would appreciate receiving your comments by November 20, 1992 . please send your comments to:

\author{
Neil S. Weber, Chief \\ DOE Oversight and Monitoring \\ $1190 \mathrm{St}$. Francis Drive \\ P.O. Box 26110 \\ Santa Fe, New Mexico 87502-6110 \\ Phone (505) 827-2728
}

If you have any questions or concerns, please feel free to contact me or Mr. Weber. Thank you for your cooperation and input.

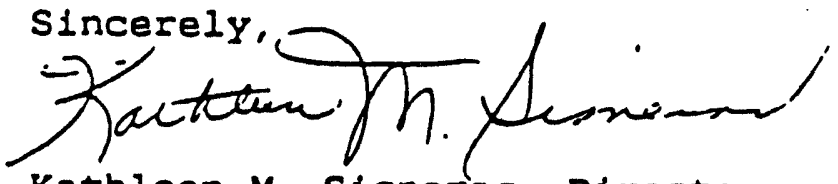

Kathleen M. Sisneros, Director

Water and Waste Management Division

KMS : NSW : dg

CC: Neil S. Weber, Chief

DOE Oversight and Monitoring 


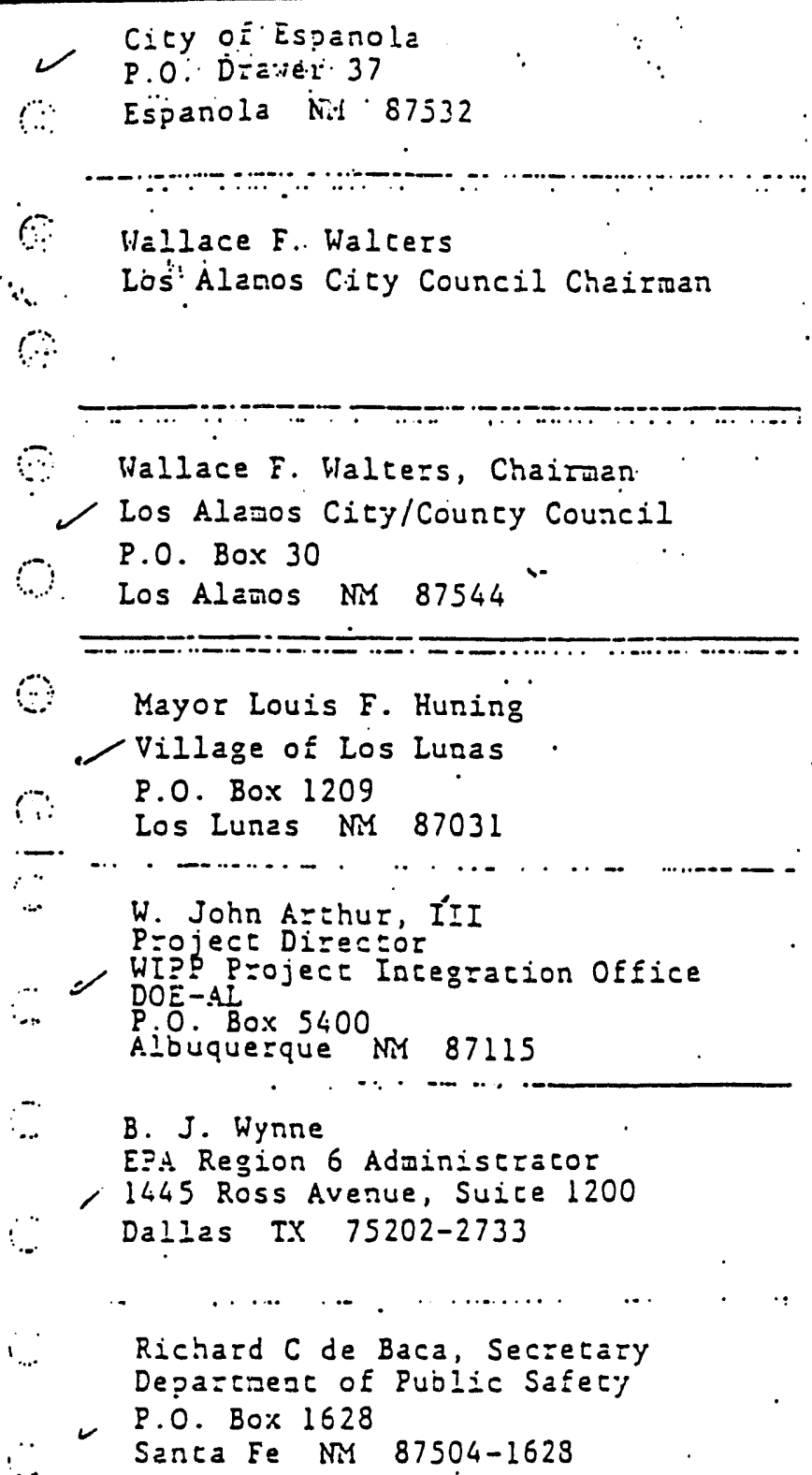

Governor Ale: Lucero

Isleca Pueblo

- P.O. Box 317

Isleta Pueblo Ni! 87022

Governor Ruben L. Baca

Sandia Pueblo

Box 6008

Beznalillo NRI 87004

Governor Jacob Viarrial

Pojoaque Pueblo

Rouce 11, Box 71

- Sanca Fe' Ní 87501

Governor Joseph Marvin Herrera

: Tesuque Pueblo

Roule 11, Eo: 1

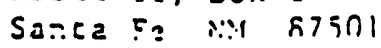

Sania Clara Pueblo

P.0. Bo:: 580

Espanola ini 87532

Leroy Ortiz

Rio Arriba Councy Connissione:

- P.O. Box 1250

:i. Espanola Nis 87532

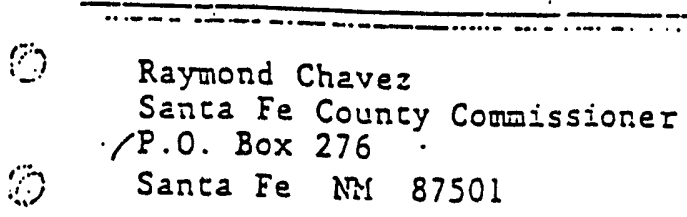
(1) Patrick G. Baca
Sandoval Councy Commissioner
P.O. Box 40
Bernalillo N:I 87004

$\therefore=-\therefore=1-$

Patrick J. Baca

Bernalillo Cointy Co=missioner

One Civic Plaza, $10 \mathrm{FI}$

Albuquerọue hil 87102

$\because$ - -

$\because \quad$ Julius Doubrava

Eddy Councy Comaissioner

a. P.O. Box 1139

Carlsbad Nil 88221

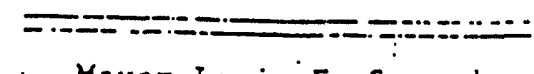

$\because$. Mayor Louis E. Saavedza

Cicy oE Albuquerque

P.O. Box 1293

$\therefore \quad$ Albuquerque Nis 87103

$=$

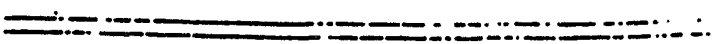

Mayor Erase A. Aguilaz

Town of Bernalillo

/ P.o. Box 638

$\because \quad$ Bernalillo Nir 87004

.

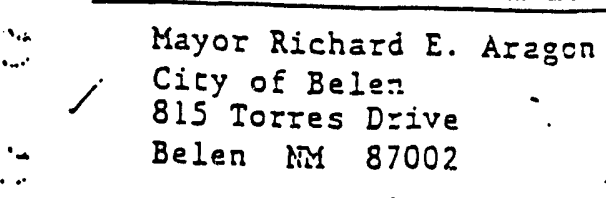

$\therefore \quad$ Belen sim 87002

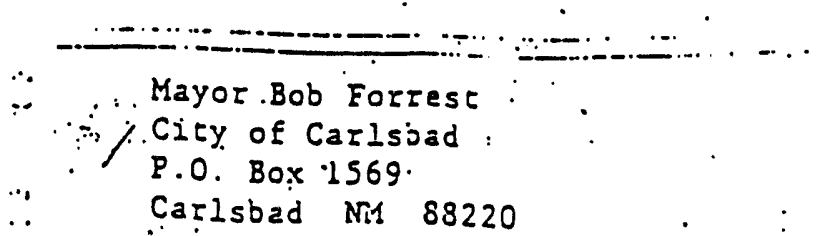

Carlsbad Nis 88220

Governor Pece Martinez

San Ildefonso Pueblo

Route 5, Box 315-A

Santa Fe AII 87501 
ATTACHMENT B

NEW MEXICO AGREEMENT IN PRINCIPLE (AIP) IMPLEMENTATION REVIEW EXIT BRIEFING 
DRAFT - FOR DISCUSSION ONLY -DECEMBER 11,1992

NEW MEXICO AGREEMENT - IN-PRINCIPLE (AIP) IMPLEMENTATION REVIEW

EXIT BRIEFING AT SANTA FE, NM DECEMBER 11, 1992

PREFACE :

The statements provided below reflect the observations and recommendations of the AIP review team based upon the review of the documents provided and the discussions held with the DOE-AL and NMED-AIP personnel concerning implementation of the AIP between the DOE and New Mexico. These observations and recommendations address specific issues in the areas identified. DOE-AL and its affected Area Offices, in close cooperation and coordination with the State of New Mexico, have recently implemented several administrative mechanisms that should continue to be used to resolve the issues identified and to further enhance effective implementation of the program.

\section{Environmental Monitoring Activities}

Status :

- The State has developed a basic framework for conducting DOE monitoring program review as follows:

- State AIP infrastructure is in place with the New Mexico Environment Department having the lead in coordinating the state program

- The state has made site visits to all DOE facilities included in the AIP to become familiar with monitoring systems

The state has established an office at each DOE site

The state has developed a statewide umbrella protocol. A final site-specific protocol has been developed for the waste Isolation Pilot Project (WIPP) and sitespecific protocols are being developed for Los Alamos National Laboratory (LANL), Inhalation Toxicology Research Institute (ITRI), and Sandia Nutional Laboratories, New Mexico (SNL/NM)

- The state has developed a statewide umbrella work plan. Site-specific work plans are being developed for SNL/NM, ITRI, WIPP, and LANL

- The state has completed a draft environmental sampling statement of work for the AIP program 
DRAFT - FOR DISCUSSION ONLY -DECEMBER 11,1992

NEW MEXICO AGREEMENT-IN-PRINCIPLE (AIP) IMPLEMENTATION REVIEW

EXIT BRIEFING AT SANTA FE, NM DECEMBER 11, 1992

- The State WIPP office has provided WACC and generator oversight for RFP, LLNL and WIPP audits

- The state was given advisory status during earthquake damage assessment surveys at the WIPP

Observations :

- Some DOE facilities are not releasing some requested environmental monitoring data to the state in a timely manner

- Where DOE has not yet provided environmental monitoring data to the state, the state has conducted or intends to conduct independent monitoring

- The AIP implementation review team reviewed a number of State recommendations for improvements to DOE environmental monitoring programs that had not been formally forwarded to DOE

- The state has indicated the need for DOE to upgrade its $\mathrm{QA} / \mathrm{QC}$ programs for environmental monitoring at a number of its facilities

Recommended Actions:

- DOE-AL to review policy issues impeding the timely release of data that has gone through QA/QC to the state under the AIP program

- DOE-AL to meet with the state to discuss developments on these policy issues

- DOE-AL/NMED AIP bi-monthly meetings should continue to discuss a program to exchange routine comments/ recommendations to DOE before the annual reporting requirements are due

- DOE-AL to meet with the state to review and assess the adequacy of its QA/QC programs 
DRAFT - FOR DISCUSSION ONLY -DECEMBER 11,1992

NEW MEXICO AGREEMENT - IN-PRINCIPLE (AIP) IMPLEMENTATION REVIEW

EXIT BRIEFING AT SANTA FE, NM DECEMBER 11, 1992

DOE Environmental Document Review Activities

Status :

- The state has reviewed and provided written comments on numerous DOE environmental documents including: site specific technical documents and DOE programmatic and technical documents

- The state has implemented a document review tracking system to track the review of environmental documents

\section{Emergency Response Activities}

\section{status :}

- The DPS performs emergency management functions for the NMED

- JPS DOE Oversight:

- Interacts directly with DOE-AL AIP officials (WPIO and DOE Site POCs), DOE site contractor emergency response planners, NMED site representatives, and emergency response planners of the 3 counties where DOE facilities are located (Bernalillo, Eddy, and Los Alamos)

- Is implementing the State's Emergency Information System (EIS) as the vehicle for updating emergency response plans

- Intends a two-phased update of plans:

- Update of the 3 county Emergency Operations Plans (EOP) by development of annexes integrating DOE site data

- Update of the State EOP by development of an annex integrating relevant DOE and county data

- State site representatives also are involved in emergency response activities, including drills and actual responses

- The state demonstrated an ability to respond quickly to environmental concerns with high visibility: 
DRAFT - FOR DISCUSSION ONLY -DECEMBER 11,1992

NEW MEXICO AGREEMENT - IN-PRINCIPLE (AIP) IMPLEMENTATION REVIEW

EXIT BRIEFING AT SANTA FE, NM DECEMBER 11,1992

-. Responded to and mitigated the Rocky Flats HEPA filter incident

- The State's AIP emergency response activities are characterized by:

- An experienced state and county emergency response planning infrastructure

- A designated emergency response focal point

- A reasonable approach for updating emergency response plans

Observation:

- New Mexico is meeting the intent of the emergency response objectives of the AIP

Recommended Action:

- None at this time

\section{Worker Health and Safety}

Status :

- The state has completed an umbrella AIP health and safety program plan for all DOE facilities

- WIPP site-specific health and safety plan has been completed

- Site-specific health and safety plans are in development for the remaining facilities

Observation:

- The state's action requirement under the AIP concerning health and safety has been fulfilled

Recommended Action:

- None at this time 
DRAFT - FOR DISCUSSION ONLY -DECEMBER 11,1992

NEW MEXICO AGREEMENT - IN-PRINCIPLE (AIP) IMPLEMENTATION REVIEW

EXIT BRIEFING AT SANTA FE, NM DECEMBER 11,1992

\section{Public Awareness}

Status :

- The state believes soliciting public comment for review of State AIP program and DOE documents is a good way to heighten public awareness of DOE/State environmental issues

- The state actively participates in DOE sponsored meetings on a variety of DOE programs

- The state has responded to public inquiry on DOE monitoring activities

- The state has coordinated a variety of news releases in response to public concern of DOE environmental compliance

Observation:

- The state indicates that in certain cases DOE has isolated its own environmental program concerns from other federal programs even when these concerns cross jurisdictional lines

Recommended Action:

- DOE-AL will investigate participation in working groups to which DOE environmental compliance issues may be commingled with other agency jurisdiction

\section{Funding Allocation}

Status :

0 AIP funding is authorized by DOE and provided to New Mexico through a letter of credit established under the Department of Health and Human Services (HHS). The state is reimbursed for costs incurred through periodic submission of Federal Cash Transaction Reports to HHS

- The State's fiscal year (FY) runs from July 1 through June 30; DOE'S FY, which is the same as the AIP budget period, runs from october 1 through september 30 
DRAFT - FOR DISCUSSION ONLY -DECEMBER 11,1992

NEW MEXICO AGREEMENT - IN-PRINCIPLE (AIP) IMPLEMENTATION REVIEW

EXIT BRIEFING AT SANTA FE, NM DECEMBER 11, 1992

- DOE's funding obligation for the first budget period (DOE FY 1991) was $\$ 3,125,000$; no funding was committed for the second budget period (DOE FY 1992) due to budget carryover from the first budget period

- For the third budget period (DOE FY 1993), a provisional grant of $\$ 3,125,000$ has been committed. Out of the FY 1993 provisional grant, DOE-AL has set a spending limit of $\$ 1,250,000$, pending DOE approval of the FY 1993 budget submitted by the state

0 As of November 16, 1992, the State has submitted six Cash Transaction Reports to HHS for reimbursement of AIP expenditures, and has been paid for a total of $\$ 1,039,057$. Reimbursement for the Cash Transaction Report dated November 16 , 1992, in the amount of $\$ 666,000$, has not yet been made to the state

- The state's total expenditure associated with the AIP through September 30,1992 amounts to $\$ 2,372,811$

\section{Grant Reporting}

Status :

- The State's proposed AIP budget for FY 1993 was submitted to DOE in September 1992

- The State expects to submit its annual Technical. Progress Report for FY 1992 in early February 1993

Observations :

- The grant calls for the Technical Progress Report to be submitted 30 days after the end of the project period and with any continuation or renewal application

- The state has expressed difficulty in meeting the due date for the Technical Progress Report as specified in the Grant

- DOE-AL contract administration and AIP oversight by the program office could be enhanced if the proposed budget and work plan were evaluated at the same time 
DRAFT - FOR DISCUSSION ONLY -DECEMBER 11,1992

NEW MEXICO AGREEMENT-IN-PRINCIPLE (AIP) IMPLEMENTATION REVIEW

EXIT BRIEFING AT SANTA FE, NM DECEMBER 11,1992

Recommended Actions :

- To improve timing with the state's requirements, DOE-AL should consider amending the reporting due dates specified in the grant 


\section{ATTACHMENT C}

ENVIRONMENTAL SAMPLING STANDARD OPERATING PROCEDURES FOR THE NMED HRMB DOE OVERSIGHT PROGRAM 


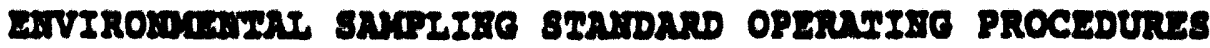

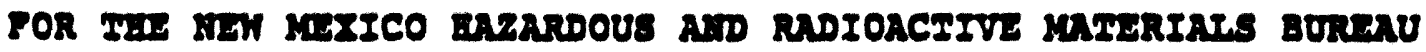
DOZ OVIRSIGET PROORN 
INTRODUCTIOH: . . . . . . . . . . . . . 1 ORGNIZATION AND RESPONSIBIIITY . . . . . . . . . . 1 obrecrIVE . . . . . . . . . . . . . . 3 SAMPIING BROCEDURES . . . . . . . . . . . . . 3 I. Ground Water ................. 3

A. Pre-field Precedures ............ 3

3. Water Elevarion and Tosai Jepth Measurements . . . 5

c. Detection of Imiscible tayers ........ 7

D. Well Evacuation............. 7

z. Sample Withdrawa: and Collection ........ 9

II. Soil and sediment . . . . . . . . . . . 12

A. Introduction ............. 12

3. Sample Contairers and Preservation . . . . . 13

c. Soil and Sedimen= Sampilag Technigues . . . . . 13

J. Decontaminatics Requirements ....... 16

III Surzace Water Sampies . . . . . . . . . . 16

IV. Air Particulates .............. 18

v. Ambient Gamma Monitorigg . . . . . . . . . . . 19

vI. Filid Measurements .............. 19

A. $\mathrm{pB} \ldots \ldots . . . . . . . . . .19$

B. Specific Conductance ........... 20

c. Temperature............. 20

D. volatile organic ............ 20

g. Radiation ............. 20 
vII. Sample Preservation and Bandling . . . . . . . 20

A. Containers .............. 21

B. Preservation methods ............ 23

c. Bolding times . . . . . . . . . . . 23

D. Additional sampie handling considerations..... 23 vIII.Recordkeeping . . . . . . . . . . . 29

A. Sample Analysis Request Sheet..... . . . . 29

B. Sample labeis ................ 33

c. Field notebooks ............. 33

D. Photographs .............. 36

B. Chain of Custcdy Record . . . . . . . . 36

F. Laboratory Logkecx ........... 36

IX. Decontaminarion prscedures ............ . 37

A. Organic Paramerers. . . . . . . . . . . 37

B. Inorganic paramerers. . . . . . . . . . . 37

x. Fieid Quality Assurance Quality Cont=ol . . . . . . 37

A. Sample blaniks .............. 38

B. Duplicates .............. . 38

C. Split samples . . . . . . . . . . . 39

D. Spiked sampies . . . . . . . . . . 39 


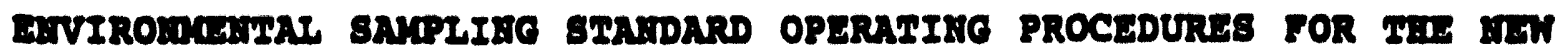
MUXICO BMARDOUS AND RADIOACYIVE MATERIAIS BUREAU DOS OVARSIOAY PROGRA

\section{IXIRODUCTIOA:}

On October 22, 1990 an agreement was entered into between the U.S. Department of Energy (DOE) and the state of New Mexico for the purpose of supporting state activities in environmental oversight, monitoring, remediation and emergency response at the LOs Alamos National Laboratory (IANL), the Inhalation Toxicology Research Institute (ITRI), Sandia National Laboratory (SNL), and the Waste Isolation Pilot Plant (WIPP).

This document is intended to provide the standard Operating Procedures for sampling and analysis activities planned for the DOE facilities in New Mexico. These activities will provide part of the independent monitoring and environmental surveillance responsibilities as determined by the agreement described above. Sampling procedures for ground-water, surface water, sediment and soils, and other topics relevant to sampling will be discussed.

The Guidance Protocol for Implementation of the agreement between DOE and the New Mexico Environmental Department (NMED) requires that field sampling procedures follow the U.S. Environmental Protection Agencies's (EPA) Test Methods for Evaluating Solid Faste Physical/Chemical Methods (SW-846); The Environmental Regulatory Guide for Radiological Effluent Monitoring and Environmental Surveillance (DOE/EE-0173T, 1991); and other procedures of sound scientific design. This document also references: The RCRA Sampling Procedures Bandbook, the MMED Bazardous Waste Program Sampling and Analysis Plan, the NMED Superfund Standard Operating Procedure For Site Investigation Field Practices, The Surface Water Quality Bureau's Quality Assurance Project Plan, EPA's Technical Enforcement Guidance Document (TRGD), and other sources.

\section{ORGAIZATIOA AND RESPOASIBIIITY}

The Umbrella Protocol for implementation of the DOE-NMED Agreement In Principle (AIP) specifies the protocol for notification, lines of communication and sampling at the DOE facilities. Site specific protocol will determine how site-representatives are responsible for coordinating with their DOB counterpart to implement site security requirements, implement health and safety plans, acquire and access data and other information from DOE and their contractors.

The objectives of the sampling activities are delineated in the Program Plans for the Mixed Waste Section and IANT Oversight and Technical Section. For each sampling event outlined in the Program 
Plan, a sampling and analysis plan will be developed describing it's objectives and logistics. A sampling event may include a number of events that have the same objective. This document can be referenced for the sampling procedures described in the sampling and analysis plan.

The NMED will provide DOE or a DOE designate the opportunity to split any sample taken within a facility boundary. This will occur through NME''s notification to DOE at least ten days prior to such sampling. Because of the nature of sampling spills or other emergency releases, or where statutes/regulations predispose the Umbrella protocol, this notification requirement will not apply. These requirements are described more fully in the DOE-NMED AIP.

Figure 1 depicts the organization of the New Mexico Environmental Department, DOE Oversight Program.

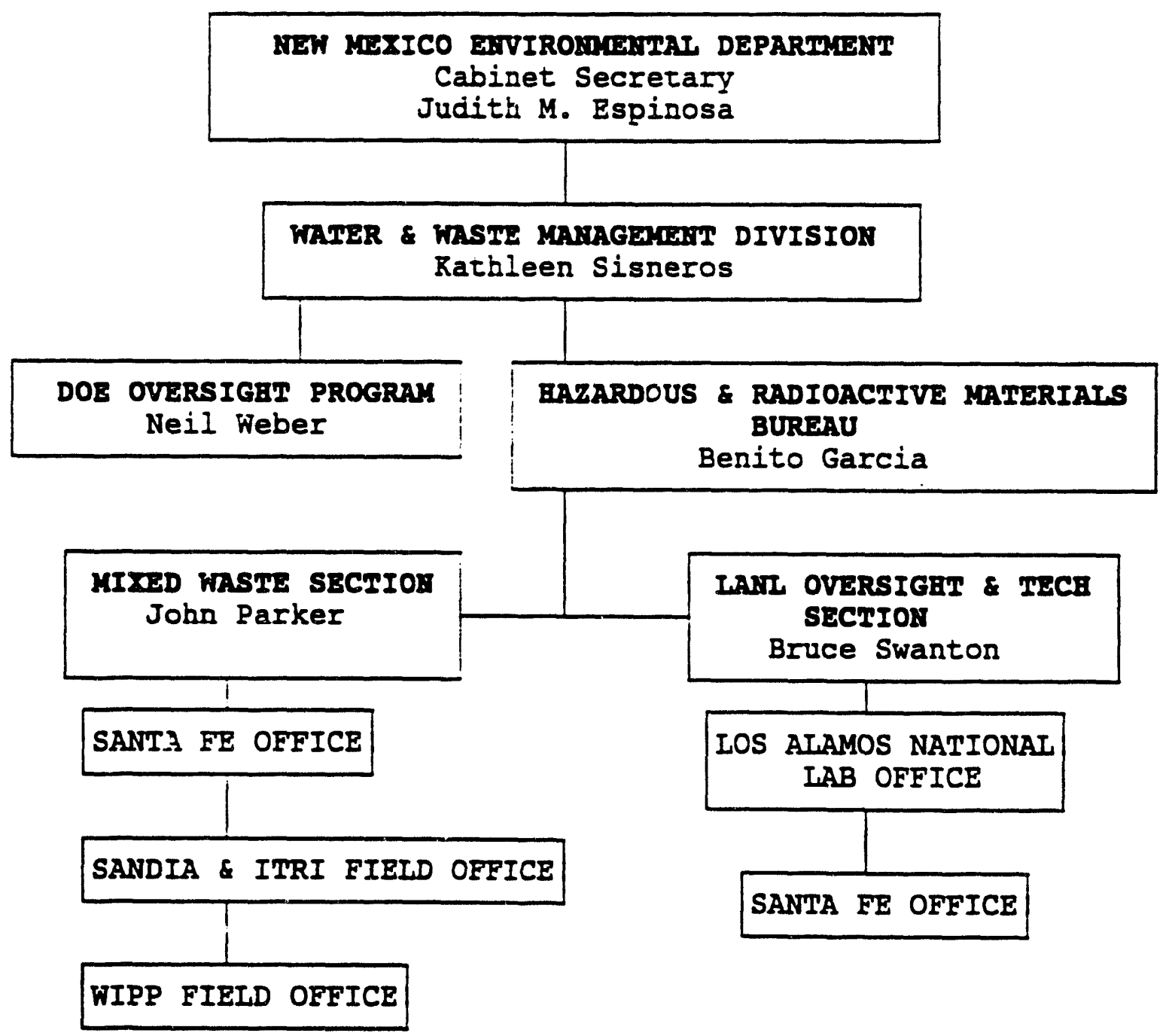

Figure 1. 


\section{OBNECTIVE}

The primary objective of the New Mexico Environment Department is to represent the state of New Mexico in protecting the environment and public health. The Bazardous and Radioactive Materials Bureeu's is to provide indepencent oversight and monitoring of the envizonment at DOE facilities. Results of the state sampling programs are used to indegendenty review and verify DOE

environmental surgeillance programs.

Sampiing programs at each DOE facility may have different objectives and should be ciearly and conciseiy stated in a samoling and analysis plan before the samoling event. The missions and envizonmental impacrs at each DOE facility are different and the samping objectives must address those issues. The purgose or goais at each facility could inciuce: monitoring of on-signt disciarges; evaiuation of warer gualizy monitoring; derecrion of off-sigit discharges; surreillance of radioactive imacts; monitoring of environmentai restorarion programs; assuring that waste management programs are not impacting the environment; and/ or other comoliance issues.

Resuits and conciusions will be provided to DOE by cerified receipt within 30 days of suci Eindings. DOE is required to inform their state councer parss of samoing sciedules and submit their resuits and conclusions as reouired by the AIP protocoi.

\section{SAMPLIXG PROCEDURES}

Collection of representarive sampies that are accurate and precise are the goals of a sampiing investigation. The following prccedures are intencied to provide reliable samples of high quaiity. These procedures iave been summarized from the TRGD, the Bazarcious Waste Samiing and Analysis Plan and Superfund's Site Investigation Fieid Practices. Many of these procedures used duriag collection of grounciwarer samples also apply to other media sampling and will be reierzed to later, including for example: sampie preservation, shipment, field measurements and anaivtical paramerers.

\section{Ground Water}

\section{A. Pre-field Procedures}

After a Samoling and Analysis Plan has been created describing objectives, analytes and site logistics, preparation for the field activities should begin. These tasks include the following: 
1. Prepare the tield equipment as needed. Field equipment will be maintained at each satellite office with supplementai supplies at the Santa Fe office. Verify that ali sampling equipment, containers and preserrarives, as described in the appropriate Sampling and Anaiysis Plan are present.

2. Calibrate and verify that appropriare field instruments are in gocd working order (i.e. pB meter, coscuctivity merer, organic vapor meter, and/or fieid radioactivity neters). Calibration procedures are proviced in the manufactirer's service zanuais inciuded in Appendix I.

3. Contact the Laboratories that are to be used to ensure thar the apprsoriase forms, containers, preservarifes and mettcós are used.

4. Researc: available informacion for eaci samoling station. Contact DOE or their contractor for relevant data regarcing objectives of the samoling investigatisn. Review MNED documents, files and records to deveiop as gcod an understandizg of the site as cossible.

इ. Contac a zepresentatije at least ten days before the samoi: og event, as requized by the AIP prctocol. Site represencarives can be nelpiul in decermining logistics asd upciating site information.

6. Decontamiare any samoiing and field measurement equipment to be utilized. Ensure that enough disposabie cailers are available for each monitoring weil that is to be samoied or thoroughly decon the stainless steei bailer iefore use. Decon procedures are as foilows:

a. Disassemile the bailer and clean check valves and inside of bailer. Wash with a dilute hycreciloric acid solution, followed by a thorcugin rinsing with deionized warer. If samoiing parameters include organics, the baijers must also be rinsed with hexane and merhanoi followed by a nonphosphatic detergent wash and finally rinsed with deionized water. The approximate voiume of the bailers should be determined and reccrded before going into the Iield; 
b. Decon the steel tape used for measuring water levels with the same method as described above, and

c. Decon soil augers and soil sampling equipment as previously described.

7. Ensure that sources of ice are available for preservation of samples. Clean cubicontainer filled with deicnized water and frczen can be used to assist in cooling the sampies and also provide emergency drinking water supplies. Frozen cubicontaizers used for this purpose must be clearly marked as deicnized warer:drigking water.

8. Reserve a Eieid vehicie and ensure that the venicle is in good =zaning orcier.

9. Review anc coserve the provisions of the DOE Oversight ?rcgram's Beaitb anc Safety Plan.

B. Water Elevation and Total Deptb Measurements

In an attempt to sotain a representative water sample, a weil should be gurged the equivaient of three (3) to ten (10) well-sore volumes to zemove stagnant water or water that is ciemicaily different than what is representative of ine aquifer. To calculate the volume of water that mor be removed, an accurate measurement of the static ware level and the toral depth of the well must be made. This calculation will be discussed in the foilowing 'Tell Evacuation' section.

1. All measurements shouid be made and recorded to the nearest 0.01 Eoot, frcm a visibly marked, surveyed point on twe weil casing rim, well apron or protective casing, whichever is appropriate. This referenced point must also have an eievation measured to the 0.01 foot with respect to sea level by a licensed surveyor. Completion reports from the facility should contain this information.

2. The water eievation is also recorded at regular intervals to provide information about the hydrologic conditions at the facility. Changes in the hydroicgic conditions may necessitate modification to the design of the ground water monitoring sysrem.

a. To determine the static water elevation, subtract the deptb measured to standing water 
in a well from the elevation establisined for the casing rim.

Our Section uses a 300 foot stainless steel "Cam Iine" with a plumb bob weight for water well measurements. The lower three feet of the line is chalked and then carefully lowered into the water in the weil. Bistorisal data acouired from previous sampling events, or trial and error are required to deterine how far to lower the tape. A measurement is then made and recorded to the nearest 1.0 fcot from the casing rim.

Then zeel the tape back and use a tape measure graduared in ar ieast one hundredths ci a foot to derezmine and zecsrd the measurement where the ciaik has iceen darkened by the stat:= water levei in the weil. See seiow.

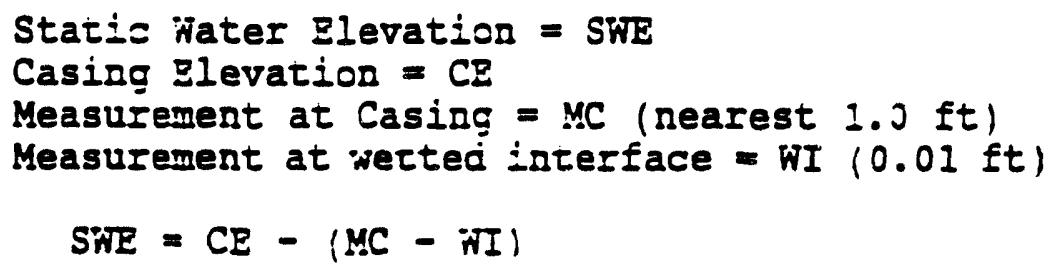

3. Comparison of the toral jeprs of the wei: after compietion and the existing depth musc be sade to determine the integrisy of the well (i.e. siltation problems/. If the weil has a dedicated camp and total depri measurements are restricted, provisions must be made by the faciiity to provide zegular measurements with incervais of less than 三ive (5) years.

a. After the static water elevation is determined, a measurement mus be made of the totai depth, TD, of the well. Lower the tape into the well until the bottan is felt. The slack must be taken out while the tape remains on the bottom of the well. Record this depth to the nearest 0.01 foot. Compare this depth with the TD measurement recorded in the completion report to determine well integrity.

To determine the elevation at TD, subtzact the $T D$ measurement from the elevation determined for the top of the casing.

b. An additional calculation for the standing water column is aiso required to determine the 
purge volume of the weil. Subtract the water levei elevation from the total depth elevation to determine the standing water column in the well.

c. Decontaminate the tape by spraying the wetted end off with deionized water, then wash with a non-phosphatic detergent and rinse again with deionized water. Hice dry with paper towels.

\section{Detection of Imiscible Lagers}

The Permittee must use the guideiines in the TEGD for decermining the presence, measuring the thiciness, and collectiag a sampie of any ligite or dense immiscible layers (TEGD, Seciion 4.2.2). These procedures mast be accomplished $E=i o r$ to purgizo tte weil.

The ais above the weil head shouid be monitored is order to determine the potentiai for jire, expiosion, and/or toxic effects on workers. This screening merhod also provides an indication of the presence of a light imiscible phase on the warer table. The Santa Fe office maintains Organic Vapor inaiyzer's (OVA's) for these field screeniro prccedures. As an additional sheck, observe the purged water sor separation of piases.

If an imiscibie phase is detected several methods exist to determine the thickness. The use of interface probes and clear baiiers is described in the TEGD. This type of equipment carsently does nor exist at our offices. Facility norificarion and requirements to delineare the exrent of suci contamination will be necessarg.

\section{Well Evacuation}

In order to obtain an accrrate and precise water guality analysis, a representative water samole of the aguifer most be obtained. Water that bas stood in a well bore for more than 24 hours is chemicaily different than water in the aquifer of interest. A general rule of thmb in obtaining a representative sampie is to purge the well of at least three weil-bore volumes of water. Monitoring of water $\mathrm{pH}$, temperature and specific conductivity to assess stability of these field parameters is recommended.

Depending on the depth and volume of the well to be sampled, different methods may be required to purge the well. Onless pumos are renced or made available by the facility the weils will be purged by bailing. Below are some considerations to be made when evacuating the well. 
1. To determine the volume of wacer to be evacuated refer to the well depth and static water level to determine the water column in linear feet. (i.e. Well depth minus the water level)

Square the radius of the weil bore-hole (converted to a fraction of a foot) and zuitiply by oi (3.14). Multiply this figure by the linear feer of the standing warer column to obsain the cubic feet of water in the well.

Multioly the cubic feet of warer in the weil by 7.48 gallons/cubic foot to determize the gallons of water in one weil jore-hole. To jerermine three casing volumes of warer, muitipiy jy 3. See beiow.

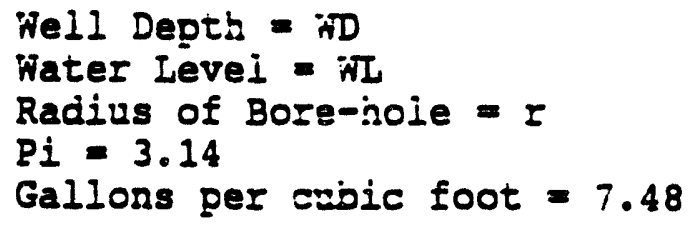

2. Fieid measurements of $\mathrm{pB}$, temperature, and specific concucrance siouid be obtaired before, darizg, and after purging in an attempt to verify that these parameters are stabilized. If stability can not be verified witin ten (10) parged volumes a sample should be taken. Additional withdrawal frsm the weil nay orcoide a sample thar represents water far from the boreiole and not representative.

a. Stability is acbieved when two consecutive measurements are plus or minus $0.01 \mathrm{pB}$ units for pQ, pius or minas ten (10) umbos for conduciivity, and plus or minus one (1) degree for temperature.

3. If bailing to purge a well, determine the volume of the bailer and record the nomiber of bails required to sufficiently purge the weil.

4. If using a pump in a high yieid formation, the pump should be positioned so that water be drawn from the uppermost part of the column. This ensures that fresh water will be drawn upward through the well screen. In low yield formations, water should be purged so that it is removed from the bottom of the screened interval. 
a. To ansure that an adequace volume of water has been purged by pumping, the pumping rate and time pumped must be determined and recorded. The simplest method to establish the pumping rate is to measure the time it takes to fill a container (1.e. a 5-gallon bucket). Then divide the volume of water to be purged by the volume of the container, multiply that by the tire it took to fill the container. This is the toral time required to pump an adequate purge volume of water from the weil.

Meters are commoniy available to measure flow races and/or volumes, however they are currenty not available at MMED. Measurements, if available, mast be recorded in the field log book.

5. At no tine should a weil be pumped at a race that causes water recharge into the well to cascade, causing an accelerated loss of volatiles. Iisten carefully (with the pump off) for splashing water in the weil casing to determine if the water is 'cascading'.

6. Low yieid wells should be purced no more than once to dryess. The officiai field measurements for $\mathrm{pH}$, temperarure, and specific conductance musc be obtained as soon as the weil has recovered to yield enough water for a samole.

7. Purged warer should be coilecred and screened with OVA, radicacrivity, pH, temperature and specific concuctivit? merers. If these parameters and facility background daca suggest that the water is contaminared, proper disposal of the purged water will be reguired. .

\section{E. Sample Hithdranal and Collection}

Sample withdrawai and collection techniques must ensure that a represencative aquifer sample is obtained. Considerations mast be made to prevent chemically contaminating or physically altering the samples. Some of those considerations include sampling equipment, withdrawal and collection technigues and are discussed below.

1. Use of bailers constracted of inert material, such as fluorocarbon resin (i.e. teflon) or stainless steel, is recommended. Our section has a stainless 
steel bailer and disposable polyethylene bailers stored at the Santa F'e office.

a. Precautions must be taken to ensure that sampling equipment does not contact soil or other contaminated surfaces. Plastic tarps can be placed around the well to provide a clean working surface. The plastic can be disposed of after use.

b. The staiziess steel baiier will be used for purgiag and sample collection when the groundwater is suspecred to be contaminated. After each sampling soint, it must be disassembled and thorouginly decontaminated.

note: in equipment blank zust be taken from a risse of the equipment before sampliza. Not all eouizzent blanks sust be submitted to the laboratc: for anaiysis. Refer to the Quality Assurance Secrion to determine frequencies of analyrical.

c. The baijer cord must be composed of inert maceriai. Disposable non-dyed nyion cord can be found at most disccunt stores and gurchased

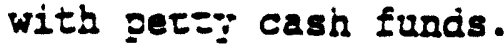

d. Then coijectiag a sampie with a bailer, care must be jaken to prevent unnecessary agitation suci as rapidily dropping the bailer into the weil wacer.

2. Use of posi ije gas dispiacement pumps (bladder pumos 1 macie irom inert marerials is acceptable for obtaining samies. Our office does not have a pump of this type, but a facility may prefer to provide this equipment, particulariy if sampies are historicaily collected this way. Duplication of historical coilection methods may provide more comparable results. Other fum types may be used for purging weils if time is allowed for chemical and piysicai properties to stabilize in the well.

a. If the pumps used for purging or sample withdrawai are not dedicated, prccedures described by the pum manufacturer mot be followed for disassemily and decontamination.

note: An equipment blank sample must be taken before eacb use. 
b. Pumps used for collection must be operated in a continuous manner so that they do not produce pulsating samples that are aerated in the retura tube or upon discharge.

c. When collecting samples where volatile constituents or gases are of interest and a positive gas displacement bladder pump is used, pumping rates shouid not exceed 100 milliliters ill per minute. Bigher rates can increase the loss of volatile constituents and cas cause flucsuation in $\mathrm{pH}$.

Once the samples for the volatile components have been collecred, a higher pump rate may be used especially if a large volume sample is requized. The sampling flow rate shcuid not exceed the flow rate used while purging.

3. The order in which weils are sampled and the order that sampie parameters are taken must be considered to reduce the possibility of cross-contaminarion of the warer samoles. The Samoiing and Analysis Plan should conrain the orcier of samples and the order of paramerers that wiil be taken.

a. If zossible, prioritize the sampling czier of weils from the Least probable contaminated (background) to the most probable contaminated weils. The facility personnel may be ielpiul in making these determinations.

Because logistics may prevent obtaining samples in this fasinica and disposable or deaicated sampiing equipment is nor always available, decontamination procedures will become particularly imporcant in obtaining representative samples.

b. Sampies should be collected and containerized in the order of the volatilization sensitivity of the selected parameters. A preferred collection order for some common ground-water paramerers follows:

* Volatile organics (VOA)

* Purgeable Organic Carbon (POC)

* Purgeable Organic Balogens (POX)

* Total Organic Balogens (TOX)

* Total Organic Carions (TOC)

* Extractable Organics

* Total Metais 


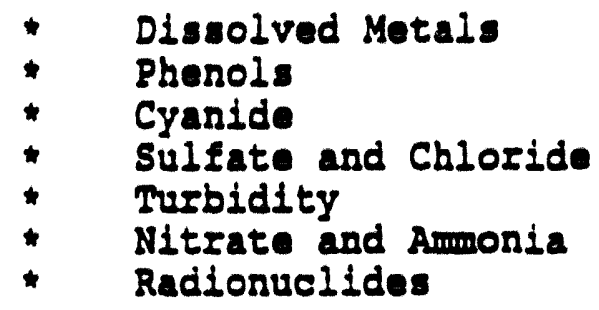

Temperazure, $\mathrm{pB}$, and specific conductance should be measured in the field in conjunction with purging and immediately after sample collecizion.

4. Splitting samples with the facilities should always be offered. Because MME data will be compared with the facilit: daca, it is critical that the sample materials are hemogeneous. The procedures followed to obtaiz a spitt sample are outlined beiow.

a. When wi=hdrawing a sampie for each parameter ensure enougi volume is available for your sample and a replicate.

b. Collece samples in the orcier described in the preceding section, except that a replicate is taken siter each paramerer (i.e. Fili your concaiser for volarile organics first, then fiil a second container for the faciilty). Contiaue to aitersate samole collection for NOIE and the facility until the full suite of paramerers have been coilected.

\section{Soil and Sedimont}

A. Introduction

Soil and sedimene samoling is an important adjunce to an environmental surveillance or assessment program. Sampling of the soils above the groundwater table or stream sediments may detect contaminants before they can migrate inco the groundwater or impact other environmental media. It becomes particularly important as some contaminants are not very mobile in solution yet be transported in mass quantities. Radionuclides and heavy metals are examples of suci contaminants.

Soil types, grain size, cohesiveness, moisture content, other physical properties and vegetation vary a great deal and affect the way contaminants migrate. These properties also limit the methods of sample collection and sometimes restrict access to representative samples. This section will describe technigres and tools available 
to this program to best acquire representative soil and sedimant samples.

In addition to the properties just mentioned, subsurface conditions such as temperature, available oxygen and light penetration can also affect the rate of chemical reactions and/or the microbiological community that further alters the chomical conditions. These chemical conditions could change radicaliy as samples are exposed to light and air during acquisition. To limit these chemical alterarions, it becomes necessary to coilect as undisturbed a sampie as possible. It is also important to keep detailed descriptions of the physical properties of the sampled zedia and samplizg zethods.

B. Sample Contaisers and Preservation

Containers to se used for soil and sediment sampiing are 8 or 10 ounce glass jars with Teflon lined iids. Preservarion wish chemicais is nor usually recomended but the laborarory shouid be contacted to confirm this for individual paramerers. Normaily the sample will be refirgerated to 4 degrees Centigrade immediateiy after sampling and during sinipment. Bolding times should be shortened is possible.

C. Soil and sodimont Sampling Technigaos

The tools used to take soil sampies available to this program inciude stainiess steel scoops, spoons, soil augers and bowis. These toois do not linit the possibilities of collecting samies if sampling can be coordinated witb other assessment procedures such as drilling or tremching. Proper care must be made to obtain as undisturiced and representative a samole as possible, partisularly for purgeable organic anaiyses.

Grab or composite samples may be collected depending on the objectives of the sampling event. Grab samples are single samples taken from a specific location at a given point in time. A grab sample is most representative of a soil matrix if the source is homogeneous. Several samples are required to fully characterize a site.

Composite sampies are combinations of aliquots collected at various sampie locations. The aliquots are collected into a large bowl or other appropriate container and then thoroughly mixed. A composite sample yields an average value for the sampling sites. Compositing may mask problems by diluting concentrations of some hazardous compounds below limits of concern or detection. Compositing is not recomended if analyzing for purgeable 
organics as chemical reactions are accelerated and the sample will no longer be representative of the site environment.

1. The simplest, sost direct method of collecting soil samples is to use a spade and/or scoop. This method can be used in most soil types but is limited to the near suriace. The prceedures described below will provide an adequate sample, although discussion with the lab or roview of jistcrical data is necessary as responses of chemical compounds vary in the environment:

a. Collect the necessary equipment and clean accorisis to ibe requirements for the anaiyricai paramecers to be measured.

b. Caref:i:y remove the sop layer of soil to the desired sampie depth with a spade.

c. Usirg a staipless sreei scoop or spoon to collect the desired quantity of soil.

d. Remove =ivigs, zoots, or large pebbles from the samoie and transfer the remaining portion into an 3 or:0 ounce jar.

e. Checi jiar a Tefion iner is present in the cap. Secure the cap tightly. The chemical preserration of soijds is generaily not reccmended. Ref=-geration is usually tbe best apprcaci suppiemented by a minimal holding time.

f. Labei the sampie jar with the appropriate sampie label. Be sure to fill the label out careicliy and cieariy, addressing all the categories or parameters. Complete all chainof-cusccoy documents and record the appropriate informacion in the field log book.

9. Place the properiy labeled sample bottle in an appropriate cooler to maintain the temperature at 4 degree Centigrade tbroughout the sampling and shipping.

2. If a greacer depth is regrired for a sample, the soil auger can be used. With care, an auger can be used in a wide variety of soil conditions. The presence of rock or unstable soil might limit the depths that can be sampied. Our program has available two 5 foot extension flights limiting 
depth to less than ten feet. If required, additional flights can be acquired. Procedures for taking samples using a soil auger are described below.

a. Collecr the necessar: equipment and clean according to the requirements for the analyical paramerers $=0$ be measured.

b. Attaci the auger bit to a drill rod excension and fu-her attacis the "I" handle to the drill rod.

c. Clear the area to be samoled of any surface debris (twigs, rccks, litter). It nay be advisable to remove the first 3 to ${ }^{\circ}$ incies of surface soil sor an area approximareiy 12 inches in diameter arsund the drilling site.

d. Begi= augering, seriodically removing accumulated soils. This prevents accicientally brusining loose maceriai back down the borebole when removing the auger or adding extension zods.

e. After reacring the desired sampiing depth, carefaily remove the auger and soil. Transier the soil into the appropriate sample jar and properiy labei and store the samoie as desc zised previousiy.

3. Sediments can be coilecred in much the same manner as descrited above; however, a number of additional facrors must be considered. Streams, lakes, and impoundments will likeiy demonstrate significant variations in sediment composition with respect to distance from inflows, discharges, or other disturbances. In addition, the presence of rocks, debris, and organic materiai nay complicate sampling and precluce the use of or =equire modificarion to our equipment. Sampiling of sediments should therefor be conducted to zerlect these variants. Documentation of field conditions and the sampling procedures is important.

4. If a soil or seciment solit sample is being collected ensure the sample is as homogeneous as possible by stirring or mixing the material. Alternate sample collection with the facility as described in the ground-water section, page 13. 
Before containerizing the sample eliminate large particles (stones, clods) and organic materials (grass, twigs).

If coilecting for volatile organics do not stir or mix, select the most homogeneous of the sample, immediately place into a seaied container and place into a cooier for storage to prevent unnecessary volatilizarion of the organics. Do not add chemical preservatives.

\section{Decontamination Requirements}

Decontaminarion procedures are the same for soil and sediment sampiizog equipment as was described in preceding sections; briefiz,

1. Equizment used to sampie for inorganic paramerers are cieaned initially with a nonpiospinatic jetergen mixture. The first rinse should be a dilure $(0.1 \mathrm{~N})$ hydrociloric acia koilowed by a thorough rinse of discilled or deicnized water. Use of the garden sprayers provicies a convenient zechanism for the water İise.

2. Equicment used to sampie for organic parameters are cieaned initiaily with a nonphosphatic detergent mixture and =insed with tap water, and then followed with another rinse of distilled water. Then use methanol for a rinse foilcwed by a pesticide-ouality hexane rinse. The equipment must be thoroughly dried before use at the next samoling point.

III. SURFACE WATER SAYPLES

Surface water is relativeiy easp to collect. Bowever, obtaining representative samoles is more difficult. Temperature, currents, soiubility of compounds, and other mechanisms cause changes in the composition of water with respect to bort time and distance. Accurate sampling must be responsive to these dynamics and reflect their actions.

Samples can be readily collected by carefully submerging the sampie container. This method is particularly advantageous when the sampie might be significantly altered during transfer from a collection vessel into another container (i.e. volatile organics). 
If a known or high level of contamination is suspected use a dipper or pond sampler. The pond dipper is simply a telescoping poie with an attached clamp that a beaker can be clamped into. Using a dipper decreases the chance of cross-contaminarion between samoles.

A commoniy available vessel that might be used as a dipper include pyrex glass beakers or cubicontainers. The beakers must be thorcughiy cieaned in the manner described under Section IX. Decontamination Procedures. The cubicontainers, if used, would be used as a deaicated (disposable) item. The foilowing procedures generally describe the metiscas for sampiing with a dipper or pond sampler:

1. Collect the appropriate equizment and ensure that the equigmes: has been prsperiy decontaminated.

2. Submerge tie 'dipger' wi=h mininal surface disturbance.

3. Retrieve the vessel with minimal disturbance.

4. Remove the cap fzom the sampie bottle and sightly tilt the mouri of the bottie below the vessei edge.

5. Emory the vessei slowly, allowing the water sample to flow gentiy down the sice of the bortle with minimal ent: turiulence.

6. Continue deiivery of the sampie until the bottle is almost ccmpiereiy filled. Some space shouid be left in the concainer to allow for expansion unless collectirg for VOA's. The smail space left unililed is a judoement decision based on the water quality. A highly carionare water or gas entrained water sample will degas. This space should be left available so that the container will not deteriorate and leak. Contact the lab to determine the minimum sampie guantity if a problem is anticipated.

7. Preserve the sample as recommended.

8. Check that a Teflon liner is present in the cap and secure the cap tightly.

9. Iabel the sample bottle and carefully fill in the appropriate information. Record the same information in the field logiook and complete the chain-of-custody form. Foilow the guidelines described in Section VIII. Recordkeeping. 
10. Place the samoie in a cooler and maintain at 4 degrees Centigrade throughout the sampling event and transportarion.

11. Dismantle the sampler and follow decontamination procedures. See Secrions IX. and X. regarding deconramination and field quaiity assurance.

\section{Air Particulates}

Equipment Needed:

Empty glassing enveiope for used fiiter,

New filter in glassing enveiope,

Screwdriver to adjust Elow,

Field logbook and pen;

For cailbration: Mass Iisw merer and adijiional unused fiiter.

\section{Filter Change}

a. Recors time, date and Ilow race, being sure to keep levei wit: the flow meter to avoid parallax error.

b. Turs off sampier and isconnect filter head.

c. Remove $f i \vdots \pm e r$ jy edges, taking care not to lose dust from the $3 i$ ijer, and piace in a glassing enveiope.

d. Put sew fiiter on and zarn on sampler to hoid filter in piace.

e. Repiace İiter head.

f. Adjust Elow race to the desired setting.

g. Record flow race, time anc date in field logbook.

2. Calibration

a. Tura on mass flow merer and let warm up for five minures. With both encis of the meter covered, adjust the zero point.

b. Follow steps :.a. thrcugh 1.c. above.

c. Put the additional filter on, connect the mass flow meter, and tarn on the sampler.

d. Set flow rate to 20 liters/minute, let mass flow meter stabilize, and record reading.

e. Repeat 2.d. for flow rates of $30,40,60$, and 80 lpim. 
f. Repeat steps 2.d. and 2.e. once.

g. Remove the mass flow meter and filter, then continue with step 1.d. above.

\section{Ambient Gamma Mositoring}

Ambient gama levels will be monitored using Thermoluminescent Dosimeters (TLDs). Four lithium fiuoride chips, packaged together, constitute one dosimerer. The TID chips are to be supplied by Eberine Instzument Corporation, including reading data and annealing the chips. MUED personnel will be responsible for depioying the TIDs at their stations on a quarterly basis. An extza set of ms shall be transported in the field wille depioying the reguiar cirivs. These 'transit' TIDs shail then be anaiyzed to determine tie dose received by the chips during zransit. The transit dose shall then be subtracted $\equiv=s m$ lae cose on the Eield starion TIDs.

\section{FIEID MEASUREMGITS}

Standard fieid measuremenrs will isciude; pH, temperature, specific concuctivitz, an organic vapor screen, and a betagama screen. These fieid Measurements can be userul for detecting and determinizg the excent of contamination; providing data for monitsring and evaiuating heaith and safety criteria; and screenirg for constituents that have unstable, short holding times. Althougi these fieid measurements are helpiul, they do not zeet the levei of precision and accuracy that can be obtained in the laboraccr. Great care must be taken in following the manuiacrüers's directicas for calibration and use as consistent with SW-846. Those descriptions can be found in Appendix 1 of this document.

Below is a brief discussion of the field measurements that will be used depending on the objecrives of the sampling event.

A. $\quad$ B is a measure of the hydrogen ion concentration of a solution. A pH meter is accurate to the nearest $0.01 \mathrm{pH}$ unit, and has excellent stability and consistency in the field.

Field pH measurements are standard practice for water samples. Since pl is an unstable property, Measurements must be taken and recorded before and after collecting a sample. 
B. Specific Conductance - The ability of water to conduct an electric current is direcrly related to the concentration of ionized compounds. This measurement can also be used to obtain a zough estimate of the concentration of total dissolved solids (TDS). IDS can be used to identify and comore different quality waters, and to detect gross contamination.

Interpretation of specific conductance values to obtain a measure of TDS reguires compensation for the sample temperature. Consequently, temperature measurements are generally made along with specific conductance measurements.

C. Temperature - Normaiiy, temeerature measurements may be made with any good nercury-iilled Celsius thermomerer. At a minimum, the thermometer sicuid have a scale marked for every 0.1 degree Ceisius, with markings etcied on the capiliar? giass.

note: Speci三⿰氵 conducsivizg, temperature, ph measurements are ccmoniy used as an indication that enough water has been purged from a groundwater well. Concurrent readisgs from sequentiai samples of the purged water begin to stabi:ize as the stagnant water is removed from the weil.

D. Volatile Organic ccnstituents may be detected with an Organic Vapor Inaiyzer (OVA). The OVA is userul in evaluating beeiti and sarety criteria, screening samples for furber testing, or obtaining a preitimary delineation of a contaminared area.

B. Radiation derect:sn will be accomolished using a micro$R$ merer. These instruments are very sensitive and are commonly used to derect low level gamma, beta and/or alpha radiation. Again, these instruments are useful for evaluating heaith and safety criteria, screening samples for furcher testing, or obtaining a preliminary delineation of a contaminated area.

\section{Sample Preservation and Banding}

All samples will be handled and analyzed according to EPA's "Test Methods for Evaiuating Solid Waste - Physical/Chemical Methods (SW-846)". This section includes a discussion, by analyte, of appropriate preservation methuds, container types and holding times.

Examples of analytical request sheers from the scientific Iaboratory Division are included at the end of this section. labeling and record keeping requirements are also discussed. 
Discussions with laboratories selected to analyze the samoles, historical data and discussions with facilities will be helpful in selecting handing methods for the parameters to be used. Refer to Table $A$ at the end of this section for a summarization of parameters and appropriate handling methods.

The Sampling and Anaiysis Plan should ourline the appropriate paramerers, prepararions and samole hanciling methods required to accomplish a successiul sampling event.

A. Containers After determining the sample matrix and parameters to be analyzed, selece the containers and determine the availability of concainer type. The SID or a contrace lab will provide cersified clean 40-mi and 1-liter glass bortles for orçanic analysis. The MMED inventory inciucies one gailen and one guart cubicontainers for radiociemistry and metais.

The most imorzant factors to consider when choosing containers, are comparibiiity of the container with the samoie, resistance to breakage, required sample volume, and size of opening. The contaizers must be properiy cieaned before use so that concaminants are not $i=t=s c i u c e d$ into the samole. The cleaniiness of a batsi of pre-cleaned botties should be verified in the laboratory. The resicue analysis should be available prior jo samoling is the field.

1. When METAIS or RADIONUCIIDES are the anaivtes of interest, fluorocarion resin or polyerhyiene containers with poiypropyiene caps should be used. When oRGuics are the analytes of interest, giass bottles with fluorocarbon resinlined caps should be used.

2. The following are examples of sample container types:

\section{DESCRIPTIOA}

80-02 amier glass bottle with teflon-Iined black phenolic cap

40-ml glass vial with teflonbacked silicon septum
SAYPLE TIPE

Extractable Organic

Volatile

Organics 
1-I high density polyethyiene bottle with poiy-iined, baked poly cap

120-ml glass rial with teilonlined, white poly cap

16-oz wide-mourhed glass jar with teflon-lined, black soly cap

8-oz wide-mouth glass jar with teflon-lined, black poiy cap

4-oz wide-mourbed glass jar wiخt terlon-1ized, black poiy cap

1-I amber glass bortle wit: teflon-iined, blacx poly cap

32-0z wide mourb glass jar with teflon-iined, blacx poly cap

4-i amiber glass bortled wi=h teflon-ijed, blacix pinenoizc cap

500-mi bigh densizy polyerjylene bortle with poiy-inea, baked poiy cap

4-I high density colyethyiene bottle with poiy-ined, baked poly cap
Metals, Cyanide and Sulfide

Volatile

Organics (Soil)

Ext. Organics \&

Metals in Soils

Ext. Organics \& Metals in Soils

Ext. Organics \&

Metals in Soils

Extraciable Organics

Ext. Organics \& Metals in Soils

Extracrable Organics

Metals, Cyanide and Suifide

Radiociemistry

B. Preservation methods should be identified in the Sampling and Analysis Plan and can be determined by reference to Table A, SW-846 and discussions with the laboratory chosen to analyze the samples. Methods of sample preservation are relativeiy limited and are generally intended to (1) retard biological action, (2) retard hydrolysis, and (3) reduce sorption effects. Preservation methods are generaily limited to pE control, chemical addition, refrigeration, and protection from light. Table $A$ at the end of this section is copied from the TEGD and outline the preservation methods, containers, and holding times for a selection of parameters.

1. After a sampling event has been scheduled, acoraisition of the chemicals to preserve the samples 
is necessary. The Santa Fe office will maintain a supply of preservation and decontamination chemicals or the laboratory selected for the analysis may pis:preserve for selected parameters.

Although preservation techniques vary depending on analysis, matrix and concentration, lowconcentration water sampies taken for metals analysis are acidified with $5 \mathrm{ml}$ nitric acid (ENO3) per 1 liter of sample (to a pB of less than 2), volatile organics water samoles are preserved with 2 drops hyorochloric acid (ECL) per $40 \mathrm{ml}$ vial, and non-purgeable organics and radioactive analyres are unpreserved.

Some anaiyces must be maincained at a temcerature of less than 4 degrees Centigrade but not fieezing. After adding the preservatires, place sampies into cooiers ccoied with double bagged ice, water Erozen in cubicontainers, or comerciaily available 'blue ice'.

Anaiyces whic: must be cooied include all organic samoles, bur ensure that the $40 \mathrm{ml}$ volatile organic sampies are not placed to close to the ice increasing the risik of freezing and therefore breakage. Samoies for radionuciides and merals do not require ccoling although references described above should be checked before samplizg and subseguent shipping.

C. Holding timas vary Exom 24 hours to montbs depending on the possibilitg of degradation of an anaiyte. Refer to the rererences described above for the appropriate holding times, as scieculing of samole acquisition and shipping becomes very imortant. Close communication (at least two week advance notice) with the laboratory is also necessary so that they are prepared to begin appropriate samole preparation within the reguired holding times. If the holding times are exceeded a tremendous amounc of efsort, time and expense may have been wasted, in addition to irrerrievable informarion.

D. Additional sample handling considerations that are to be made follow:

1. The sampling and analysis plan should include the methods to be used for transierring the sampies into their container. Agitation and aeration of the organic samples must be avoided (i.e. transferring samples from one container to another, taking samoies from high volume pumoing rates (greater than 
$100 \mathrm{ml}$ per minute), spiasing bailers into wells, or exposing samples to the sun and atmosphere for an unnecessary timel.

Sorption and cross-contamination effects may be limited by thoroughly =insing the containers with the sample water prior to collecting the sample. This is recomended if the samole containers have not been pre-preserred and containerization of the purged water has been addressed.

2. Water samoies are not generally filtered. In the past sampies that were to be analyzed for dissolved metals were filtered. To avoid filtration, specify the Total Metais anaiysis. For no reason should a sample for an organic analysis be filtered.

3. Volati-e organic sampies siouid be collected such that no headspace (air buibies within the warer samplel is allowed in the 40-mi vial. Collection technigues should minirize agitation and aeration of the sampie to preven volatization of the volatile organics. The viais are to be filled until a meniscus deveiops at the top of the vial and then carefuily capped. mura the bottle upside down and gently tap the viai and observe the absence of any air buobles. If air subbies are observed, repeat the ccilecrion procedures.

Great care mast be taken to prevent overfiling or spilling tie samoie Iluid when collecting the volatile organic samoies. The 40-mi viais may contain a specified amount of Bydrochloric acid or Mercuris-sijoride for preservation. Use protective gloves.

To eliminace impact frcm ambient atmospheric conditions, coilect sampies as near the sampie point as possible. (i.e. do not sollect the sampie near engine exhaust systems).

Volatile organic sampies should be packaged in a manner thar prevents concamination througin the teflon seprom cap. The vial sets $(2$ viais per samplel should be placed in plastic baggies or whirlpacks separate from other sample sers and transported upside down. 


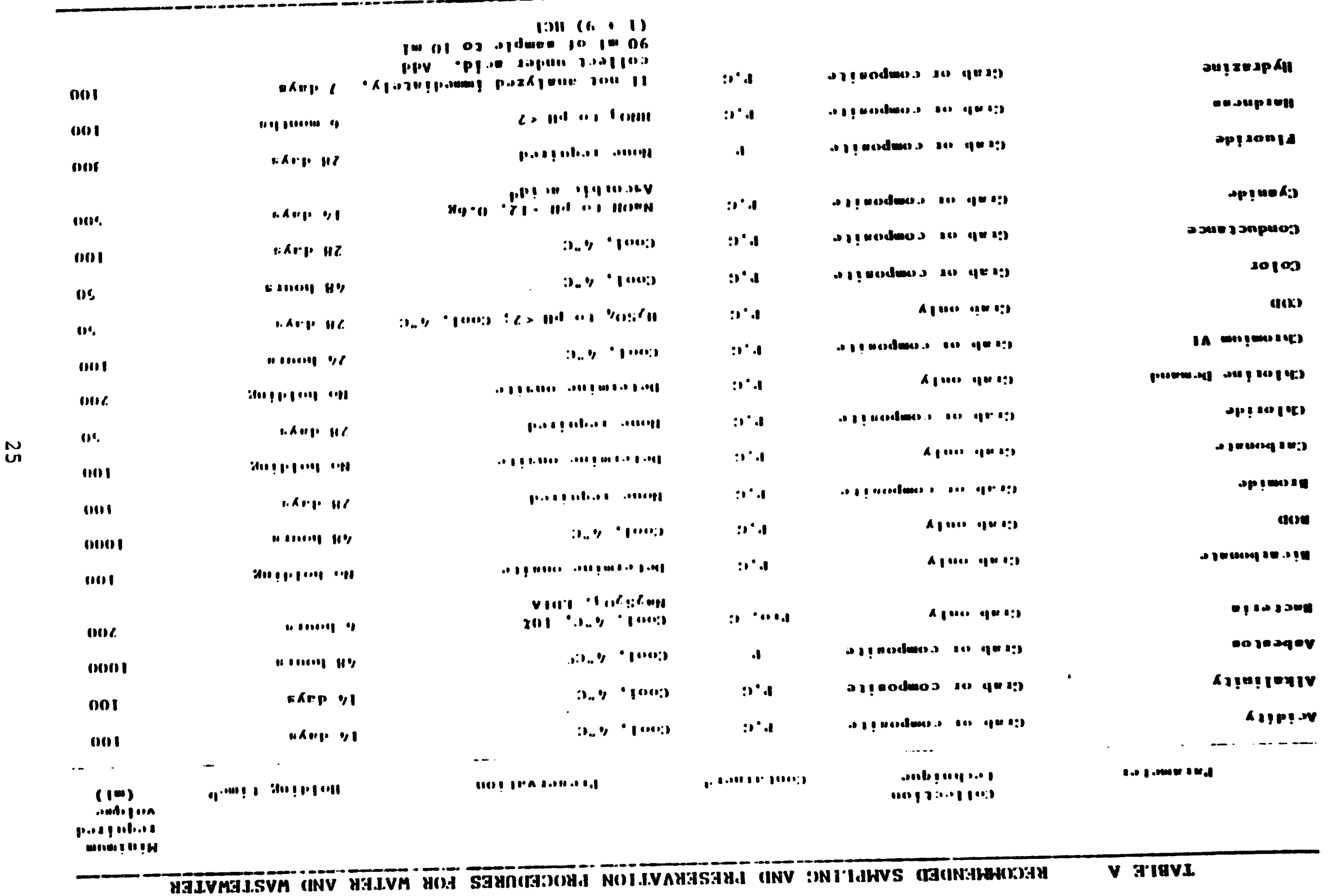




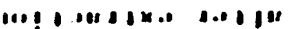

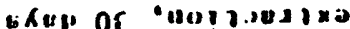

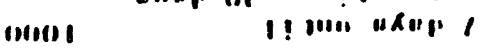
m(1)1 Wand He 11. (III) Dsonen II" (11)! Wa1) WI. IIII. n

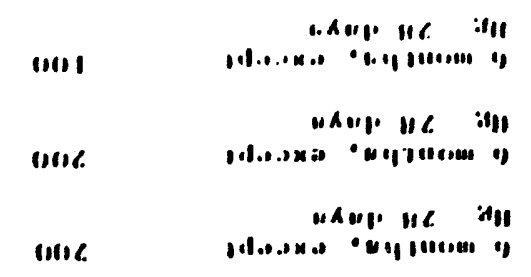

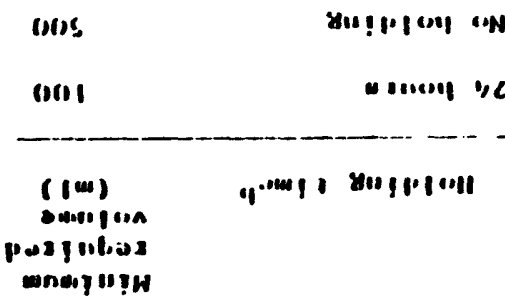

At: + 10.11!!

(16.) $11.01 \cdot 9$

$\therefore \ldots, \cdot 1 \cdots . .1$

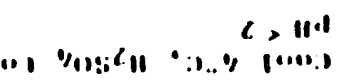

...,, $1 . . . .1$

$\therefore$

$: P^{\prime}$,

$: 1+1$

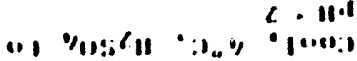

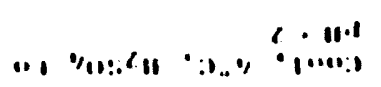

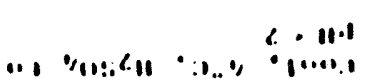

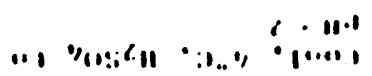

"A.H WC.

$\therefore \cdot .1$

(a)

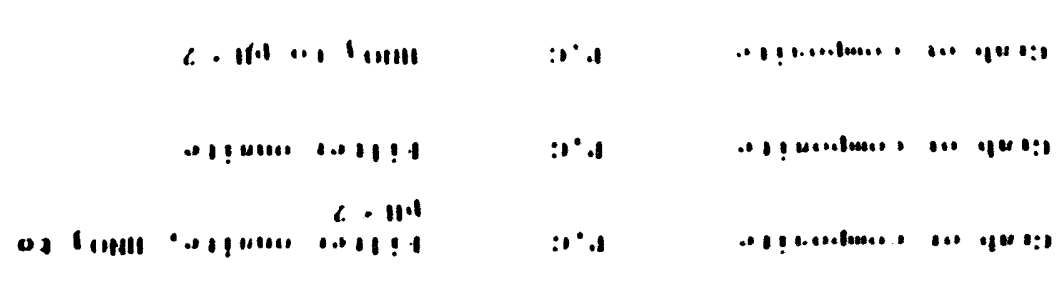

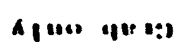

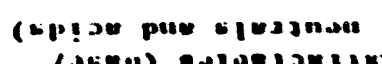

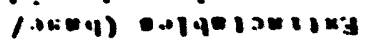

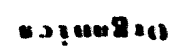

aces:as 1 !!1

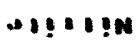

$+102, n$

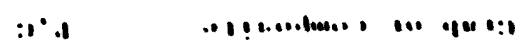

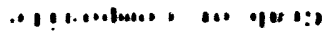

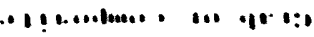

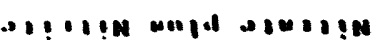

(10)

u counman

4..9.1 0 !n

$1 \times 1 \cdot 1$

propmo.oolan on:

poragenom gat

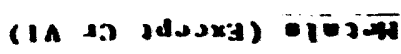
su! !ou!

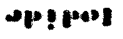




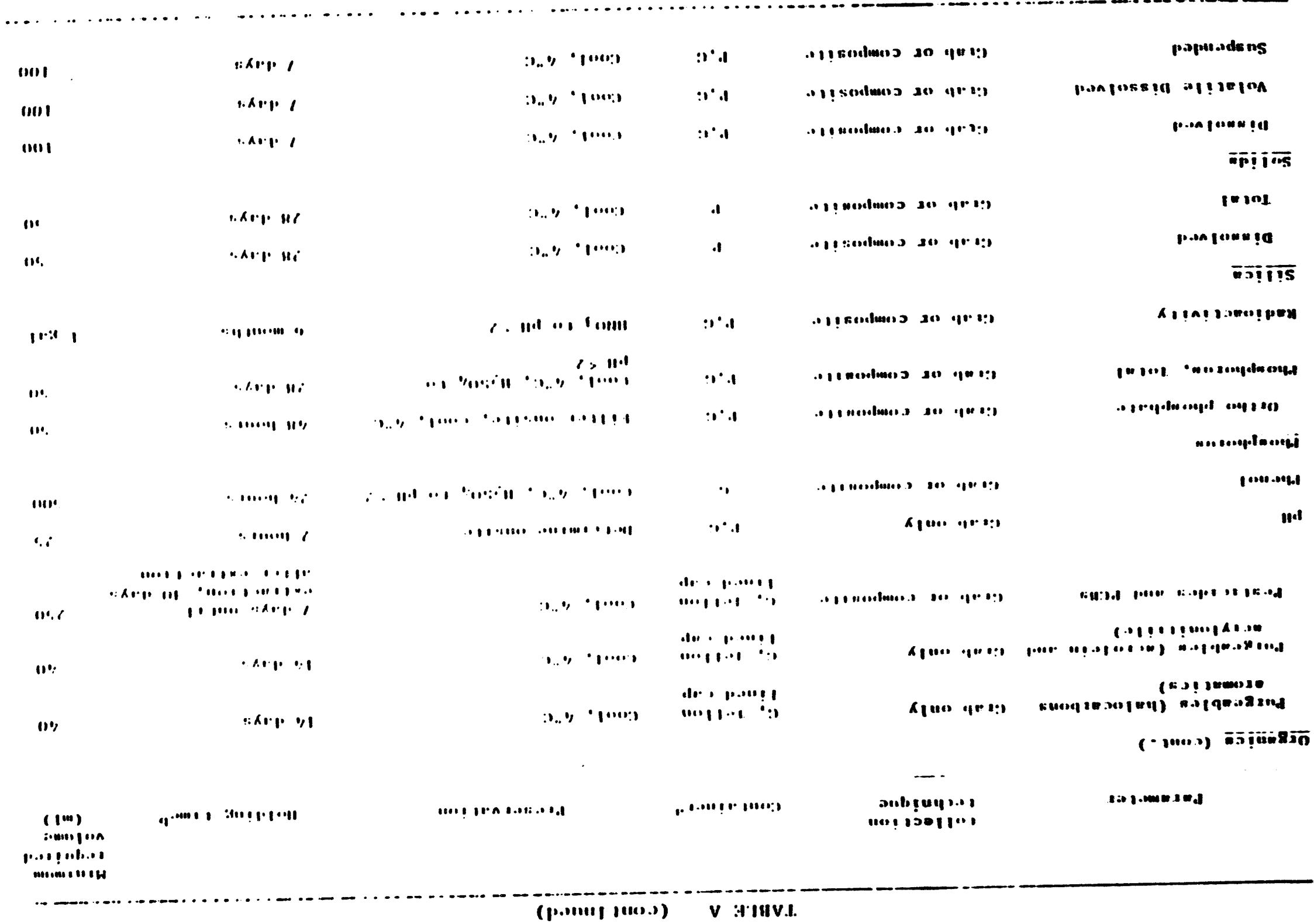




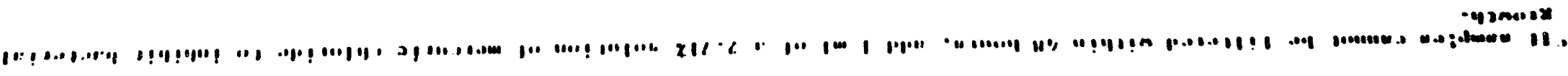

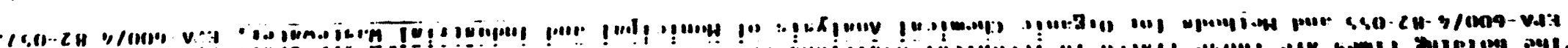

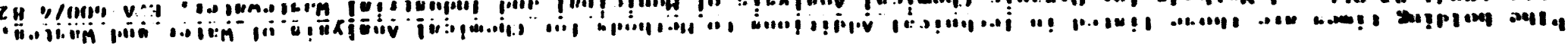

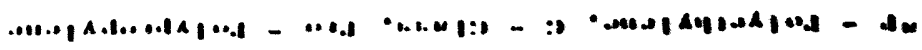

(II)!

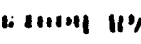

101

, 6

(11.6.

$\underset{\infty}{N}$
III

(1)1.

114

(11)1

(III)

o11

001
:.

$: 10^{\circ}$

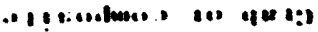

ine.

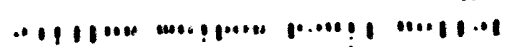

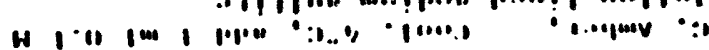

.1. • 1.....! !!

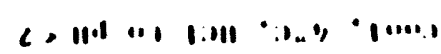

:1.. $91.1 . .1$

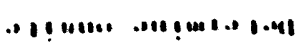

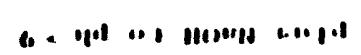

$: 1$

$\therefore \cdot .1$

$\because \because$

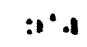

$: 0,1$

$: 0.1$

uxte $\ell$

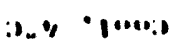

:1. 1000

0.) •(10):

:... • 1 $10 . .1$

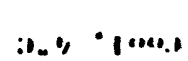

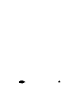

\section{(Im)}

acenfica

batiogios

enaju?h

III) ina ine ond

a.eng

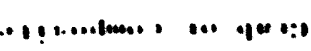

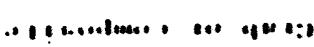

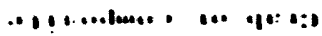

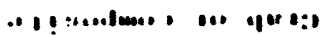

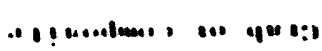

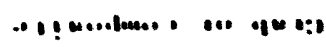

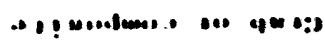

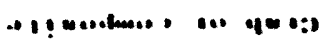

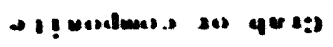

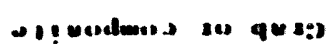

$: 1$

-

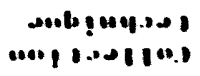

C:18!q:111

xire

:mo

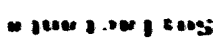

+1! 11 ons

ap! II ons:

+1011 cosi

atyosiling

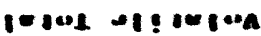

$103 \omega_{1}$

pupuadons oll jeira

(-jwos) बpl10s

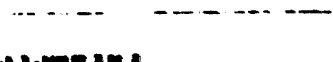

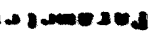




\section{VIII.Recordkeoping}

Sufficient data and observations aro required to demonstrate that the samples taken are as representative as possible. Documantation must be factual, detailed and objective enough to identify and track samples through the sampling and analysis process. The following sections outline the information to be compiled and recomended formats.

A. A sample Analynis Request sheot must accompany all samples to the laboratory and clearly identify the sample and the analysis requested for that sample. Examples of Laboratory Request Sheers from the State Laboratory Division (SID) are provided beiow and include the following types of information:

1. SID No., ccnstrued $5 z o m$ the aumerical representation of the date and 2400 hour time of sampling (i.e. date of July 1, 1992 at 2:15 p.m. is represenced as 920701:315),

2. User Code will be $5 \$ 802$,

3. The Reguest ID No. is suppilied in the Sorm of sticixers to be appiled so that each sampie sheet and corzesponding bortle(s) are identified with the same number,

4. The Priority Code No. will be 3 for normal tursaround times. If a higher priority is reguired, concace your supervisor and the lab for a bigher priority.

5. Facility and samole location information,

6. Name of the person coilecting the sample and the date and tire collecred,

7. Submitter cocie will be 535 for the Santa Fe and Sandia offices and 536 for the WIPP cifice. The Organization code will be 550040 ,

8, The LatitudeiLongitude of the sample location,

9. Name, address and telepione no. of the person the results should be sent to,

10. Purpose and other information applicable to the sampling event,

11. Fieid data to inclucie: $\mathrm{pB}$, conductivity, and temperature of the sampie 

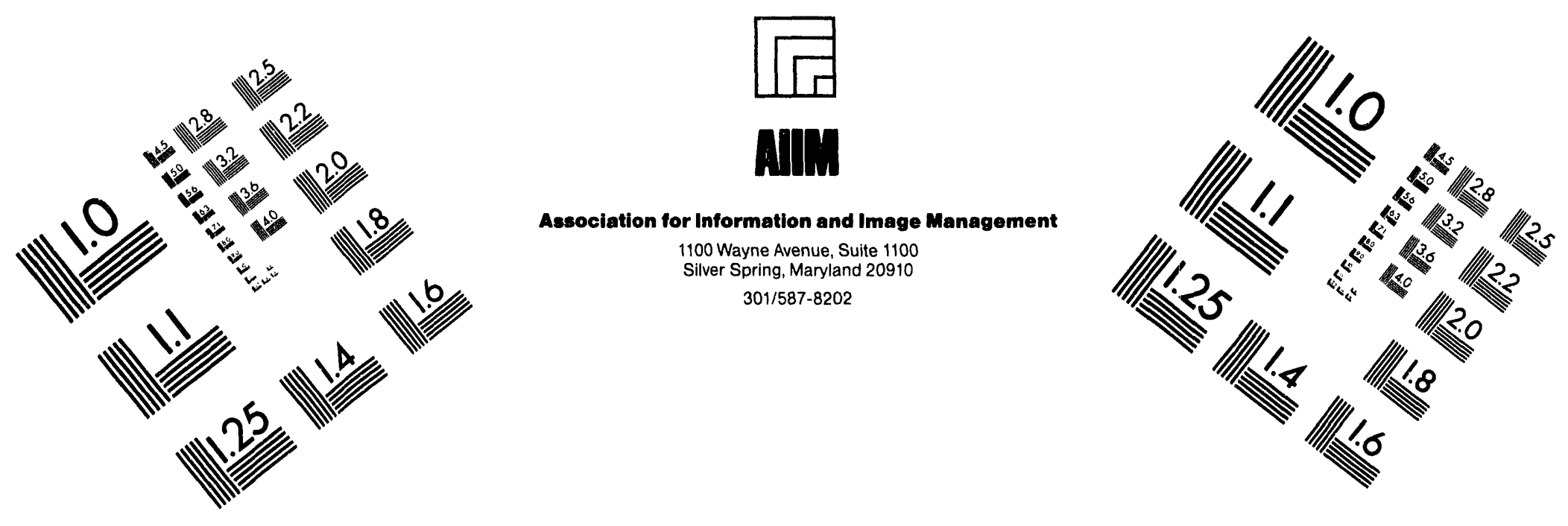

\section{Centimeter}

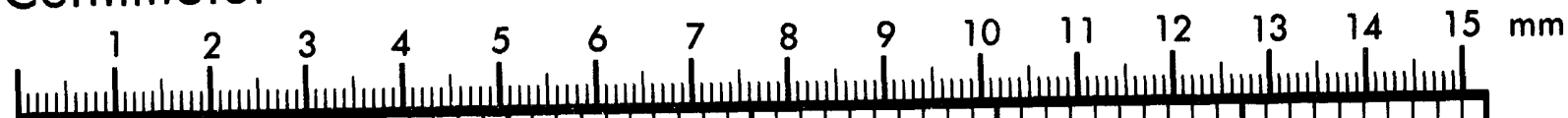

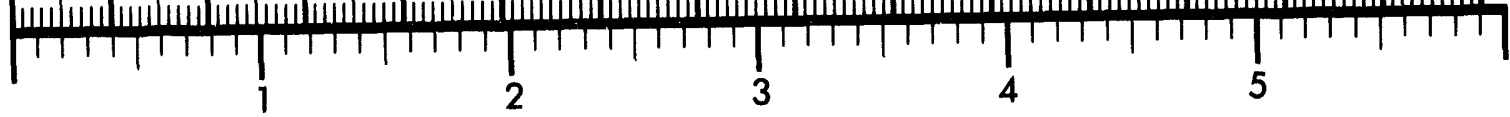
Inches

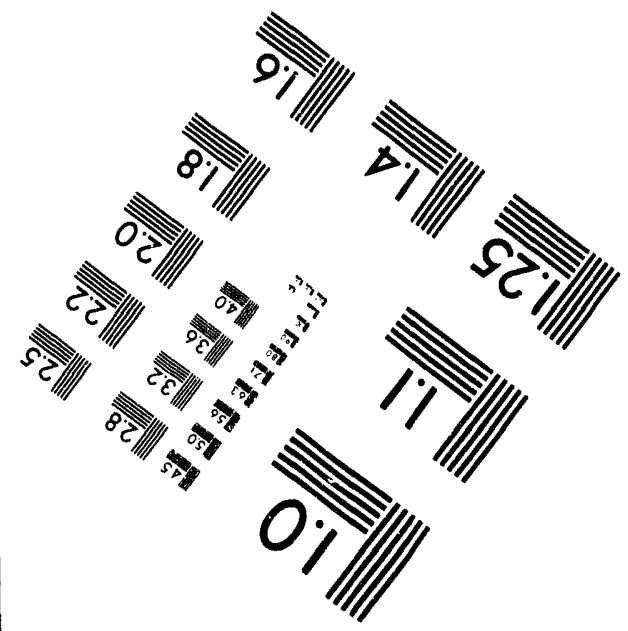

MANUFACTURED TO AIIM STANDARDS BY APPLIED IMAGE, INC.

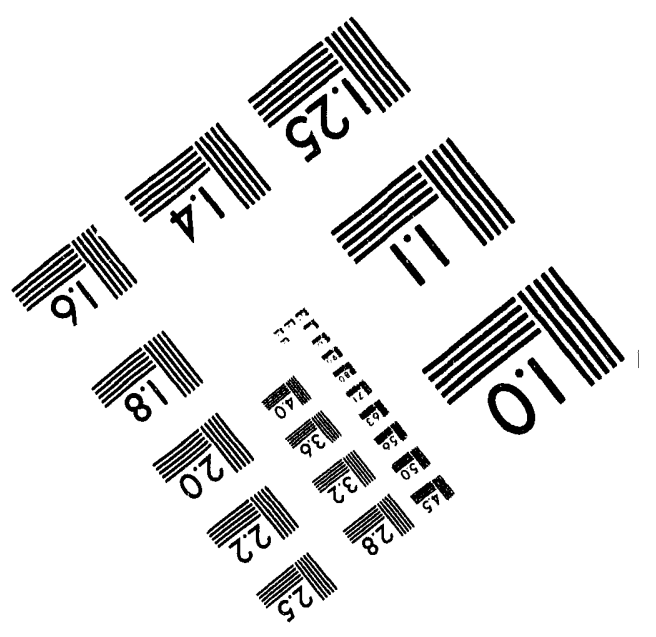



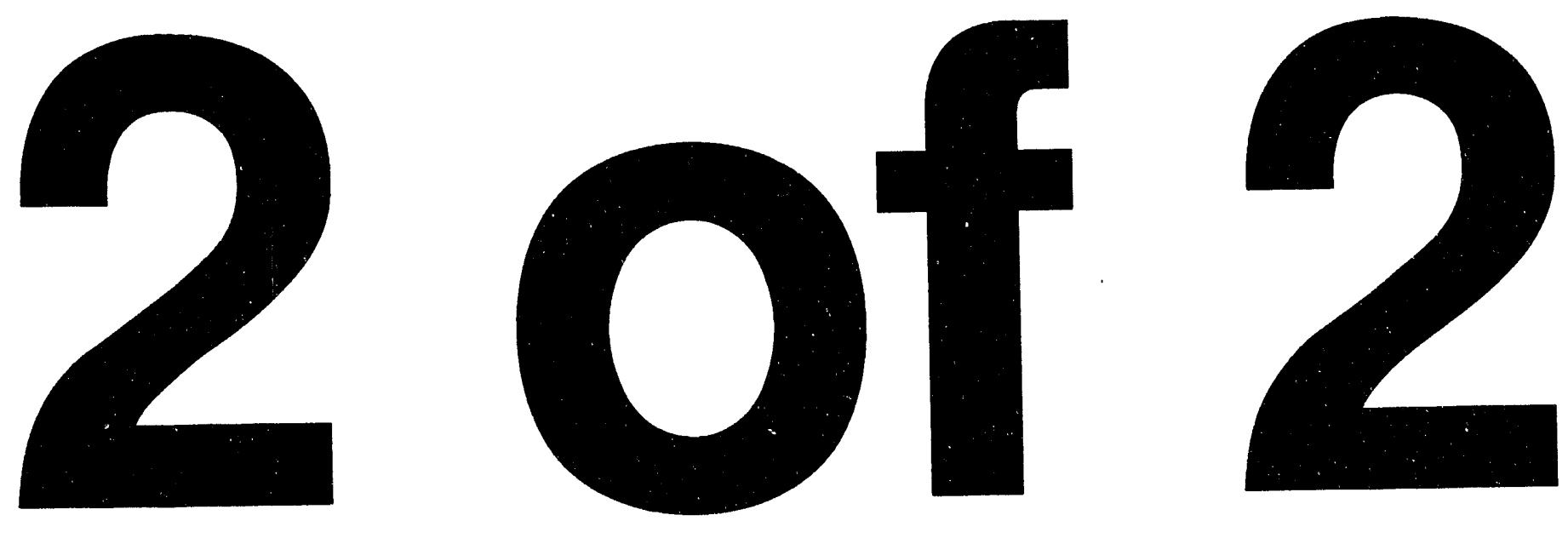
12. Sample source,

13. Field notes,

14. Sample type or matrix,

15. Preservation methods used,

16. Analysis reguested - Bach section at the lab provides an analysis request sheet that inciudes an array of analyses it is responsible for. The Air and Beavy Metals Section, Organic Section and The Radiochemist=y Section have similar but different request forms. Contact the appropriate section if additional information is required concerning the objectives of the samiling event.

note: The Organic secsion requires separate request sheets for Voiatile Screens and Semivoiatile screens.

17. Additionai remarks regarding unusual field conditions and the levei of contamination suspected shouid be added. Indicating high leveis of contaminatisn is imortant in protecting the laboratory cersonnei and their equipment.

Regardiess of what $l a b$ is used, the information described above should be icciuced with the paperwork and enclosed with the samoies submitted to that lab. 
SCEENTFCLABORATCAY DMSION

700 CANINO OE SALUD N.E ALQUQUEROUE NM 87106

Ar \& Heew Metais Seccion - Telochone: (505) 841 -2553
Date

Recaived:

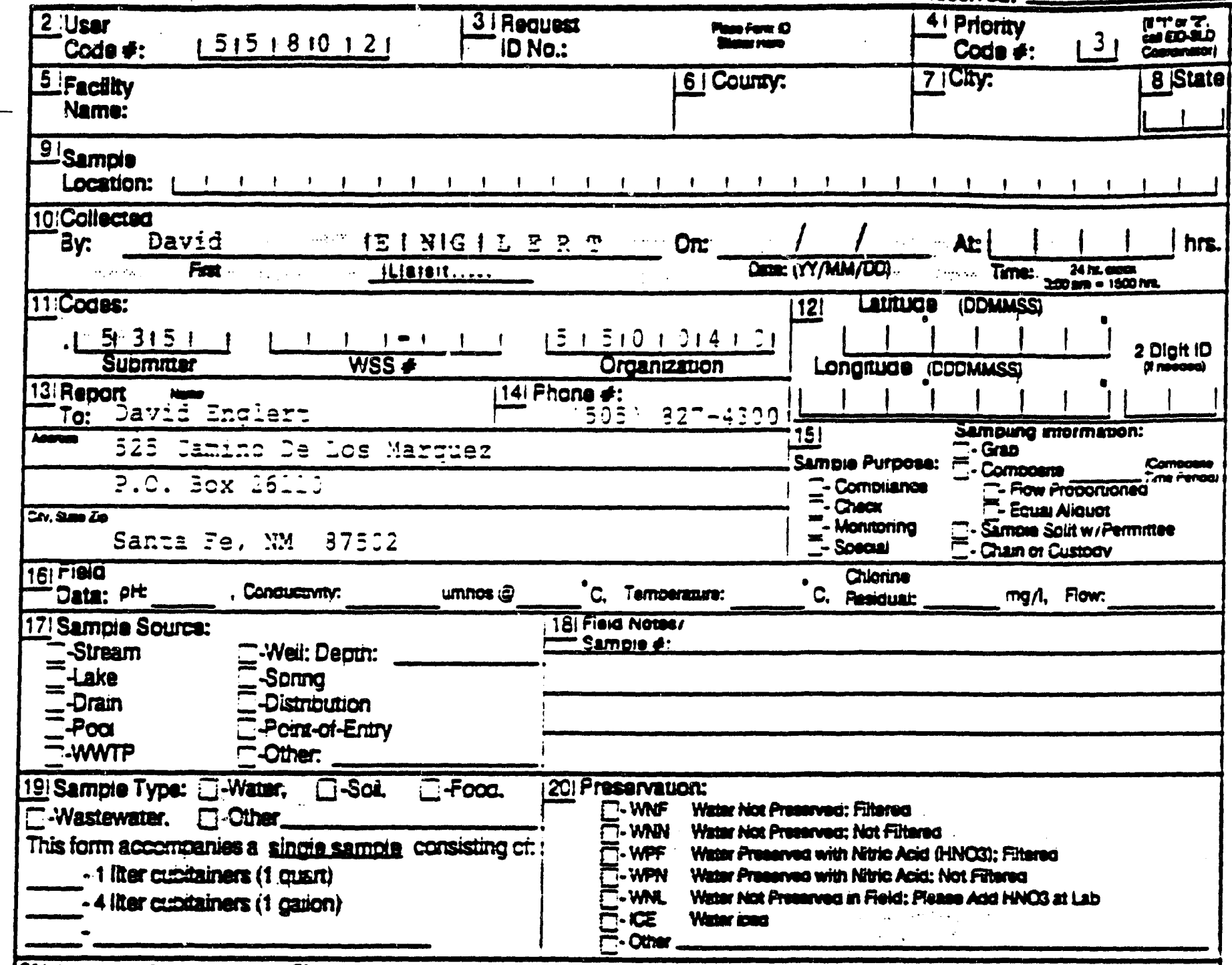

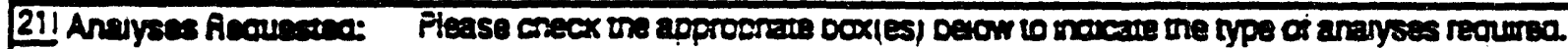

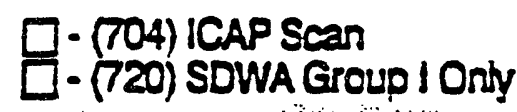

[- (72:) SDWA Group 1 + otser parameter(s) marked below
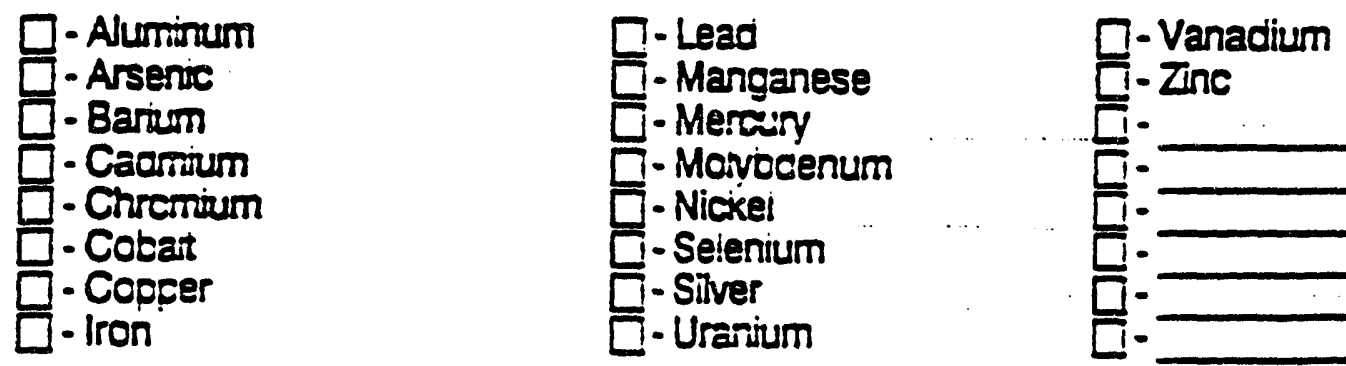

Remarks: 


\section{DEFINITIONS:}

The term ICAP Scan shall mean that the following parameters will be determined by ICAP Scan: Aluminum, Barium, Beryilium, Boron, Cadmium, Calcium, Chromium, Cobatt, Cocper, Iron, Lead, Magnesium, Manganese, Molybcenum, Niekel, Sijicon, Silver, Strcnium. Tin, Vanadium, and Zinc. Minimum sampie quantity, one liter (1 quar). Preserve with nitric acic ( $\left.\mathrm{HNO}_{3}\right)$.

The term SDWA Group I Onty shall mean that the following parameters will be determined: Arsenic, Barium, Cadmium, Chromium, Lead. Mercisy, Seienium, and Sïver. Minimum sample quanuty, one liter (1 quart). Preserve with nitric acid ( $\mathrm{HNO}_{3}$ ).

The term SOWA Group I + other parameteris) rarked below shai mean that the following parameters will be cetermineo: All SDWA Group i metals sius accitionai markeo sarameters. Minimum sample quantity, one itter (1 quar). Preserve with nitric acic (HNO,).

\section{CHWN OF CUSTODY}

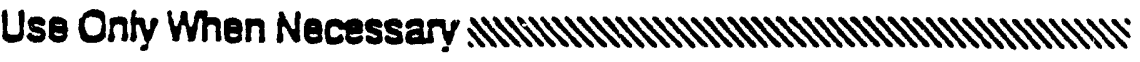

I centify that this samdie was transierreo from

at (location)

Evidentiary Seais: E-Not Seaied

Signatures

and from (if appicade)

at (location)

Evidemiary Seais: :- Not Sealed

Seais intace Z-Yes Z-No to

to on at $10 \mathrm{mo}$

Seals Inter Z-Yes Z-No on at $\lim$ 
B. Sample labels must be affixed to each sample container to prevent misidentification of the sample.

The labels should be sufficiently durable to remain legible even when wet, although care should be taken when packaging the samples to prevent unnecessary wear of their labels.

Clear plastic tape, wide enough to cover the sample label, should be applied over the label after the required informarion has been transcribed onto it.

Indelible black marker pens are best for marking plastic cubicontainers and black ball-point pens are best for marking paper labeis with the required informarion. As much information as possible siouid be marked on the samole concainers before the concainers are filled as spilled water may make marking the labels difficuit. At a minimum, the foilowing informarion should be included on the label:

1. Sampie identification number

2. Name of collector

3. Date and time of collection

4. Place of collection

5. Parameters requested

6. Volume and type preservatives added

C. Fleld notebooks are maintained to record significant events, observations, and measurements taken during the sampling event. Individuals taking the field notes should standardize their note-taking techniques so that they are systematic and include the following information:

* Surrey Site

* Sample ID *

* Samole Matrix

- Date and Time of Collection

* Sample Location

* WelI Deprb

* Static Water Level

* Presence of Immiscible Lavers

* Collection Method for Immiscible Layers

* Mell Yield - high or low

* Purge Volume and Rate 
* Time Well Purged

* Sample Withdrawal Procedures/Equipment.

* Well Sampling Sequence

* Types of Containers

* Preservatives

- Parameters requested for Analysis

* Field Analysis Data and Method(s)

* Sample Distribution and Transporter

* Field Observarions (Matrix Description)

* Climatic Description

* Name of Collector

* Internal Temperature of Field and Shipping Containers

The field gersonnel responsible for taking notes might creare a form similar so that in Figure 3 on the following page. 


\section{FIGURE 3. ETAYPLE OF FIETD LOG FORY}

\section{(TO BE MODIFIED DEPEADIXG ON SAMTIING EVEAT)}

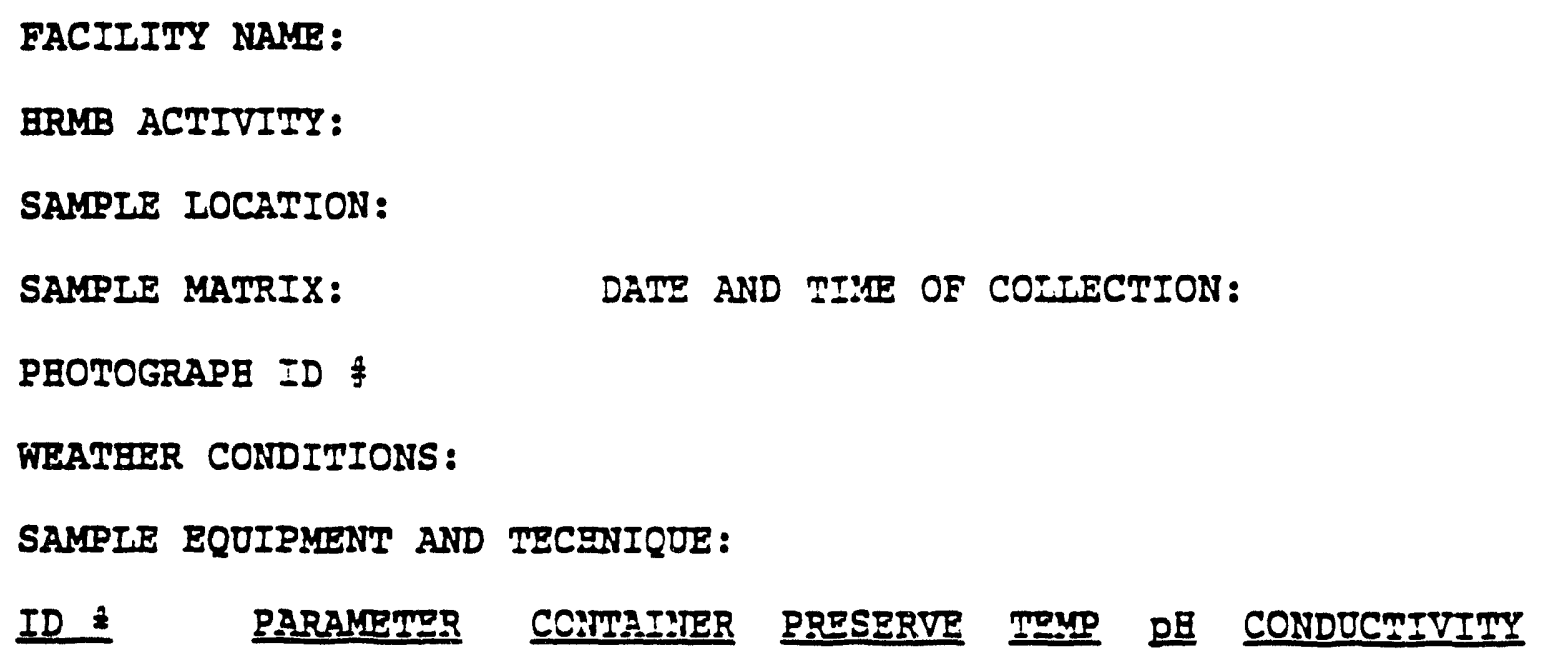

HRMB PERSONNEL:

FACIIITY PERSONNEL:

NAVE OF COLTECTOR:

SEIPPING CONDITIONS: 
D. Photographs can and should be used for additional documentation of the sampling event. While taking photographs, maintain a log detailing the date, time, subject, compass direction camera is aimed, frame number, roll number, photographer and witness for each picture.

note: Photography within federal security areas may be restricted. In such a situation request the facility personnel to provide photograpis as needed.

Develop the film as soon as possible. After receiving the prints, describe the significance on the back of each photo. Include the corresponding data from the pioto log (i.e. date and time, photographer, witness, site name and specific description of imagel.

E. An adequate Chain of Custody Record will establish the documentation necessary to trace sample possession from the time of collection to analysis. This record and procedures described below are important safeguards for certifying that the samoles have not been tampered with.

After a samole has been taken, evidence tape should be placed around the cap of the container in a manner that tampering with the container is immediately evident. After the shipping container has been filled, affix custody seais on the front and side of the container and cover the seais with clear plastic tape.

Ensure that the sample paper work is completely filled out and corresponds with the samoles in the shipping containers. Insert the paperwork into a waterproof plastic bag and tape to the inside of the container lid.

The SID Request for Analysis forms has the necessary Chain of Custody format on the back of each request form. Opon transfer of samples, the individual responsible for sampling and the lab recipient should sign and date the chain of crstody form.

F. Laboratory Logbook Once the sample has been received in the laboratory, the sample crstodian should clearly document the processing steps that are applied to the sample in the Laboratory Logbook. All sample preparation techniques (i.e. extraction) and instrumental methods must be identified in the logbook. The use of specific reagents (i.e. solvents, acids), temperatures, reaction times, and instrment settings, should be noted. The results of all quality contsol samples should be identified specific to each bacch of samples analyzed. The laboratory logbook should include the time, data, 
and name of the person who performed each processing step.

sote: Verify that the laboratory follows these conditions during the preliminary discussions.

\section{Docontamination Procedures}

Decontamination proceciures must be carefully followed for all sampling equipment which is non-disposable. The Sampling and Analysis plan should include dismantling and decon procedures for ail pumps, bailers, measuring tapes or any item that is exposed to the sampiing matrixes during a sampling event.

Decontamination suppiies include deionized water, methanol, hexane, Alkanox deterjent, pressurized garden sprayers, and an assortment of piastic squirt bottles, buckets and cleaning suppiies.

The appendices of this document address the operating, dismanting and decontamination procedures for the equipment available to our bureau, which include $\mathrm{pH}$ meters, concuctivity-temoerarure meters, organic vapor analyzers, and beta-ganma meters.

A. Equipment used to sample for inorganic paramaters should be cleaned initially with a nonphosphatic derergent mixture. The fi-st rinse should consist of a dilute (0.1N) hydrechloric acid followed by a thorough rinse of distilled or deionized water. Use of a garden sprayer for the deionized water provides a convenient mechanism for the rinses. It may take up to a gallon of deionized water per bailer so plan the deionized water supplies with that in mirc.

B. Bquipment used to samole for organic paramaters should be cleaned initially with a nonphosphatic detergent mixture and then rinsed with tap water. Follow with another rinse of distilled water. Then rinse with methanol and firally rinsed with a pesticide-guality hexane rinse. The equipment must be thoroughly dried before use at the next sampling point.

\section{Field Quality Assurance/Quality Control}

Field QA/QC samples mast be collected and reported to ensure the reliability and validity of field and analytical laboratory data. Samples that will be routinely collected and used as Quality Assurance/Quality Control include sample blanks (trip blanks and equipment blaniks), duplicate samoles, split samples and spiked samples. Below is a description of QA/QC samples and the frequency of collection required. 
A. Sample blanks are samples of deionized/distilled water, rinsed collection devices or conrainers, sampling media (e.g., sorbent), etc. thar are hanoled in the same manner as the sampie and subsequently analyzed to identify possible sources of contamination during collection, preservarion, handing, or transport.

1. Trip blanks are prepared by seiecting a bortle from eaci type bortle to be used during the samoling event (i.e. glass, cubicontainer) and filled with deionized warer. The bottles should be transported to the samoling lccarion and returned to the laborarory in a manner identical to the handing prccedure used for tte samoles. These trí blanks shouid be subjected to the same analysis as the accuirea samile. Any concaminants found in the trip blaniks couid be ar=ijured to (1) inceraction between the sampie and the container, (2) contamizated rinse warer, or (3) a handing prccedure that alters the sampie anaiysis results.

note. One tzip blanx per sampling event is reccmenced.

2. Equizment bianxs are saken to ensure that the nondedizared samolizg cevices have been effectively cleaned (in the lacorarory or field). Before a samie is taken, risse the equipment with deionized warer and collect the rinse water into sample botties and return so the laboratory in the same maner as the acoruired sampies.

note. A ninimum of one equipment blank for each day that samoies are taken is recomended. Adjitionai samoies are normally taken but oniy one samie is submitted. Submit the samoie frcm equipment used after sampling a site suspected of being contaminated, or the most contaminated.

B. Duplicates are essentiaily identical samples collected at the same time, in the same way, and conrained, preserved, and transporced in the same manner. These sampies are often used to verify the reproducability of the data. When submittiag the sampie to the laboratory, label the samole with a fictitious identification.

note: Recomencied freouencies for taking duplicate samies are one duplicare set of samples for eací samoling evenc. 
C. Split samples are dupiicere sampies shared with the owner, or faciity representative.

1. During samole acquisition the following procedures should be followed. Take duplicate samples for each parameter sefore collecting the next parameter. For each parameter the samole must come from the same sampiing rolume (i.e. bailer full of ground water or bowl of seciment). The seguence of filling the containers should alternate between your container and the Eacility's container. For examole, if sampiing water for VOC's the sample will consist of two (2) $40 \mathrm{ml}$ vials. Fill one of your vials and then anot:er for the Eaciitity before filling your second viai.

note: The progran pian or site specific objectives will derermine the irequencies, aumers anc locations of split samples.

D. Spiked samoles are duplicare sampies that have a known amount of a suestance of interest added to them. These samples are used to corzsborare the accuracy of the anaiyticai tecsnigue and could be used as an indicator of sampie cegrajation duri二g shipment.

note: Norzaily spiked sampies are adiressed by the anairical laboratory's quality assurance proctam and resuits should be included with the analyticai zesuits of the environmental samoies. Additicnai soiked samoles originating in tie field is a judoement call for the indiridual planoing a samoiing event, depending on the success of previous events, reiazionships with the analytical lab and/or the controversies that migint be associated with a pianned sampling event. 

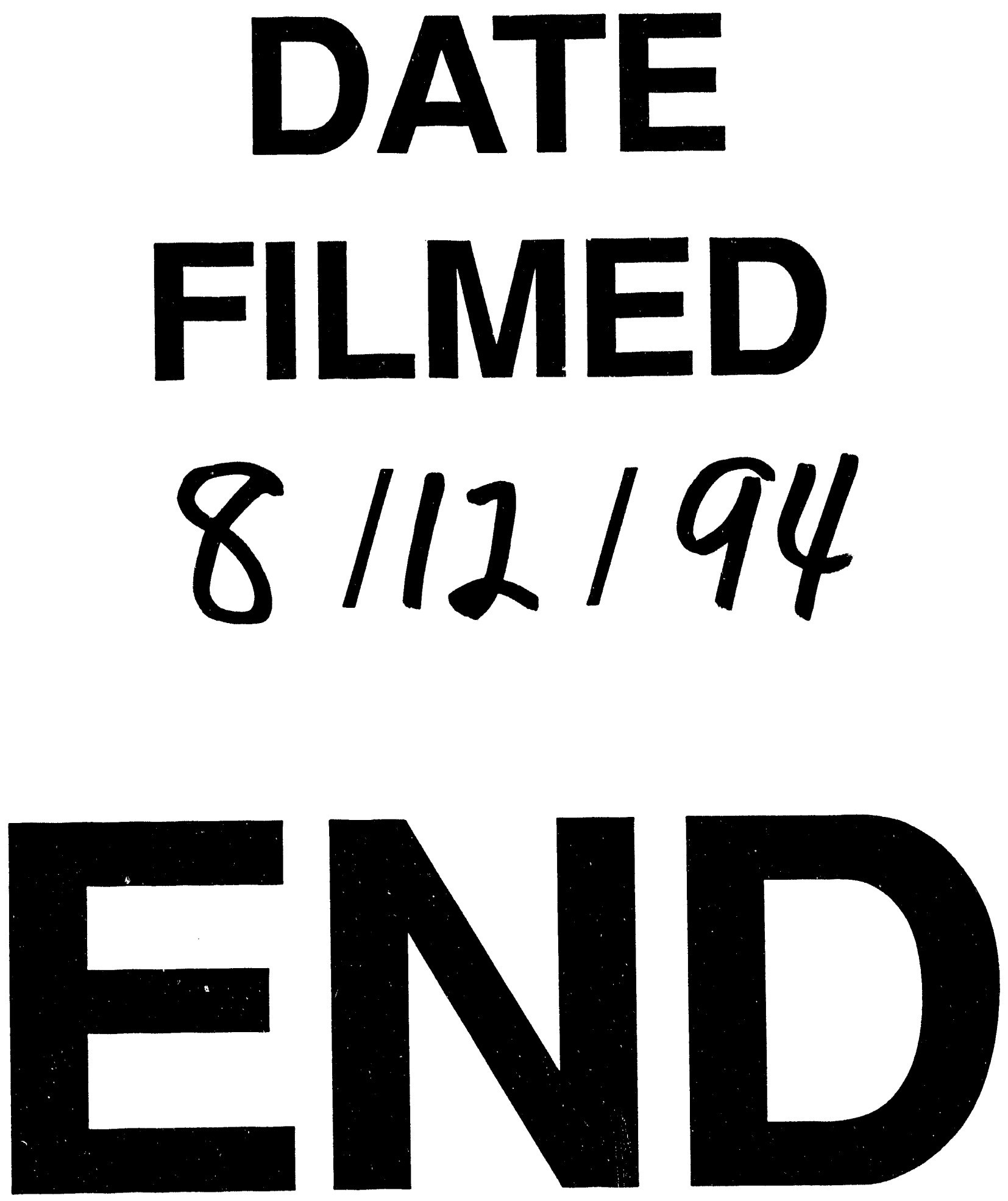